\title{
Space Use and Habitat Associations of Long-Distance Migratory First-Year Golden Eagles (Aquila chrysaetos) from Interior Alaska in a Changing Landscape
}

Mark D. Paulson

Follow this and additional works at: https://researchrepository.wvu.edu/etd

\author{
Recommended Citation \\ Paulson, Mark D., "Space Use and Habitat Associations of Long-Distance Migratory First-Year Golden \\ Eagles (Aquila chrysaetos) from Interior Alaska in a Changing Landscape" (2017). Graduate Theses, \\ Dissertations, and Problem Reports. 6391. \\ https://researchrepository.wvu.edu/etd/6391
}

This Thesis is protected by copyright and/or related rights. It has been brought to you by the The Research Repository @ WVU with permission from the rights-holder(s). You are free to use this Thesis in any way that is permitted by the copyright and related rights legislation that applies to your use. For other uses you must obtain permission from the rights-holder(s) directly, unless additional rights are indicated by a Creative Commons license in the record and/ or on the work itself. This Thesis has been accepted for inclusion in WVU Graduate Theses, Dissertations, and Problem Reports collection by an authorized administrator of The Research Repository @ WVU. For more information, please contact researchrepository@mail.wvu.edu. 


\title{
SPACE USE AND HABITAT ASSOCIATIONS OF LONG-DISTANCE MIGRATORY FIRST-YEAR GOLDEN EAGLES (AQUILA CHRYSAETOS) FROM INTERIOR ALASKA IN A CHANGING LANDSCAPE
}

\author{
Mark D. Paulson
}

Thesis submitted to the Davis College of Agriculture, Natural Resources, and Design at West Virginia University in partial fulfillment of the requirements for the degree of

\section{Master of Science}

in

Wildlife and Fisheries Resources

Petra B. Wood Ph.D., Chair

Todd E. Katzner Ph.D.

Carol L. McIntyre Ph.D.

School of Forestry and Natural Resources

Morgantown, West Virginia

2017

Keywords: Aquila chrysaetos, Denali, first-year, Golden Eagle, habitat association, home range, land cover change, summer, winter Copyright 2017 Mark Paulson 


\section{Abstract \\ SPACE USE AND HABITAT ASSOCIATIONS OF LONG-DISTANCE MIGRATORY FIRST-YEAR GOLDEN EAGLES (AQUILA CHRYSAETOS) FROM INTERIOR ALASKA IN A CHANGING LANDSCAPE}

\section{Mark D. Paulson}

Understanding a species space use and habitat associations is integral to comprehensive wildlife management. Habitat associations change spatially and temporally and those changes may be especially dramatic for animals that cover long distances throughout their annual cycle. While many studies of habitat associations and space use concentrate on breeding season behavior, studies of migratory connectivity demonstrate how condition of habitats on nonbreeding ranges potentially affect key demographic parameters, such as survival, reproduction, and movement in other seasons. This is also important because wildlife habitats, especially land cover, are changing rapidly from both anthropogenic and natural forces in direct and indirect ways.

The goal of this research was to describe (1) space use and habitat associations of a longdistance migratory avian predator, the Golden Eagle (Aquila chrysaetos) during summer and winter, and (2) to assess land cover change in eagle use areas. I studied first-year Golden Eagles hatched in Denali National Park and Preserve, Alaska (Denali). Radio-tagged eagles spent winter in western North America and summer in Alaska and northwest Canada. The birds I studied were a subset of those radio-tagged as nestlings in Denali from 1997 to 1999.

I first used three different home range models to characterize winter space use of 15 firstyear Golden Eagles hatched in Denali. Size of home ranges in winter was most biologically reasonable when measured with Kernel Density Estimates (KDEs). KDE home ranges were 4,429 to $69,478 \mathrm{~km}^{2}$ in size and did not differ between sexes. I used land cover, topography and physiographic data to test a priori defined hypotheses to evaluate drivers of movement behavior. Ranging behavior was best explained by the presence of steep slopes and canyons and degree of topographic roughness. The presence of topographic factors were, in general, more important than presence of land cover in explaining size of home range. Results from this study further the understanding of drivers of space use and habitat associations for young Golden Eagles on their wintering grounds

To characterize how land cover change may influence these Golden Eagles, I also studied how land cover changed over an 11 year period $(2001$ - 2011) within summer and winter areas used in 1997 - 2000 ( $n=16$ individuals; comprising 25 seasonal ranges, 15 winter, and 10 summer). Summer home ranges calculated with Kernel Density Estimates were larger than those in winter, they ranged from 20,990 to $224,375 \mathrm{~km}^{2}$, and those of males were larger than those of females. Land cover within summer home ranges was predominantly shrublands $(>48.0 \%$ cover). Land cover within winter eagle use areas was comprised mostly of grasslands $(>47.9 \%$ cover). Change in land cover was more prevalent in areas eagles used in winter than in those they used in summer. From 2001 to 2011 in wintering areas, percent cover of Deciduous Forest decreased and percent cover of Evergreen Forest and Water increased. Over the same interval on summer 
range, percent cover of Evergreen Forest and Grasslands increased, and percent cover of Barren ground and Snow/Ice decreased.

Previous work has shown long term declines in reproductive output of Golden Eagles in Denali but was not able to explain those declines based on conditions or changes on breeding grounds. This research is consistent with the earlier study because it shows that habitat eagles use may be changing faster on non-breeding grounds than on breeding grounds. This information may provide a useful starting point for further research to understand trends in populations of this apex avian predator. 
SPACE USE AND HABITAT ASSOCIATIONS OF LONG-DISTANCE MIGRATORY FIRST-YEAR GOLDEN EAGLES (AQUILA CHRYSAETOS) FROM INTERIOR ALASKA IN A CHANGING LANDSCAPE

\author{
Mark D. Paulson
}

Thesis submitted to the Davis College of Agriculture, Natural Resources, and Design at West Virginia University in partial fulfillment of the requirements for the degree of

\author{
Master of Science
}

in

Wildlife and Fisheries Resources

Petra B. Wood Ph.D., Chair

Todd E. Katzner Ph.D.

Carol L. McIntyre Ph.D.

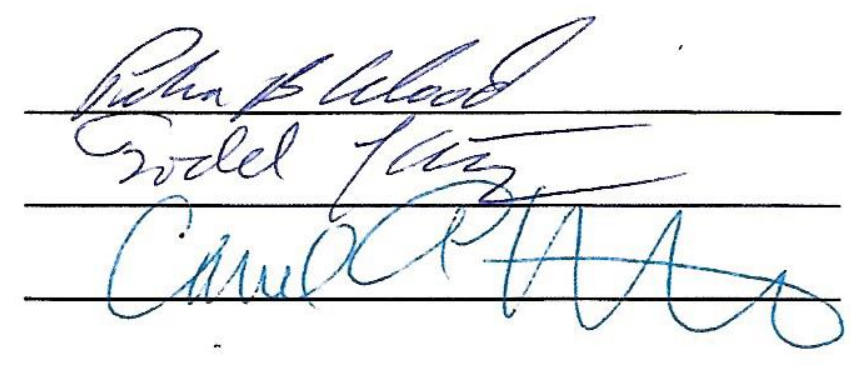

School of Forestry and Natural Resources

Morgantown, West Virginia 


\section{DEDICATION}

I dedicate this thesis to my late father-in-law Daniel R. Pellegrom. His strength and courage in the most difficult of situations was truly inspiring. Dan's love of the outdoors and fishing northern Michigan ran deep, and we shared a passion of "camping to the max", among many other activities. I am so thankful for the opportunity to get to know him. 


\section{ACKNOWLEDGMENTS}

I would like to thank Dr. Todd Katzner for the continual encouragement, direction, and advice. I would like to thank Dr. Petra Wood for her guidance and suggestions, not only on the thesis, but also with the University. I would like to especially thank Dr. Carol McIntyre, whom without taking me under her wing years ago, I would not have been afforded this opportunity. All committee members deserve immense thanks for their patience and helping me progress in my writing and analytical abilities. I must specifically thank Trish Miller, Missy Braham, Adam Duerr, and Leah Dunn for analytical and technical assistance throughout my graduate career. A huge thank you to the other past and present members of the Katzner lab, wide and far (V. Slabe, J. Hall, M. Jensen, A. Dennhardt, M. Wheeler, C. Slover, S. Behmke, C. Concepcion, B. Drahota, L. Stiffler, M. Sur, S. Poessel), for technical, analytical, and mental assistance, and making the experience enjoyable.

I need to thank Dan O'Brien for his guidance, especially very early in my career as I was just being introduced raptor work. Watching the immense power of Dan's Peregrine Falcon making a kill as a young child ignited a passion in me that is still growing. I also want to thank my immediate and extended family, this would not have been possible without their unwavering support. Most of all, I must thank Audrey Pellegrom Paulson, the most devoted, caring, and resilient person I know. 


Acknowledgments

\section{CHAPTER 1: LITERATURE REVIEW}

Wildlife-habitat associations and habitat change...........................................

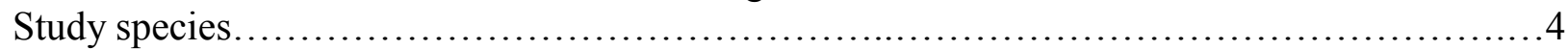

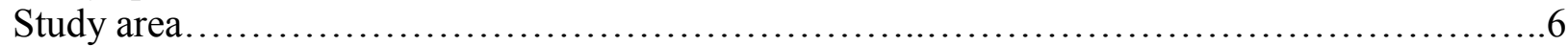

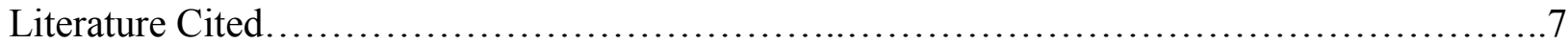

\section{CHAPTER 2: WHAT EXPLAINS WINTER HOME RANGE SIZE OF FIRST-YEAR MIGRATORY GOLDEN EAGLES FROM INTERIOR ALASKA?}

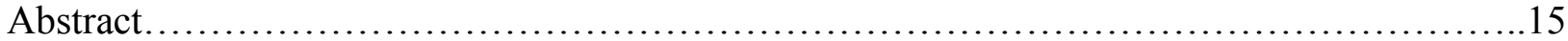

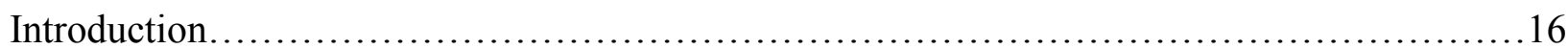

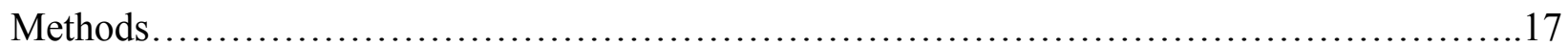

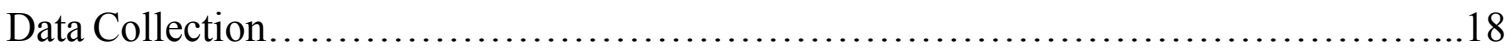

Data Processing and Management.............................................. 18

Golden Eagle Winter Home Range and Core Use Estimation............................19

Habitat Association.................................................................. 19

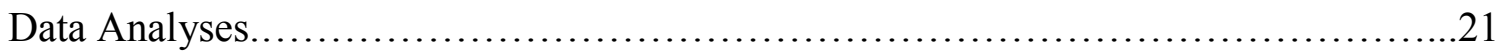

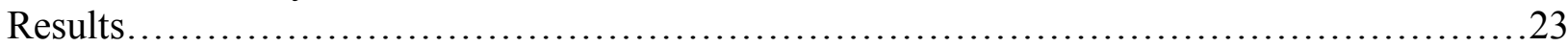

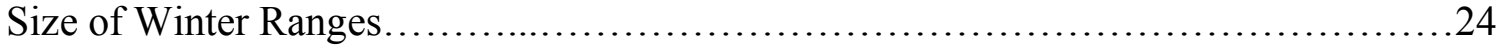

Characteristics of Winter Home Ranges............................................

Characteristics of Winter Core Use Areas..............................................24

Determinants of Winter Home Range Size ..........................................25

Determinants of Winter Core Use Area Size ......................................25

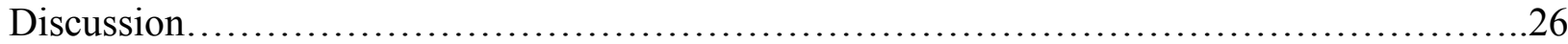

Space Use and Habitat Association.................................................26

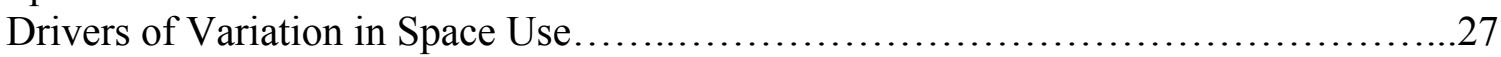

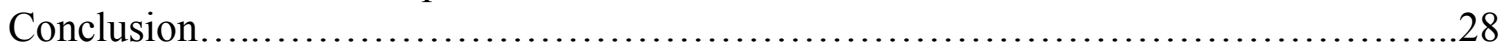

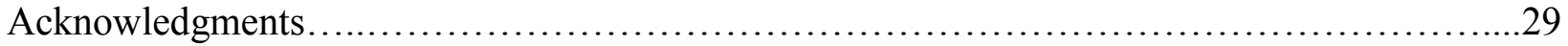

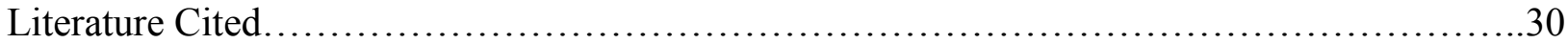

\section{CHAPTER 3: LAND COVER CHANGES IN HOME RANGES OF FIRST-YEAR MIGRATORY GOLDEN EAGLES FROM ALASKA}

Abstract 


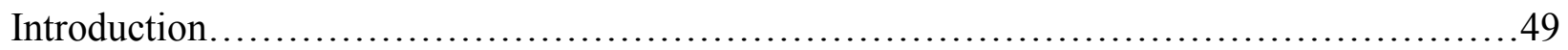

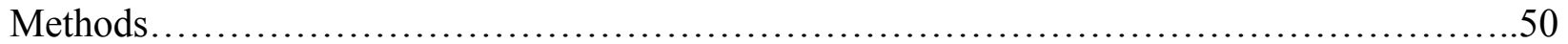

Data Collection............................................................. 51

Data Processing and Management..............................................51

Space Use, Golden Eagle Home Range and Core Use Estimation .....................52

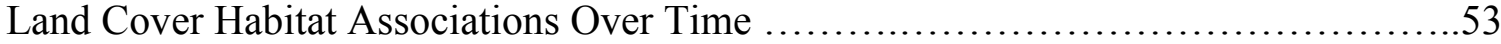

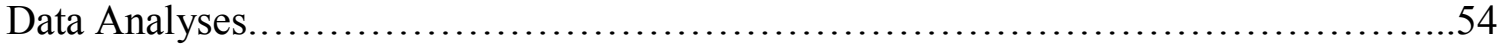

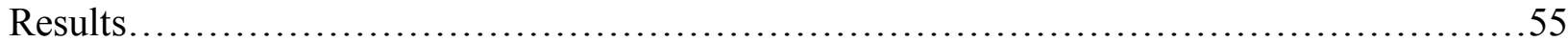

Space Use ............................................................ 55

Golden Eagle Home Range and Core Use Estimation ..............................56

Land Cover Habitat Associations Over Time .....................................56

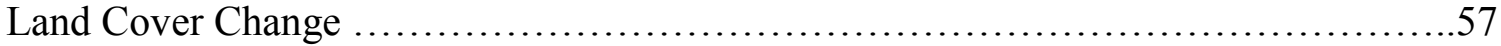

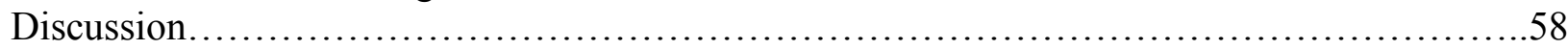

Land Cover Habitat Associations Over Time...................................... 58

Land Cover Change Over Time .............................................. 58

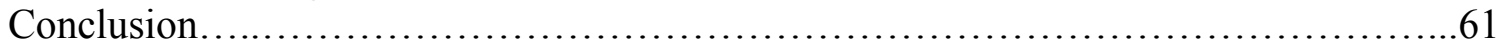

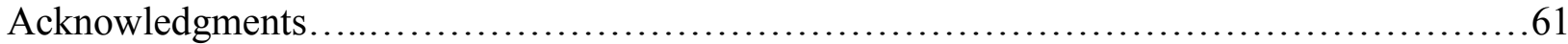

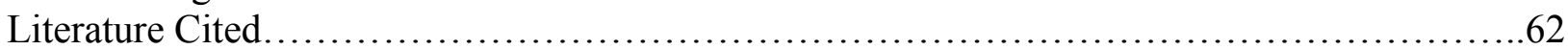




\section{LIST OF TABLES}

\section{CHAPTER 2:}

Table 1. Commission for Environmental Cooperation (CEC) land cover classes, and the reclassified variables used in analyses of winter habitat associations of first-year Golden Eagles from Denali National Park and Preserve, Alaska. Percent land cover per individual winter range

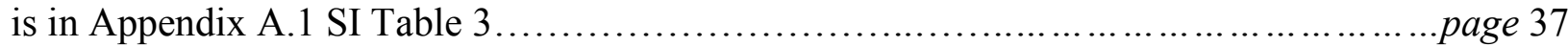

Table 2. Models used to describe variables that influence winter home range (HR) size (a; KDE 95\% isopleth) and winter core use area (CUA) size (b; KDE 50\% isopleth) of first-year Golden Eagles from Denali National Park and Preserve, Alaska. Models are listed in rank order from the most to least supported (Akaike's information criterion adjusted for small sample size (AICc) weight $\geq 0$ ). Physiography model variables include Mean Elevation of HR or CUA, latitude of centroid of HR or CUA, \% of HR or CUA made up of TPI category "canyon", \% of HR or CUA made up of TPI category "steep slope", Mean TRI of HR or CUA. Land Cover model variables include \% cover of broadleaf forest within HR or CUA, \% cover of coniferous forest within HR or CUA, \% cover of cropland within HR or CUA, \% cover of grassland within HR or CUA, $\%$ cover of shrub within HR or CUA................................................. page 38

Table 3. Model averaged effect sizes and standard errors for parameter estimates of models to describe response of size of winter home range (HR) size (A; KDE 95\% isopleth) and winter core use area (CUA) size (B; KDE 50\% isopleth) of first-year Golden Eagles from Denali National Park and Preserve, Alaska. (1997-1999). Effects measured using linear mixed effects models... page 40

\section{CHAPTER 3:}

Table 1. MODIS annual land cover data (Terra + Aqua Type 5 Yearly L3 Global 500m SIN Grid MCD12Q1) Land Cover Classification: Type 5 Plant Functional Type (PFT) scheme and combined categories used in analyses of land cover change within seasonal home ranges of migratory first-year Golden Eagles hatched in Denali. page 70

Table 2. Average percent land cover categories \pm standard deviation within areas used by firstyear Golden Eagles hatched in Denali, Alaska, on winter and summer home ranges and core use areas. Cover was estimated from MODIS imagery from 2001, 2006 and 2011. Land cover classes are as in Table 1. page 71

Table 3. Changes in percent land cover within areas used by first-year Golden Eagles hatched in Denali, Alaska, on winter and summer home ranges and core use areas. Results shown are from Mann-Whitney U-test (V, p) with sequential Bonferroni correction adjusted critical value (Rice 1989) across three time intervals (2001 - 2006, 2006 - 2011, and $2001-2011)$. Land cover classes are as in Table 1. Within summer core use areas the land cover category Urban did not appear.... .page 72 


\section{LIST OF FIGURES}

\section{CHAPTER 2:}

Figure 1. Telemetry data from winter home ranges of first-year Golden Eagles tracked from nests in Denali National Park and Preserve, Alaska in 1997 and 1999. Panels are a) Individual winter season Argos telemetry locations; and b) winter home range of one individual (2688) estimated with Brownian Bridge Movement Models (BBMM; $95 \%$ isopleth), Kernel Density Estimates (KDE; $95 \%$ isopleth) and Minimum Convex Polygon (MCP). The 95\% KDE home range of Individual 2688 also is shown in map panel a. .....................................page 41

Figure 2. Average proportion of seven land cover classes (described in Table 1) within a) winter home ranges (KDE 95\% isopleth) and b) winter core use areas (KDE 50\% isopleth) for first-year Golden Eagles from Denali National Park and Preserve, Alaska (1997-1999). ..page 42

Figure 3. Model averaged results of relationship between key habitat variables and size of winter home ranges (HR; 95\% KDE isopleth) and core use areas (CUA; 50\% KDE isopleth) of firstyear Golden Eagles from Denali National Park and Preserve, Alaska, (1997 - 1999). Results suggested that a) HR size increased as the proportion of TPI steep slopes increased; b) CUA size decreased as the proportion of broadleaf forest land cover increased; and c) CUA size increased

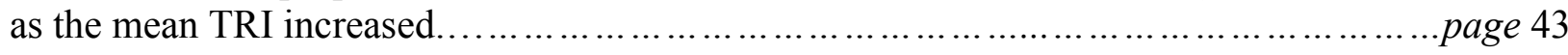

\section{CHAPTER 3:}

Figure 1. First-year Golden Eagle core use areas (KDE 50\% isopleth) across summer $(\mathrm{n}=10)$ and winter seasons $(n=15)$, displayed over a shaded relief base map. Summer ranges are those in Alaska, U.S.A., Yukon Territory and Northwest Territories, Canada. Winter ranges are those that occur from central Alberta, Canada, to New Mexico, U.S.A., and from Washington State to South Dakota, U.S.A. The eagles' natal area of Denali National Park and Preserve is shown in cross hatch in central Alaska. Map projected to North America Equal Area Conic projection. page 73

\section{LIST OF APPENDICES}

Appendix A.1... ..page 44 SI Table 1. Argos satellite locations by location-quality class before and after Douglas Argos accuracy filtering, and only filtered winter season locations used in analyses, obtained from radio-tagged first-year Golden Eagles born in Denali. ..page 44

SI Table 2. Area (km2) of winter home ranges (95\% isopleth) and CUAs (50\% isopleth) for (a) female and (b) male Golden Eagles telemetered in their first-year from Denali National Park and Preserve using three estimation methods (Brownian bridge movement model (BBMM), kernel density estimate (KDE), and minimum convex polygon (MCP)). An asterisk (*) in the "BBMM" 
columns indicates that we were unable to calculate the home range for these individuals and in the "winter end" column indicates either death or radio failure while on winter range......page 45

SI Table 3. Winter land cover per home range (KDE 95\% isopleth) and core use area (KDE 50\% isopleth). Land cover variables were derived from the 2005 CEC North American land cover dataset (CEC 2013). CEC land cover categories were simplified and grouped according to text and Table 1 for analyses. Land cover values shown are percent cover per individual home range. page 46

Appendix A.2 ..............................................................page 82 SI Figure. 1. Space use estimation for pre-adult Golden Eagles from Alaska, including Kernel Density Estimate (KDE), Brownian Bridge Movement Model (BBMM), and Minimum Convex Polygon (MCP). Home ranges calculated at 95\% isopleth (KDE95, BBMM95), and core use areas calculated at 50\% isopleth (KDE50, BBMM50). Each displayed 1:2,200,000 scale. We were unable to calculate BBMMs for four individuals. KDEs were used for subsequent

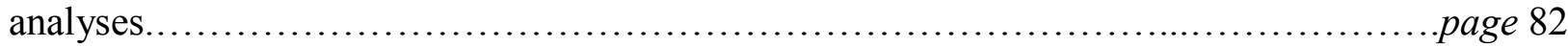

Appendix B.1 ..page 75 SI Table 1. Argos satellite locations by location-quality class before and after Douglas Argos accuracy filtering, and only filtered non-migratory summer and winter season locations used in this study, obtained from radio-tagged first-year Golden Eagles from Denali...............page 75

SI Table 2. Summary statistics for individual seasons used to calculate summer KDEs for (a) male and (b) female first-year Golden Eagles hatched in Denali. Including individuals (ID), area of space used (km2) for summer home range size (KDE95) and summer core use area size (KDE50), season start and end date, number of days on summer range, and number of telemetry location fixes. A single asterisk (*) in season end date column denotes a radio failure, and (D) denotes mortality before departing summer range. For summary statistics on winter space use see

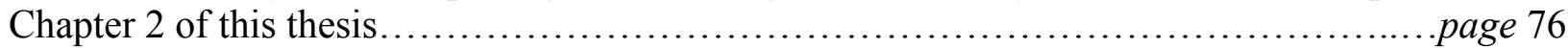

SI Table 3. Percent land cover categories \pm standard deviation by individual on winter and summer home ranges and core use areas for first-year Golden Eagles at three time stamps (2001, 2006, 2011), reported in percent cover by combined MODIS land cover category as in Table

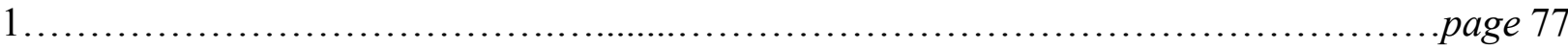

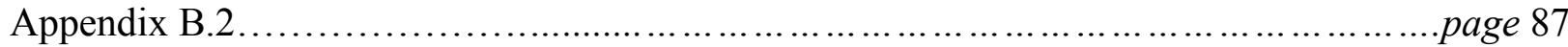
SI Figure 2. Space use estimation for pre-adult Golden Eagles summer use areas derived from Kernel Density Estimate (KDE), Home ranges calculated at 95\% isopleth (KDE95), and core use areas calculated at 50\% isopleth (KDE50). Denali National Park and Preserve is displayed for reference. Each displayed 1:5,000,000 scale. Maps projected in Alaska Albers for display purposes. ...page 87 
Chapter 1

INTRODUCTION 


\section{WILDLIFE-HABITAT ASSOCIATIONS AND HABITAT CHANGE}

Habitat is sometimes defined simply as vegetative structure (Morrison et al. 2012). As understanding of habitat and its importance expanded, the definition was broadened to include components such as topography, soils, elevation and latitude (Haegen et al. 2000, Kaboli et al. 2006, Mitchell et al. 2006, Braham et al. 2015). For birds, the definition of habitat is more complex and also includes aerial environments, referred to as the aerosphere (Kunz et al. 2008, Swartz et al. 2008).

Habitat use is a term that describes the way an animal uses the physical and biological resources within its ecosystem (Litvaitis et al. 1996, Hall et al. 1997). Different habitats may be used for foraging, cover, nesting, escape, denning, or other life history traits at different times of year or during different life stages (Litvaitis et al. 1996, Hall et al. 1997). Habitat selection by an animal is considered to be an active behavioral process, categorized in a hierarchical manner. Biologically, it involves a series of innate and learned behavioral decisions made by an animal about what resources it uses (Hutto 1985). Habitat use and selection are often viewed as hierarchical, with first-order selection defined as the geographical range of a species, secondorder selection determined by the home range of an individual or social group, third-order selection pertaining to the usage made of various habitat components within the home range, and fourth-order selection referencing the procurement of resources within these microsites (Johnson 1980, Hall et al. 1997, Johnson et al. 2006). Incorporated into habitat selection are Resource Selection Functions (RSFs), in which use of resources by an animal or population of animals in a fixed period of time is compared to available resources within the area (Manly et al 2002).

Habitat change is a defining feature of wildlife and landscape management in the modern era (Opdam and Wascher 2004, Parmesan and Yohe 2003, Parmesan 2006, Parry et al. 2007, Morris et al. 2013). Understanding the habitats of areas used throughout the lifespan of an organism has direct implications for wildlife management (Krausman 1999). For many species conditions on non-breeding seasonal ranges are linked to survival and reproductive output on breeding grounds (Steenhof et al. 1997, Marra et al. 1998, Greenberg and Marra 2005). Effective wildlife management, especially for long lived birds, requires incorporating studies across the entire annual cycle including migration and wintering grounds of all age classes (Kochert and Steenhof 2002, McIntyre et al. 2008). Understanding how the habitats these animals depend 
upon are changing, and what drives the changes, can elucidate potential effects on wildlife species and is an important aspect of wildlife management and conservation.

Change in habitat is variable in space and time, and some areas are transforming more rapidly and along different trajectories than are others (Serreze and Francis 2006, Parry et al. 2007). There are numerous factors driving habitat change at different spatial scales. Among the most salient processes causing change are direct human-caused anthropogenic habitat alteration of land cover and land use and indirect alteration via global climate change (Parry et al. 2007, Theobald 2010, Burton et al. 2014, Raynolds et al. 2014). Climate change is projected to have numerous direct effects on bio-physical processes, water availability, and weather events, (Parmesan 2006, Parry et al. 2007). As a consequence of these changes, there may be significant indirect effects on wildlife population dynamics, species distributions and interactions, food web structure, biodiversity, and ecosystem processes (Convey and Smith 2006, Parmesan 2006, Grosbois et al. 2008, Keith et al. 2008, Hunter et al. 2010).

As the structure and resources available in the habitat are altered, there are cascading effects for the communities of organisms that rely on the habitat. Some organisms are highly affected by landscape alteration or fragmentation that reduce habitable area, that increase distance between suitable patches, and that result in alterations in movements (Opdam and Wascher 2004, Schooley and Branch 2009, Gibson et al. 2013). Impacts to organisms and the ecological significance of cascading effects within the community may also be defined by the trophic position of the organism in question (Sergio et al. 2006).

The degree to which habitat change impacts a species is a function of the organism's ability to adapt to these changes. This adaptability is, in turn, a function of the species' life history traits, trophic level, and movement capabilities (Dunning et al. 1992, Pope et al. 2000 Prugh et al. 2008, Schooley and Branch 2009, Van de Pol et al. 2010, Gibson et al. 2013). Apex predators, with their generally small populations and more constrained ranges, may be especially vulnerable to change (Hunter et al. 2010). Because highly mobile organisms can move longer distances, it is easier for them to avoid habitats that are not suitable. They also have a better chance than a more sedentary species of encountering alternative suitable areas throughout their annual movements and as they mature (Wiens 1992a,b). 
Because of the interacting effects of habitat and climate change on life history traits, demography, and movements, organism response to change is a central theme for modern wildlife management and conservation biology. Long-lived, long-distance migratory avian apex predators, such as Golden Eagles (Aquila chrysaetos) at northern latitudes, are a useful model to study this issue. Their mobility enables them to respond to local habitat change and to select habitats that they perceive are best suited to their survival and reproduction. Parameters of habitat change that may be biologically relevant to Golden Eagles include percent change in land cover, mean patch size, patch density, road density, urban development, mean shape polygon index of habitat characteristics, total edge length, nearest neighbor distances to suitable habitat and fragmentation indices (Marzluff et al. 1997, Whitfield et al. 2001, 2007, Gillanders et al. 2008, Miller et al. 2014, Watson 2014).

My research investigated space use and habitat associations for this long-lived, longdistance migratory apex predator. I also investigated percent change in land cover due to natural and anthropogenic effects and potential impacts on Golden Eagles. This thesis is organized into two research chapters.

- Winter home range size and correlates of ranging behavior of first-year migratory Golden Eagles from interior Alaska.

- Land cover changes in historical home ranges of first-year migratory Golden Eagles from interior Alaska.

\section{STUDY SPECIES}

Golden Eagles are a large, long-lived apex predator with a Holarctic distribution (Watson 2010). Across their entire range Golden Eagles nest on cliffs, in large trees, on the ground, and on infrastructure (Watson 2010). Golden Eagle diet includes medium to large birds and mammals, and carrion (Watson 2010). Within North America, the species breeds across Canada and Alaska and from the western Great Plains to California and into Mexico (Kochert et al. 2002). Their winter range includes most of the contiguous USA and portions of Canada and Mexico (Kochert et al. 2002). 
Golden Eagle life history traits differ temporally by latitude (Watson 2010). For example, egg laying in southern latitudes has been documented as early as November (Watson 2010) while northern latitude breeders do not begin egg laying until February or later (McIntyre and Adams 1999). Additionally, Golden Eagles with natal areas at latitudes greater than $50^{\circ} \mathrm{N}$ in North America are usually migratory, whereas eagles at more southern latitudes appear not to engage in long-distance migration (Kochert et al. 2002, McIntyre and Adams 1999, McIntyre et al. 2008, Katzner et al. 2012)

A population of Golden Eagles that breeds near the northern reaches of the species global range is found in the foothills of the Alaska Range in and around Denali National Park and Preserve (Denali) in interior Alaska. These birds migrate long distances between seasonal ranges. The duration of migration, on both fall and spring movements, by eagles from Denali can be $>5$ months (McIntyre and Adams 1999, Kochert et al. 2002, McIntyre et al. 2008). Banding and telemetry data collected from the Denali population suggest that wintering areas extend from the Rockies in British Columbia and Washington to the central Great Plains and north-central Mexico (McIntyre et al. 2008, McIntyre 2012).

Denali eagles are the subject of an ongoing long-term ecological study which began in 1988 (McIntyre and Adams 1999, Kochert et al. 2002, McIntyre and Schmidt 2012). This area is home to one of the highest documented Golden Eagle breeding densities in North America (Kochert et al. 2002). Within Denali, eagles nest solely on cliffs, and feed primarily on snowshoe hare (Lepis americanus), ptarmigan (Lagopus sp), and Arctic ground squirrel (Spermophillis parryii) (McIntyre et al. 2006). Prey abundance cycles of snowshoe hare and ptarmigan species have been shown to affect laying rates and nestling productivity, as eagles depend on them before obligate hibernators emerge (McIntyre and Schmidt 2012).

Although Golden Eagles are protected by two acts of Congress, the Bald and Golden Eagle Protection Act and the Migratory Bird Treaty Act, they are experiencing population declines to varying degrees, and they are exposed to threats through much of their range (Kochert et al. 2002, Watson 2010). The Denali population of Golden Eagles has shown longterm declines in nesting rates and fledgling production while territory occupancy has remained steady (McIntyre and Schmidt 2012). These declines in reproductive output are not well explained by conditions on breeding grounds and previous work has suggested they may be 
caused by deterioration of winter habitat (McIntyre and Schmidt 2012). Concerns about the effects of land cover and land use change, especially via energy development, have spurred substantial interest in new movement studies to evaluate these effects year-round (McIntyre 2012).

Pre-adult eagles of the Denali population begin fall migration around September when individuals move away from the summer or natal range (McIntyre et al. 2008). Fall migration initiation dates are usually similar, while variability of end dates suggests some individuals continue migrating until suitable resources are found on winter range (McIntyre et al. 2008). Both southward and northward migration paths for pre-adult eagles from Denali are broad, and different routes are used in fall and spring (McIntyre et al. 2008).

Spring migration begins in late March and early April, and most pre-adult Golden Eagles do not return to Alaska until sometime between mid-May and mid-June. Variability of end dates for pre-adult eagles on spring migration suggest individuals continue migratory movements until adequate resources are found on summer range (McIntyre et al. 2008). In contrast, breeding Golden Eagles return to their territories in the Denali area in late March and complete their egg laying by mid-April (McIntyre and Adams 1999, McIntyre et al. 2008).

\section{STUDY AREA}

The study area for this research incorporates the annual range of the first-year Golden Eagles tagged in Denali. To clarify how behavior may change through the year, I partitioned the annual range into biologically important periods including winter and summer ranges. A brief description of natal range in Denali is also included.

Natal range. Eagles used in this study hatched in a $2100 \mathrm{~km}^{2}$ study area centered at $63^{\circ}$ $35.8^{\prime} \mathrm{N}, 149^{\circ} 38.2^{\prime} \mathrm{W}$, in the northern foothills of the Alaska Range in Denali in central Alaska. Elevations in the natal study area range from $427-2590 \mathrm{~m}$. Topography in this area is rugged and mountainous, and is characterized by steep-sided mountains, swift-running glacial rivers, glacially-carved valleys, and extensive gravel bars (McIntyre et al. 2006). The majority of the study area is above tree line $(800 \mathrm{~m})$. For a more detailed description of the natal study area see McIntyre et al. (2006), and Murie (1944, 1963). 
Winter range. Areas first-year eagles use in winter include the western contiguous United States, from Washington State to the Great Plains, and western Canada, including British Columbia, Alberta, and Saskatchewan, and into northern Mexico (McIntyre et al. 2008). Topography on winter ranges is also highly variable as it includes the high peaks of the central and eastern Rocky Mountains, but also reaches to the flat Great Plains and Prairie Pothole regions. Land cover over this large area is also highly variable, namely due to the wide latitudinal band encompassing winter ranges. Land cover varies from southern New Mexico's shrub desert, to large coniferous stands in the Rockies, and to the grasslands and agricultural areas of the plains (Goward et al. 1987, CEC 2013, NASA LP DAAC, 2013).

Summer range. Areas eagles use in summer include large portions of south central, interior, and northern Alaska, western Yukon Territory, and just into Northwest Territories. Tagged individuals from Denali make extensive movements during the summer season, and do not appear to exhibit a strong degree of homing to their natal areas within Denali (McIntyre et al. 2008). Many individuals use areas north of the Brooks Range in northern Yukon Territories and northern Alaska during their first few summers after hatch year (McIntyre et al. 2008). Topography across their summer range is highly variable, including the Alaska and Brooks Ranges, rolling hills between mountain ranges, and large flats of the coastal plain north of the Brooks Range (Gesch et al. 2002). Vegetative cover in the Arctic and sub-Arctic of these ranges is predominantly shrub cover with large tracts of forest in lower elevations and glaciated and barren mountains at higher elevations. Areas with less topographic variability in this area have relatively more wetlands and bodies of water (Goward et al. 1987, CEC 2013, NASA LP DAAC, 2013).

\section{Literature Cited}

Braham, M., T. Miller, A.E. Duerr, M. Lanzone, A. Fesnock, L. LaPre, D. Driscoll, And T. KATZNER. 2015. Home in the heat: dramatic seasonal variation in home range of desert golden eagles informs management for renewable energy development. Biological Conservation 186:225-232.

Burton, A.C., D. Huggard, E. Bayne, J. Schieck, P. Soolymos, T. Muhly, D. Farr, S. 
Boutin. 2014. A framework for adaptive monitoring of the cumulative effects of human footprint on biodiversity. Environmental Monitoring and Assessment. 186: 3605-3617.

CONVEY, P., AND R.I.L. SMITH. 2006. Responses of terrestrial Antarctic ecosystems to climate change. Plant Ecology 182:1-10.

CEC 2013. 2005 North American Land Cover at $250 \mathrm{~m}$ spatial resolution. Produced by Natural Resources Canada/Canadian Center for Remote Sensing (NRCan/CCRS), United States Geological Survey (USGS); Insituto Nacional de Estadística y Geografía (INEGI), Comisión Nacional para el Conocimiento y Uso de la Biodiversidad (CONABIO) and Comisión Nacional Forestal (CONAFOR). http://landcover.usgs.gov/nalcms.php (last accessed online 9 February 2016).

DunNing, J.B., B.J. DANiELson, AND H.R. Pulliam. 1992. Ecological processes that affect populations in complex landscapes. Oikos 65(1): 169-175.

Gesch, D., M. Oimoen, S. Greenlee, C. Nelson, M. Steuck, And D. Tyler. 2002. The national elevation dataset. Photogrammetric Engineering and Remote Sensing 68: 5-32.

Gibson, L., A.J. Lynam, C.J.A. Bradshaw, F. He, D.P. Bickford, D.S. WoodrufF, S. BUMRUNGSRI, W.F. LAURENCE. 2013. Near-complete extinction of native small mammal fauna 25 years after forest fragmentation. Science. 341: 1508-1510.

Gillanders, S.N., N.C. CoOps, M.A. Wulder, S.E. Gergel, and T. Nelson. 2008. Multitemporal remote sensing of landscape dynamics and pattern change: describing natural and anthropogenic trends. Progress in Physical Geography, 32(5), 503-528.

Goward, S. N., Dye, D., Kerber, A., \& Kalb, V. (1987). Comparison of North and South American biomes from AVHRR observations. Geocarto International, 2. 27-39.

GREENBERG, R, AND P.P. MARRA EDS. 2005. Birds of two worlds: the ecology and evolution of migration. Baltimore, MD. John Hopkins University Press.

Grosbois, V., O Gimenez, J.M. Gaillard, R. Pradel, C. Barbraud, J. Clobert, A.P. MOLLER, AND H. WeIMERSKIRCH. 2008. Assessing the impact of climate variation on survival in vertebrate populations. Biological Reviews. 83:357-399. 
HAegen, W., F.C. Dobler, AND D.J. PierCE. 2000. Shrubsteppe bird response to habitat and landscape variables in eastern Washington, USA. Conservation Biology 14: 1145-1160.

HALL, L.S., P.R. Krausman, AND M.L. MorRison. 1997. The habitat concept and a plea for standard terminology. Wildlife Society Bulletin. 25:173-182.

Hunter, C.M., H. Caswell, M.C. Runge, E.V. Regehr, S.C. Amstrup, I. Stirling. 2010. Climate change threatens polar bear populations: a stochastic demographic analysis. Ecology. 91(10): 2883-2897.

Johnson, C. J., S.E. Nielsen, E.H. Merrill, T.L. MCDonald, M.S. BoyCE. 2006. Resource Selection Functions Based on Use-Availability Data: Theoretical Motivation and Evaluation Methods. Journal or Wildlife Management. 70 (2): 347-357.

JOHNSON, D.H. 1980. The comparison of usage and availability measurements for evaluating resource preference. Ecology. 61: 65-71.

Kaboli, M., A. Guillaumet, AND R. Prodon. 2006. Avifaunal gradients in two arid zones of central Iran in relation to vegetation, climate, and topography. Journal of Biogeography 33: 133-144.

Katzner, T., B.W. Smith, T.A. Miller, D. Brandes, J. Cooper, M. Lanzone, D. Brauning, C. Farmer, S. Harding, D.E. Kramar, C. Koppie, C. Maisonneuve, M. Martell, E.K. Mojica, C. Todd, J.A. Tremblay, M. WheELER, D.F. Brinker, T.E. ChubBs, R. Gubler, K. O’Malley, S. Mehus, B. Porter, R.P. Brooks, B.D. Watts, And K.L. BILDSTEIN. 2012. Status, biology, and conservation priorities for North America's Eastern Golden Eagle (Aquila chrysaetos) population. The Auk. 129(1), 168-176.

Keith, D.A., H.R. Akcakaya, W. Thuiller, G.F. Midgley, R.G. Pearson, S.J. Phillips, H.M. Regan, M.B. ARAuJo, AND T.G. ReBELO. 2008. Predicting extinction risks under climate change: coupling stochastic population models with dynamic bioclimatic habitat models. Biology Letters. 4: 560-563.

KoCHERT, M.N., AND K. STEENHOF. 2002. Golden Eagles in the US and Canada: status, trends, and conservation challenges. Journal of Raptor Research 36: 32-40. 
------, K. Steenhof, C.L. MCInTyRe, And E.H. Craig. 2002. Golden Eagle (Aquila chrysaetos). Number 684 in The Birds of North America. A. Poole and G. Gill, editors. The Birds of North America, Incorporated. Philadelphia, Pennsylvania.

Krausman, P.R. 1999. Some Basic Principles of Habitat Use. Grazing Behavior of Livestock and Wildlife 85-90.

Kunz, T.H., S.A. GauthreauX, N.I. Hristov, J.W. Horn, G. Jones, E.K. KalKo, R.P. Larkin, G.F. MCCRACKEN, R.B. SRYGLEy, AND R. DUdLEy. 2008. Aeroecology: probing and modeling the aerosphere. Integrative and Comparative Biology 48, 1-11.

LitVAitis, J.A. Titus AND E.M. ANDERSON. 1994. Measuring vertebrate use of territorial habitats and foods. P. 254-74. In: T.A. Bookhout (Ed.). Research and Management Techniques for Wildlife and Habitats. 5th ed. The Wildlife Society. Bethesda, MD.

Manly, B.F.J., L.L. MCDonald, D.L. Thomas, T.L. MCDonald, AND W.P. ERICKSON. 2002. Resource selection by animals: statistical analysis and design for field studies. Nordrecht, the Netherlands: Kluwer.

MARRA, P.P., K.A. HobSON, AND R.T. Holmes. 1998. Linking winter and summer events in a migratory bird by using stable-carbon isotopes. Science 282: 1884-1886.

MarZluff, J.M., S.T. KnicK, M.S. VeKaSy, L.S. SchueCK, AND T.J. ZARRIELlO. 1997. Spatial use and habitat selection of golden eagles in southwestern Idaho. The Auk 114(4): 673687.

MCINTYRE, C.L., L.G. ADAMS. 1999. Reproductive Characteristics of Migratory Golden Eagles in Denali National Park, Alaska. Condor. 101:115-123.

------, AND M.W. Collopy. 2006. Postfledging dependence period of migratory golden eagles (Aquila chrysaetos) in Denali National Park and Preserve, Alaska. The Auk 123: 877-884.

-----, D.C. Douglas, M.W. Collopy. 2008. Movements of Golden Eagles (Aquila chrysaetos) from Interior Alaska during Their First-year of Independence. Auk 125: 214-224. 
------. 2012. Quantifying Sources of Mortality and Wintering Ranges of Golden Eagles from Interior Alaska Using Banding and Satellite Tracking. Journal of Raptor Research 46:129-134.

------, AND J.H. SCHMIDT. 2012. Ecological and environmental correlates of territory occupancy and breeding performance of migratory Golden Eagles Aquila chrysaetos in interior Alaska. Ibis 154: 124-135.

Miller, T.A., R.P. Brooks, M.J. Lanzone, J. Cooper, J.A. Tremblay, C. Maisonneuve, K. O’Malley, D. Brandes, J. Wilhelm, A. Duerr, T.E. Katzner. 2014 in review. Selective pressures and resource availability drive space use and movement patterns of a long-lived migratory avian predator. Journal of Avian Biology. In review.

Mitchell, M.S., S.H. Rutzmoser, T.B. Wigley, C. Loehle, J.A. Gerwin, P.D. Keyser, R.A. Lancia, R.W. Perry, C.J. Reynolds, R.E. Thill, and R WeiH. 2006. Relationships between avian richness and landscape structure at multiple scales using multiple landscapes. Forest Ecology and Management 221: 155-169.

Morris, D. L., P.A. Porneluzi, J. Haslerig, R.L. Clawson, And J. FaAborg. 2013. Results of 20 years of experimental forest management on breeding birds in Ozark forests of Missouri, USA. Forest Ecology and Management 310: 747-760.

MorRISON, M.L., B. MARCOT, AND W. MANNAN. 2012. Wildlife-habitat relationships: concepts and applications. Island Press.

MURIE, A. 1944. The wolves of Mount McKinley (Vol. 5). Washington, DC: US Government Printing Office.

MurIE, A. 1963. Birds of Mount McKinley National Park, Alaska. Mount McKinley Natural History Association.

NASA LP DAAC. 2013. MODIS Terra + Aqua Land Cover Type 5 Yearly L3 Global 500m NASA EOSDIS Land Processes DAAC, USGS Earth Resources Observation and Science (EROS) Center, Sioux Falls, South Dakota (https://pdaac.usgs.gov), accessed January 24, 2017, at https://lpdaac.usgs.gov/data_access/reverb. 
PARRY, M.L. Editor. 2007. Climate Change 2007: Impacts, adaptation and vulnerability: contribution of Working Group II to the fourth assessment report of the Intergovernmental Panel on Climate Change 4. Cambridge University Press.

OPDAM, P., AND D. WASCHER. 2004. Climate change meets habitat fragmentation, linking landscape and biogeographical scale levels in research and conservation. Biological Conservation 117(3): 285-297.

PARMESAN, C., G. YOHE. 2003. A globally coherent fingerprint of climate change impacts across natural systems. Nature 421: 37- 42 .

-----. 2006. Ecological and evolutionary responses to recent climate change. Annual Review of Ecology Evolution and Systematics 37: 637-669.

PoPE, S.E., L. FAHRIG, H.G. MERRIAM. 2000. Landscape complementation and metapopulation effects on leopard frog populations. Ecology. 81(9): 2498-2508.

Prugh, L.R., K.E. HodgeS, A.R.E. Sinclair, J.S. BrashaRES. 2008. Effect of habitat area isolation on fragmented animal populations. Proceedings of the National Academy of Sciences. 105(52): 20770-20775.

RAYNolds, M.K., D.A. WALKer, K.J. Ambrosius, J. Brown, K.R. Everett, M. KANEVSKiY, G.P. Kofinas, V.E. Romanovsky, Y. Whur, P.J. WebBer. 2014. Cumulative geoecological effects of 62 years of infrastructure and climate change in ice-rich permafrost landscapes, Prudhoe Bay Oilfield, Alaska. Global Change Biology. 20: 12111224.

SCHOOLEY, R L., AND L.C. BRANCH. 2009. Enhancing the area-isolation paradigm: habitat heterogeneity and metapopulation dynamics of a rare wetland mammal. Ecological Applications. 19(7): 1708-1722.

Sergio, F., P. Pedrini, F. Rizzolli, L. Marchesi. 2006. Adaptive range selection by Golden Eagles in a changing landscape: A multiple modelling approach. Biological Conservation. 133(1): 32-41.

Serreze, M.C., AND J.A. Francis. 2006. The Arctic amplification debate. Climatic Change 76: 241-264. 
STEENHOF, K., M.N. KOCHERT, AND T.L. MCDONALD. 1997. Interactive effects of prey and weather on golden eagle reproduction. Journal of Animal Ecology, 350-362.

SWARTZ, S.M., K.S. BREUER, D.J. WiLLIS. 2008. Aeromechanics in aeroecology: flight biology in the aerosphere. Integrative and Comparative Biology. 48. 85-98.

THEoBALD, D.M. 2010. Estimating natural landscape changes from 1992 to 2030 in the conterminous US. Landscape Ecology. 25: 999-1011.

VAn De Pol, M., Y. Vindenes, B.E. SAether, S. Engen, B.J. Ens, K. Oosterbeek, J. M. TINBERGEN. 2010. Effects of climate change and variability on population dynamics in a long-lived shorebird. Ecology. 91(4): 1192-1204.

WATSON, J. 2010. The Golden Eagle. Second Ed. T. and A.D. Poyser, London, U.K.

WATSON, J.W., A.A. DUfF, AND R.W. DAVIES. 2014. Home range and resource selection by GPS-monitored adult golden eagles in the Columbia Plateau Ecoregion: Implications for wind power development. The Journal of Wildlife Management, 78(6), 1012-1021.

WhitField, D.P., D.R.A. McLeod, A.H. Fielding, R.A. BroAD, R.J. Evans, P.F. HAWORTH. 2001. The effects of forestry on Golden Eagles on the island of Mull, western Scotland. Journal of Applied Ecology. 38: 1208-1220.

Whitfield, D.P., A.H. Fielding, M.J. Gregory, A.G. Gordon, D.R. MCLeOd, AND P.E. HAWORTH. 2007. Complex effects of habitat loss on Golden Eagles Aquila chrysaetos. Ibis. 149: 26-36.

WIENS, J. A. (Ed.). 1992a. The ecology of bird communities Vol. 1. Cambridge University Press

WIENS, J. A. 1992b. Ecological flows across landscape boundaries: a conceptual overview. In Landscape boundaries pp. 217-235. Springer New York. 


\section{Chapter 2}

WHAT EXPLAINS WINTER HOME RANGE SIZE OF FIRST-YEAR MIGRATORY GOLDEN EAGLES FROM INTERIOR ALASKA?

Formatted in the style of Journal of Raptor Research 


\section{ABSTRACT}

Understanding a species space use and associations with its environment is integral to comprehensive wildlife management. However, for some species these associations change spatially and temporally, especially for animals that cover long distances throughout their annual cycle. While many studies of habitat associations and space use concentrate on breeding season behavior, recent studies of migratory connectivity demonstrate the significance of understanding these patterns in the non-breeding season as well. We used three different home range models to investigate space use of 15 first-year Golden Eagles (Aquila chrysaetos) hatched in Denali National Park and Preserve, Alaska, and wintering in western North America. Subsequently, we used land cover, topography and physiographic data to test a priori hypotheses to evaluate drivers of movement behavior. Size of home ranges in winter ranged from 4429 to $69478 \mathrm{~km}^{2}$ and did not differ between sexes. Ranging behavior was best explained by the presence of steep slopes and canyons and degree of topographic roughness. Topographic variables, as well as the presence of broadleaf forest, were influential in explaining size of the home range and core use area, and the presence of topographic factors were, in general, more important than presence of land cover in explaining size of home range. Results from this study further the understanding of drivers of space use and habitat associations for young Golden Eagles on their wintering grounds. These results may also aid the "no net loss" conservation and management strategies for this species in a changing landscape.

Keywords: Aquila chrysaetos, Denali, first-year, Golden Eagle, habitat association, home range, winter 
Wildlife management requires an understanding of species associations with their environment (Morrison et al. 2012). These associations are commonly based on habitat, traditionally defined as vegetative structure (Morrison et al. 2012). Recently, the concept of habitat was expanded to include factors such as topography, soils, elevation and latitude (Haegen et al. 2000, Kaboli et al. 2006, Mitchell et al. 2006, Braham et al. 2015). For birds, the definition of habitat is more complex and now often includes aerial environments, sometimes called the aerosphere (Kunz et al. 2008, Swartz et al. 2008), and strongly influenced by topography.

Understanding habitat associations becomes even more challenging because numerous birds make seasonal migratory movements, across elevational, latitudinal, or longitudinal gradients (Newton 2010). Understanding habitat associations throughout the year is important because, for many bird species, conditions on winter range are linked to survivorship and reproductive output on breeding grounds (Marra et al. 1998, Greenberg and Marra 2005). Although several studies of birds focus on breeding habitat of adults (Opdam 1991, Fletcher and Koford 2002), effective understanding of biology and consequent management, especially for long lived birds, requires extending studies to migration and wintering grounds of all age classes (Kochert and Steenhof 2002, McIntyre et al. 2008).

Many Golden Eagles (Aquila chrysaetos) that breed at northern latitudes in North America are long distance migrants (Kochert et al. 2002). Their seasonal movements can span continents (McIntyre et al. 2008, Miller 2012) and they spend much of the year (often $>5$ months) away from breeding and summer ranges (Kochert et al. 2002, Watson 2010). The biomes that these eagles occupy across these different seasons vary dramatically (Goward et al. 1987). Golden Eagles can breed for multiple decades and they have a long ( $\sim 5 \mathrm{yr})$ and demographically important life stage that precedes breeding (Watson 2010). Unravelling the influence of migratory connectivity on non-breeding eagles across those diverse landscapes is important for understanding the broader relationships between their habitats and their demography (Marra et al. 1998, Kochert and Steenhof 2002, Watson 2010).

A first step towards understanding migratory connectivity is categorizing habitat associations and drivers of animal movement (Marra et al. 1998). Towards this goal, we studied 
winter habitat associations of radio-tagged first-year Golden Eagles from interior Alaska. Previous work on these eagles has focused on their probability of survival, the causes of their fatalities (McIntyre et al. 2006b), and their seasonal movements (McIntyre et al. 2008, McIntyre 2012). To provide insight on potential drivers of winter survival, we characterized the size of their winter home ranges and the habitat associations of those ranges. Specifically, we asked 1) how much space (home ranges and core use areas) do first-year migrant Golden Eagles use in winter, and is the amount of space used influenced by sex of the bird; 2) what habitats are characteristic of spaces they use; and 3) how does variation in habitat parameters explain variation in their ranging behavior.

\section{METHODS}

Nestling Golden Eagles were captured and tagged in a $2100 \mathrm{~km}^{2}$ study area centered at $63^{\circ} 35.8^{\prime} \mathrm{N}, 149^{\circ} 38.2^{\prime} \mathrm{W}$, in the northern foothills of the Alaska Range in Denali National Park and Preserve (Denali). This area is characterized by steep-sided mountains, swift-running glacial rivers, glacially-carved valleys, and extensive gravel bars (McIntyre et al. 2006a). Elevations were $427-2590 \mathrm{~m}$ above sea level and most of the study area was above current tree line (800m).

Denali has one of the highest reported densities of breeding Golden Eagles in North America (Kochert et al. 2002). Golden Eagles at Denali complete clutches by mid-April and nestlings fledge from mid-July through early August (McIntyre and Adams 1999, McIntyre et al. 2006a). Golden Eagles within the park nest solely on cliffs in mountainous terrain and feed primarily on snowshoe hare (Lepis americanus), ptarmigan (Lagopus spp), and Arctic ground squirrel (Spermophillis parryii; McIntyre et al. 2006a).

The winter range of Denali's Golden Eagles spans a large portion of western North America from northern Alberta to north-central Mexico (see McIntyre et al. 2008, McIntyre 2012). Land cover, land use, and topography vary considerably over this expansive area (Goward et al. 1987, Gesch et al. 2002). During winter, Golden Eagle diet includes carrion from wild or domestic large mammals (Marr and Knight 1983, Watson 2010), and small or medium-sized 
mammals (including Lepus spp and Marmota spp), and medium-sized birds (Phasianus colchicus and Tetraonidae) (Kochert et al. 2002, Watson 2010).

Data Collection. Golden Eagle nestlings $>56 \mathrm{~d}$ of age were radio-tagged in late July and early August in 1997, 1998, and 1999 (McIntyre et al. 2008). Eagles were fitted with a 95g satellite Platform Terminal Transmitter (PTTs; Microwave Telemetry, Columbia, Maryland, U.S.A.) attached with Teflon ribbon in a backpack configuration. These PTTs used the Argos satellite tracking system to record locations estimated based on Doppler shift and to transmit data (McIntyre et al. 2008). Duty cycles for the transmitters were $8 \mathrm{hr}$ on and $72 \mathrm{hr}$ off in 1997, and 8 hr on and $48 \mathrm{hr}$ off in 1998 and 1999 (McIntyre et al. 2008). For our analyses, we had sufficient winter data ( $>$ three weeks) to model home ranges of 15 individuals ( 8 males, 7 females); 7 were tagged in 1997 and 8 in 1999.

Data Processing and Management. Each Argos telemetry fix is associated with a location class indicating a precision that ranges from $125 \mathrm{~m}$ (class 3) to $12 \mathrm{~km}$ (class Z) (Argos 1996). Argos locations are categorized as standard-class $(3,2,1)$, and auxiliary-class $(0, \mathrm{~A}, \mathrm{~B}, \mathrm{Z})$ (Argos 1996). We applied the Douglas Argos Filter (Douglas et al. 2012) to reduce error of location fixes using the filter parameters from McIntyre et al. (2008). We then manually filtered data further, removing implausible movement spikes (e.g., three sequential points where the first and last locations were close in proximity but the middle point was $>200 \mathrm{~km}$ away with an atypically acute internal turning angle). The unfiltered telemetry data collected on individuals used in these analyses were comprised of 19.1\% standard-class and $80.9 \%$ auxiliary-class Argos location quality class fixes. After accuracy filtering the telemetry data used in these analyses were comprised of $49.3 \%$ standard-class and $50.7 \%$ auxiliary-class fixes (Appendix A.1 SI Table 1). Filtering removed $60 \%$ of the available telemetry data.

We focused analyses on data collected during the winter season. We defined arrival on winter range as data points that had $<200 \mathrm{~km}$ between consecutive telemetry fixes and that were not in the direction of migration (primarily in a southeast direction; McIntyre et al. 2008). Conversely, we defined the end of the winter season as movements between consecutive telemetry locations that exceeded $200 \mathrm{~km}$ that occurred in the direction of migration (primarily 
northwest). Because it is difficult to separate migratory stopovers from wintering locations as eagles reach the end of their first autumn migration, the $200 \mathrm{~km}$ movement threshold we used meant that arrival and departure dates are slightly different than those previously reported in McIntyre et al. (2008) and our home ranges may include some locations on migration. To adjust for the possible inclusion of migration locations in the winter range dataset we used two different home range isopleths (95\% and 50\% isopleth see below), and completed habitat associations at two spatial scales.

Golden Eagle Winter Home Range and Core Use Estimation. We tested three different approaches to model winter home range and space use of first-year Golden Eagles including minimum convex polygon (MCP), kernel density estimation (KDE) and Brownian bridge movement models (BBMM) (Worton 1989, Horne et al. 2007). We calculated MCP home ranges to allow comparisons to historical studies. Kernel density estimates (KDEs) are used more frequently than MCPs because they are generally viewed as more informative and biologically relevant and they also allow estimation of core areas within home ranges (Worton 1989). BBMMs are kernel derived and appropriate for use on species that make long-distance movements within their seasonal range (Fischer et al. 2013). They are unique in that they incorporate temporal autocorrelation and error estimation of telemetry fixes in home range calculation.

We calculated MCPs and KDEs in the Geospatial Modeling Environment (Spatial Ecology LLC, Beyer 2012) within R and ArcMap. We also estimated home ranges with Brownian Bridge Movement Models (with the R package BBMM; Nielson et al. 2011). For KDEs and BBMMs, we constructed both home ranges (95\% isopleth) and core use areas (50\% isopleth).

Habitat Association. Of the three home range models evaluated, KDEs seemed most biologically appropriate (see discussion). Thus we report home range sizes for all models (KDEs, MCPs, and BBMMs) but focus our interpretation of results and habitat modeling exclusively on the KDEs. We used ArcMap 10.2.2 to calculate the latitudinal centroid of the individual winter 
home ranges and core use areas to associate winter home ranges and core use areas with land cover, land use, topography, and physiography.

For each winter home range and core use area, we extracted land cover and land use data from the Commission for Environmental Cooperation 2005 land cover dataset (CEC 2013). These land cover data were those available that were collected closest to the time of telemetry data collection and were the most comprehensive and highest resolution $(250 \mathrm{~m})$ available for all of the countries wintering eagles used. To simplify the land cover and land use dataset, we converted the 19 CEC classes of vegetative cover into 7 broader classes used for analyses (Table 1). Within the CEC dataset many of the land cover categories have three regional types (tropical, temperate, and sub-polar), thus we combined each regional type together to create a broader land cover category. For example 'temperate or sub-polar needleleaf forest' and 'sub-polar taiga needleleaf forest' were combined into the broader 'coniferous forest' land cover category. Classes that appeared only in very small parts $(\bar{x}<2.4 \%)$ of eagle ranges were combined into an 'other' category.

We calculated three topographic characteristics for each home range and core use area (Braham et al. 2015) including mean topographic roughness ratio (mean TRI; DEM Surface Tools; Jenness 2013), categorical topographic position index (TPI; Land Facet Corridor Designer; Jenness 2013), and elevation range ( $\max$ - min elevation to calculate range). TRI is a ratio of surface area to planar area that provides a relative measure of roughness in a defined area. Mean TRI values calculated with DEM Surface Tools are continuous, and range, for example, from 1.0041 for flat areas such as eastern Montana, to 1.0395 for rugged mountainous areas such as western Montana. We selected a four-category TPI (canyon, steep slope, gentle slope, and ridge; Jenness 2013, Braham et al. 2015) to describe topography within Golden Eagle ranges and we measured the proportion of home range and core areas that was composed of each TPI category. In each case, topography data were calculated directly from (in the case of elevation) or derived from (in the case of TRI and TPI) 30m USGS digital elevation models (DEM/NED; Gesch et al. 2002). 
Data Analyses. We used a Mann-Whitney U-test to compare winter range arrival and departure dates and size of $\mathrm{KDE}$ winter home ranges and core use areas between male and female eagles. We then characterized habitat associations (topography and land cover) within individual home ranges and core use areas, again with descriptive statistics (e.g., percent land cover, elevation range, mean TRI, and categorical TPI variables).

To identify habitat parameters that may explain variation in home range size of eagles, we developed a set of generalized linear mixed models (GLMMs) that evaluated relationships of land cover and topographic parameters to Golden Eagle home range and core area size in winter. We tested variables for collinearity with all other model variables using variance inflation factors and we removed highly correlated variables from model development. In each model, we used the number of days of telemetry data, binned into $50 \mathrm{~d}$ intervals, as a random effect to control for variation in eagle and telemetry unit lifespans. We first created a global model with all parameters (Combined Full model) and we then compared the explanatory value of that model to a set of a priori defined sub-models to answer specific questions regarding land cover, topography, and physiography variables that may influence home range size (see below for questions). We performed model selection using Akaike Information Criterion adjusted for small sample size (AICc) and we model averaged results (Burnham and Anderson 2002). We report models that had support in the data as those with model likelihood of $>0.10$ (Braham et al. 2015).

Our first group of hypotheses about eagle home range sizes were based on expectations about known characteristics of eagle biology and land cover associations. Golden Eagles are commonly thought to associate with Lagomorph prey (Watson 2010), and Lagomorphs with shrub habitat (Knick and Dyer 1997, Marzluff et al. 1997, Kochert and Steenhof 2002). Therefore, to test if home range size of wintering Golden Eagles was determined by potential Lagomorph-shrub habitat associations, we modeled the response of eagle home range size to shrub cover within home ranges (we named this the Lagomorph Prey model).

Other types of land cover may provide multiple benefits to eagles. For example, Golden Eagles may benefit by associating with land cover classes that provide thermal protection or 
protection from predators or mobbing birds (other raptor species demonstrate this "sheltering" behavior; Forsman et al. 1984, Yackel Adams et al. 2000). Sheltering habitats for eagles during winter may include either conifer forest or broadleaf forest. Both forest land cover types offer protection from predators and mobbing birds, while coniferous forest may offer better thermal protection during winter. Both of these types of forests are also associated with native ungulates (e.g., elk (Cervus elaphus), and white-tailed (Odocoileus virginianus) and black-tailed (O. hemionus) deer; Telfer 1970; Unsworth et al. 1998; Mysterud and Ostbye 1999; Poole and Mowat 2005) whose carcasses are important carrion resources for wintering eagles (Watson 2010). To evaluate support for these three potential drivers of eagle resource use, we modeled the response of eagle home range size to cover of both forest types alone (Broadleaf Forest and Coniferous Forest models) and the two combined (Combined Forest model).

Wintering Golden Eagles also may feed on carrion of wild or domestic ungulates associated with grassland habitats (e.g., pronghorn (Antilocapra americana; Barrett 1984), American bison (Bison bison; Knapp et al. 1999) and cattle (Bos taurus)). Therefore, to test if home range size of wintering Golden Eagles was determined by potential grazer-grassland habitat associations, we modeled the response of eagle home range size to grassland cover within home ranges (Grassland Ungulate model). Finally, we compared all of these habitat sub-models to a full model for all land cover variables together (Land Cover model). The land cover variable 'mixed forest' was highly correlated with the other forest types in the model (coniferous and broadleaf forests) and so we removed it from the model. We also removed the land cover category 'other' as it was non-descriptive (i.e., difficult to biologically interpret) and the least influential variable in the model set. This left a total of five land cover variables in the models.

We developed a second group of hypotheses about eagle home range size that we could test with topography data. Golden Eagles use orographic updraft extensively to subsidize their migration (Brandes and Ombalski 2004) and flight at other times of the year (Duerr et al. 2014, Braham et al. 2015, and Poessel et al. 2016). Areas with higher values of mean TRI or with steep slopes have the potential to provide orographic updraft. Therefore, to test if winter home range size was determined by potential for orographic updraft, we modeled the response of eagle home range size to two different estimates of topographic roughness within home ranges: the 
proportion of the home range made up of the TPI category 'steep slopes' (Orographic Updraft 1 model), and the mean TRI of the home range (Orographic Updraft 2 model).

It seems plausible that Golden Eagles may search out similar topographic habitat in winter as in summer as it supplies essential features for eagles. Golden Eagle nests in Denali are primarily on cliffs near steep slopes (McIntyre et al. 2006a). To test if home range size of wintering Golden Eagles was determined by topographic variables, we modeled the response of eagle home range size to the proportion of the home range made up of the two TPI categories 'canyon' and 'steep slope' together (Natal Range Characteristics model).

Finally, it also seems possible that Golden Eagle ranging behavior responds to the latitude at which they settle. We know, for example, that land cover varies by latitude, and thus eagle response to land cover may reflect these trends. To test this idea, we modeled the response of eagle home range size to the latitude at the centroid of the eagle's core use area $(50 \% \mathrm{KDE}$ isopleth; Latitude model). We also compared all of these sub-models to a full model for physiography including mean TRI, two TPI categories (canyon, steep slope), elevation range, and latitude variables (Physiography model). We removed the two topographic positions categories gentle slope and ridge because they were highly correlated with the categories steep slope and canyon, respectively.

\section{RESULTS}

Winter distribution of the 15 tracked Golden Eagles included much of the Rocky Mountain region of central North America, from northern Alberta to southern New Mexico (Fig. 1a). On average, we tracked these birds for $\bar{x}=152.5 \pm 34.6 \mathrm{~d}(89-184 \mathrm{~d})$ during their first winter. Average arrival date on winter range was 11 November \pm 22 d (range: 24 October -28 December) for females and 13 November $\pm 23 \mathrm{~d}$ (23 October - 02 January) for males. Average departure from winter range by females $(n=7)$ was 19 April $\pm 14 \mathrm{~d}$ (25 March - 08 May) and by males $(n=6)$ was on 1 April \pm 31 d (10 February - 30 April). There was no significant difference between the sexes in arrival $(W=32.5, \mathrm{p}=0.64)$ or departure dates $(W=19.0, \mathrm{p}=$ 0.32 ). 
Size of Winter Ranges. Size of winter home ranges of first-year eagles varied widely from 4429 to $69478 \mathrm{~km}^{2}$. We did not detect a difference between sexes in size of first winter home range (males $\bar{x}=23581 \mathrm{~km}^{2}$, females $\bar{x}=26724 \mathrm{~km}^{2}, W=31.0, \mathrm{p}=0.78$ or core use areas (males $\bar{x}=3544 \mathrm{~km}^{2}$, females $\bar{x}=4899 \mathrm{~km}^{2}, W=32.0, \mathrm{p}=0.69$; Appendix A.1 SI Table 2).

Characteristics of Winter Home Ranges. Land cover within winter home ranges (KDE $95 \%$ isopleth) was dominated by grassland ( $\bar{x}=28.1 \pm 28.8 \%$ ), shrub ( $\bar{x}=24.9 \pm 26.3 \%$ ), coniferous forest ( $\bar{x}=21.0 \pm 22.1 \%$ ), and cropland $(\bar{x}=15.86 \pm 23.59 \%)$. Land cover categories that were least well represented in eagle home ranges included broadleaf forest $(\bar{x}=4.0 \% \pm$ $10.0 \%)$, mixed forest $(\bar{x}=3.7 \pm 9.6 \%)$, and 'other' $(\bar{x}=2.4 \pm 2.6 \%$; Fig. 2a; Appendix A.1 SI Table 3a).

TPI measurements suggested that winter home ranges were composed predominantly of ridges $(\bar{x}=35.4 \pm 10.4 \%)$, canyons $(\bar{x}=39.4 \pm 13.2 \%)$ and gentle slopes $(\bar{x}=24.2 \pm 24.0 \%)$, with very little steep slope $(\bar{x}=0.9 \pm 0.7 \%)$. TRI in home ranges was moderately flat (mean TRI $\bar{x}=1.019 \pm 0.021$ ). Actual elevation within home ranges ranged from 239 to $4199 \mathrm{~m}$ ASL and the elevational range within home ranges also tended to be highly variable (max - min elevation within home ranges, $\bar{x}=1560 \pm 1141 \mathrm{~m})$.

Characteristics of Winter Core Use Areas. Land cover within winter core use areas (KDE 50\% isopleth) were nearly identical to those within home ranges. Core use areas were dominated by grassland ( $\bar{x}=29.5 \pm 32.7 \%)$, shrub $(\bar{x}=24.8 \pm 28.3 \%)$, coniferous forest $(\bar{x}=$ $20.2 \pm 26.3 \%$ ), and cropland ( $\bar{x}=14.4 \pm 22.9 \%)$. Land cover categories that were least well represented again included broadleaf forest $(\bar{x}=6.1 \pm 14.7 \%)$, mixed forest $(\bar{x}=2.77 \pm 7.1 \%)$, and 'other' ( $\bar{x}=2.2 \pm 3.4 \%$; Fig. 2b; Appendix A.1 SI Table 3b).

TPI of winter core use areas also were similar to those of home ranges. Core use areas were dominated by canyons $(\bar{x}=45.2 \pm 16.1 \%)$ and ridges $(\bar{x}=42.3 \pm 17.9 \%)$. Gentle slopes were common in core areas $(\bar{x}=17.6 \pm 16.2 \%)$ and steep slopes were uncommon $(\bar{x}=6.8 \pm$ 25.7\%). Topographic roughness in core use areas was moderately flat (mean TRI $\bar{x}=1.022 \pm$ 
0.026), with similar mean TRI values to home ranges. Actual elevation within core use areas varied from 248 to $4,199 \mathrm{~m}$, and elevation range within core use areas were highly variable (min - max within core use areas $\bar{x}=1366 \pm 966 \mathrm{~m}$ ).

Determinants of Winter Home Range Size. Our best model of habitat associations for home range size, the first Orographic Updraft model, suggested that the proportion of home range composed of steep slopes (TPI) had the strongest influence on determining area of home range of first-year Golden Eagles in winter (Table 2). Three other models that had support in the data included variables for TPI category canyon, cover of broadleaf forests, and mean TRI within the home range. All other models we tested were generally less effective predictors of home range size, with AICc weights $<0.10$. These included the Coniferous Forest model, the Land Cover model, and the Physiography model. Likewise, models based on latitude, shrub, grassland, cropland, combined forest (coniferous and broadleaf combined) land cover variables, as well as the full model, were relatively poor predictors of home range size (Table 2a).

Model averaged results suggested that home range size was positively associated with the proportion of TPI category steep slopes (Table 3a, Fig 3a), and mean TRI (Table 3a). Likewise, they indicated that home range size was negatively associated with the proportion of TPI category canyon and the proportion of home range with broadleaf forest land cover (Table 3a).

Determinants of Winter Core Use Area Size. Our best models of habitat associations for core use area (KDE 50\% isopleth) suggested similar trends to the home range models. Again, models with TPI canyon, TPI steep slopes, and broadleaf forest land cover variables best explained size of core areas of first-year Golden Eagles in winter (Table 2b). Although broadleaf forest land cover only comprised a small percentage of the overall land cover within core use areas, and models with broadleaf forest were only weakly supported, this variable was more influential in determining space use than any other land cover variables (Table 2b). All other models we tested were generally poor predictors of core use area size, with AICc weights $<0.10$. Once again, models based on latitude, shrub, grassland, cropland, combined forest (coniferous and broadleaf combined), elevation range, and all full models were generally poor predictors of core use area size (Table $2 b$ ). 
Model averaged results suggested that core use area size was negatively associated with the proportion of core use area with broadleaf forest land cover (Table 3b; Fig 3b), and presence of TPI canyon. Core use area size was positively associated with mean TRI (Fig 3c), and presence of TPI steep slope (Table 3b).

\section{DISCUSSION}

Our analyses provided information on space use and the drivers of variation in space use of wintering first-year Golden Eagles from interior Alaska. Although winter home range and core use area size of first-year Golden Eagles showed strong responses to topographical variables that likely assist orographic soaring, home range and core use area size showed only limited responses to land cover. These data provide a context for interpreting patterns in winter habitat use and insight into potential conservation strategies for the species in the face of potential habitat changes.

Space Use and Habitat Association. In general, home ranges modeled with KDEs represented movements of the tagged eagles in a manner more biologically reasonably than did home ranges estimated with the other modeling approaches (Fig. 1b, Appendix A.1 SI Table 2). We therefore used KDEs for subsequent analyses.

First-year Golden Eagles showed great variation in space use in winter. Home ranges and core use areas we calculated tended to be larger than those reported for non-migrant populations (Marzluff et al. 1997, Watson et al. 2014, Braham et al. 2015, Poessel et al. 2016), but were more similar to those of other migrant populations (Miller 2012, Domenech et al. 2015). Home ranges we measured also tended to be larger than those of older, territorial birds (Marzluff et al. 1997, Braham et al. 2015, Poessel et al. 2016), and more similar to reported home range size for younger eagles (Weston et al. 2013). The difference in space use by the eagles we studied and those reported for non-migratory and adult Golden Eagles elsewhere may be due to several factors. First, eagles of this young age-class are not defending breeding territories, nor are they familiar with the landscape, and thus they wander more (Watson 2010). Nevertheless, birds from the Alaska population in particular are known to wander more in the summer than winter 
(McIntyre et al. 2008). Second, these birds are at the youngest end of the age range of pre-adult eagles and thus they may tend to use more space than would slightly more experienced birds (Watson 2010).

We observed a great deal of variation in land cover associations within winter home range and core use areas of the first-year Golden Eagles we monitored. This is not surprising given the wide range of latitudes (from central Canada to near Mexico) and biomes across which these birds wintered. In contrast, topographic characteristics were less variable than land cover characteristics within winter home range and core use areas. These patterns are not surprising given the generalist nature of this species, but they provide insight into the habitat features that may affect eagle ranging behavior.

Drivers of Variation in Space Use. Our averaged models describing variation in eagle ranging behavior always included important roles for measures of topographic position and roughness, consistent with hypotheses linking orographic updraft to ranging behavior. The presence of steep slopes in particular had a strong, positive influence on home range size, and a stronger positive influence on core use area size. The presence of canyons had a small negative influence on home range size and on core area size, but this parameter was still relatively more influential than land cover variables at both spatial scales (home range and core use area).

Our results demonstrate the importance of including topographic variables in habitat associations for this species. This pattern was important in both core areas and home ranges, suggesting that topography provides critical features important regardless of the spatial scale at which eagles are selecting habitat. Furthermore, when land cover variables did show up in models, they did so in unexpected ways. For example, although broadleaf forest land cover was a small percentage of overall land cover it was influential to both core use areas and home ranges. This pattern runs contrary to reports that this species is primarily an open-country bird (Watson 1991, Haller and Sackl 1997, Pedrini and Sergio 2001) and it may suggest that wintering eagles use these forested habitats for roosting or some other critical behavior such as protection from mobbing birds. 
There are several potential reasons why topography may matter more than land cover in determining eagle ranging behavior. At a basic level, topography may be important in providing favorable opportunities for hunting, and suitable perching. Likewise, topographic characteristics have a strong influence on the aerosphere (Kunz et al. 2008), especially because winds interact with topographic features to create potential orographic updraft. This matters to Golden Eagles because they rely heavily on updraft to subsidize their flight and reduce costly energetic output (Katzner et al. 2015). Thus it is not surprising that regardless of spatial scale, Golden Eagle ranging behavior would be strongly influenced by availability of orographic updraft.

The relative significance of a priori sub models we tested also are informative about other aspects of eagle biology. For example, latitude and proportion of shrub and most forest cover parameters generally poorly explained variation in home range size. By inference, this suggests that vegetative land cover, regardless of type, is of relatively low importance to habitat selection by eagles. This is unexpected since there are many reports of resource selection by eagles that have found associations between eagles and vegetative land cover (e.g., Whitfield et al. 2007, Watson et al. 2014). Our analyses suggest that these parameters are relatively less important to eagles than are topographic characteristics.

Conclusion. There are several consequences to understanding the tight relationship between topography and eagle ranging behavior. First, this knowledge contextualizes limits to eagles and illustrates how eagle ranging behavior is driven by energetics and the availability of flight subsidy. This may suggest that first-year eagles in winter are more constrained by energetic expenditures (the costs of flight) than by energetic incomes (food acquisition). Second, this knowledge contextualizes mechanisms by which eagles may be affected by climate change. Topography, and even updraft, will likely change less than land cover in response to climate change. Thus, the mechanisms by which wintering first-year eagles may be affected by climate change are likely via availability of their prey, many species of which rely on land cover types that rapidly are changing throughout much of western North America (for example Lagomorphs and shrub cover; Anderson and Inouye 2001, Knick et al. 2003, Chambers and Pellant 2008, Xian et al. 2012). Thus, it may be that the energetic limitations eagles face, currently driven 
especially by expenditures and flight subsidy, could change to be more strongly influenced by income and food acquisition.

The US Fish and Wildlife Service manages Golden Eagle populations for no net loss in eagle population size (US Fish and Wildlife Service 2016). Understanding the relative role of topography, land cover, and energetics in eagle ranging behavior may be relevant in support of this goal. Although this study focused on wintering first-year Alaskan eagles, it likely also is relevant to non-migratory and non-breeding eagles, all of which have similar flight behavior and may also use similar roosting resources during winter.

\section{ACKNOWLEDGMENTS}

This research was funded by Denali National Park and Preserve and the US Geological Survey. Eagles were captured and banded under USGS banding permit 22035. The Oregon State University Animal Care and Use Committee approved the capture, handling, and attachment protocols (AUF no. 1962). Analytical and technical assistance were provided by M. Braham, T. Miller, and L. Dunn with additional assistance from members of the Katzner lab group. 


\section{LITERATURE CITED}

ANDERSON, J.E., AND R.S. INOUYE. 2001. Landscape-scale changes in plant species abundance and biodiversity of a sagebrush steppe over 45 years. Ecological Monographs, 71:531556.

ARGOS. 1996. User's Manual. [Online.] CLS/SERvice Argos. Toulouse, France. AVAILABLE AT WWW.ARGOS-SYSTEM.ROG/MANUAL.

BARRETT, M. W. 1984. Movements, habitat use, and predation on pronghorn fawns in Alberta. The Journal of wildlife management, 542-550.

BEyER, H. L. 2012. Geospatial Modelling Environment (Software Version 0.7. 2.1). http://www.spatialecology.com/gme. (last accessed 17 May 2016).

Braham, M., T. Miller, A.E. Duerr, M. Lanzone, A. Fesnock, L. LaPre, D. Driscoll, And T. KATZNER. 2015. Home in the heat: dramatic seasonal variation in home range of desert golden eagles informs management for renewable energy development. Biological Conservation 186:225-232.

BRANDES, D., AND D.W. OMBALSKI. 2004. Modeling raptor migration pathways using a fluidflow analogy. Journal of Raptor Research. 38:195-207.

BuRnhAM, K.P., AND D.R. ANDERSON. 2002. Model selection and multimodel inference. New York. NY: Springer.

CEC 2013. 2005 North American Land Cover at $250 \mathrm{~m}$ spatial resolution. Produced by Natural Resources Canada/Canadian Center for Remote Sensing (NRCan/CCRS), United States Geological Survey (USGS); Insituto Nacional de Estadística y Geografía (INEGI), Comisión Nacional para el Conocimiento y Uso de la Biodiversidad (CONABIO) and Comisión Nacional Forestal (CONAFOR). http://landcover.usgs.gov/nalcms.php (last accessed online 9 Febraury 2016). 
Chambers, J.C., AND M. Pellant. 2008. Climate change impacts on northwestern and intermountain United States rangelands. Rangelands 30:29-33.

Domenech, R., B.E. Bedrosian, R.H. Crandall, V.A. Slabe. 2015. Space use and habitat selection by adult migrant golden eagles wintering in the western United States. Journal of Raptor Research 49: 429-440.

Douglas, D.C., R. Weinzierl, S.C. DAvidson, R. KAYs, M. WiKelsKi, AND G. Bohrer. 2012. Moderating Argos location errors in animal tracking data. Methods in ecology and Evolution. 3: 999-1007.

Duerr, A.E., T.A. Miller, M. Lanzone, D. Brandes, J. Cooper, K. O’Malley, C. Maisonneuve, J. Tremblay, T. Katzner. 2012. Testing an Emerging Paradigm in Migration Ecology Shows Surprising differences in Efficiency between Flight Modes. Public Library of Science One. 7:e35548.

FisCher, J.W., W.D. WALTER, AND M.L. AVERY. 2013. Brownian bridge movement models to characterize birds' home ranges. Condor 115: 298-305.

FLETCHER JR, R.J., AND R.R. KOFORD. 2002. Habitat and landscape associations of breeding birds in native and restored grasslands. The Journal of wildlife management, 1011-1022.

Forsman, E.D., E.C. Meslow, And H.M. Wight. Distribution and biology of the spotted owl in Oregon. Wildlife Monographs 87: 3-64.

Gesch, D., M. Oimoen, S. Greenlee, C. Nelson, M. Steuck, And D. Tyler. 2002. The national elevation dataset. Photogrammetric Engineering and Remote Sensing 68: 5-32.

Goward, S. N., Dye, D., Kerber, A., \& Kalb, V. (1987). Comparison of North and South American biomes from AVHRR observations. Geocarto International, 2. 27-39. 
GREENBERG, R, AND P.P. MARRA EDS. 2005. Birds of two worlds: the ecology and evolution of migration. Baltimore, MD. John Hopkins University Press.

HAEgen, W., F.C. Dobler, And D.J. Pierce. 2000. Shrubsteppe bird response to habitat and landscape variables in eastern Washington, USA. Conservation Biology 14: 1145-1160.

HALLER, H. AND P. SACKL. 1997. Golden Eagle Aquila chrysaetos. In Hagemeijer, W.J.M and M.J. Blair (eds) The EBCC Atlas of European Breeding Birds, their Distribution and Abundance: 170-171. T. and A.D. Poyser, London,

Horne, J.S., E.O. GARTON, S.M. KRONE, AND J.S. LEWIS. 2007. Analyzing animal movements using Brownian bridges. Ecology 88, 2354-2363.

JENNESS, J. 2013. DEM Surface Tools v.2.1.375. Jenness Enterprises. Available from http://www.jennessent.com/arcgis/surface_area.htm. (last accessed 17 April 2016).

-----, B. BRost, AND P. BeIER. 2013. Land Facet Corridor Designer v.1.2.884. Jenness Enterprises. Available from http://www.jennessent.com/arcgis/land_facets.htm. (last accessed 17 April 2016).

Kaboli, M., A. Guillaumet, AND R. Prodon. 2006. Avifaunal gradients in two arid zones of central Iran in relation to vegetation, climate, and topography. Journal of Biogeography 33: 133-144.

Katzner, T.E., P.J. Turk, A.E. Duerr, T.A. Miller, M.J. Lanzone, J.L. CoOPer, D. Brandes, J.A. TREMBLAY, AND J. LEMAÎTRE. 2015. Use of multiple modes of flight subsidy by a soaring terrestrial bird, the golden eagle Aquila chrysaetos, when on migration. Journal of The Royal Society Interface 12: 20150530.

Kochert, M.N., AND K. STEENHOF. 2002. Golden Eagles in the US and Canada: status, trends, and conservation challenges. Journal of Raptor Research 36: 32-40. 
------, K. Steenhof, C.L. MCInTyRe, AND E.H. Craig. 2002. Golden Eagle (Aquila chrysaetos). Number 684 in The Birds of North America. A. Poole and G. Gill, editors. The Birds of North America, Incorporated. Philadelphia, Pennsylvania.

KnaPP, A.K., J.M. BlaiR, J.M. BRiggs, S.L. Collins, D.C. HARTNETt, L.C. Johnson, AND E.G. TOwNE. 1999. The keystone role of bison in North American tallgrass prairie: Bison increase habitat heterogeneity and alter a broad array of plant, community, and ecosystem processes. BioScience, 49: 39-50.

KNICK, S.T., AND D.L. DYER. 1997. Distribution of black-tailed jackrabbit habitat determined by GIS in southwestern Idaho. Journal of Wildlife Management 61: 75-85.

------, D.S. Dobkin, J.T. Rotenberry, M.A. Schroeder, W.M. VAnder HAegen, And C. VAN RIPER III. 2003. Teetering on the edge or too late? Conservation and research issues for avifauna of sagebrush habitats. Condor 105: 611-634.

Kunz, T.H., S.A. GauthreauX, N.I. Hristov, J.W. Horn, G. Jones, E.K. Kalko, R.P. Larkin, G.F. McCracken, S.M. SwartZ, R.B. Srygley, and R. Dudley. 2008. Aeroecology: probing and modeling the aerosphere. Integrative and Comparative Biology 48: 1-11.

MARR, N.V., AND R.L. KNIGHT. 1983. Food habits of golden eagles in eastern Washington. Murrelet 64: 73-77.

MARRA, P.P., K.A. Hobson, AND R.T. Holmes. 1998. Linking winter and summer events in a migratory bird by using stable-carbon isotopes. Science 282: 1884-1886.

MarZluff, J.M., S.T. KNICK, M.S. VeKaSy, L.S. SChUECK, AND T.J. ZarRIELlO. 1997. Spatial use and habitat selection of golden eagles in southwestern Idaho. Auk 114: 673-687.

MCINTYRE, C.L., L.G. ADAMS. 1999. Reproductive Characteristics of Migratory Golden Eagles in Denali National Park, Alaska. Condor 101:115-123. 
-----, M.W. Collopy, J.G. KidD, A.A. STICKNEY, AND J. PAYNTER. 2006a. Characteristics of the landscape surrounding Golden Eagle nest sites in Denali National Park and Preserve, Alaska. Journal of Raptor Research 40: 46-51.

-----, M.W. COLLOPY, M.S. LinDBERG. 2006b. Survival probability and mortality of migratory Golden Eagles from interior Alaska. Journal of Wildlife Management. 70: 717-722.

------, D.C. Douglas, M.W. Collopy. 2008. Movements of Golden Eagles (Aquila chrysaetos) from Interior Alaska during Their First-year of Independence. Auk 125: 214-224.

------, C.L. 2012. Quantifying Sources of Mortality and Wintering Ranges of Golden Eagles from Interior Alaska Using Banding and Satellite Tracking. Journal of Raptor Research. 46(1):129-134.

MiLleR, T.A. 2012. Movement ecology of golden eagles (Aquila chrysaetos) in eastern North America (Doctoral dissertation, The Pennsylvania State University).

Mitchell, M.S., S.H. Rutzmoser, T.B. Wigley, C. Loehle, J.A. Gerwin, P.D. Keyser, R.A. Lancia, R.W. Perry, C.J. Reynolds, R.E. Thill, AND R Weit. 2006. Relationships between avian richness and landscape structure at multiple scales using multiple landscapes. Forest Ecology and Management 221: 155-169.

MorRISON, M.L., B. MARCOT, AND W. MANNAN. 2012. Wildlife-habitat relationships: concepts and applications. Island Press.

Mysterud, A., AND E. ØSTBYE. 1999. Cover as a habitat element for temperate ungulates: effects on habitat selection and demography. Wildlife Society Bulletin 27: 385-394.

Newton, I. 2010. The migration ecology of birds. Academic Press. 
NiELSON, R.M., H. SAWYER, AND T.L. MCDONALD. 2011. BBMM: Brownian bridge movement model for estimating the movement path of an animal using discrete location data. $R$ package, version 22 .

OPDAM, P. 1991. Metapopulation theory and habitat fragmentation: a review of holarctic breeding bird studies. Landscape ecology, 5(2), 93-106.

PEDrini, P., AND F. SERGIO. 2001. Golden Eagle Aquila chrysaetos density and productivity in relation to land abandonment and forest expansion in the Alps. Bird Study 48. 194-199.

Poessel, S.A., P.H. Bloom, M.A. Braham, And T.E. Katzner. 2016. Age-and season-specific variation in local and long-distance movement behavior of golden eagles. European Journal of Wildlife Research 62: 1-17.

PoOLE, K.G., AND G. MowAT. 2005. Winter habitat relationships of deer and elk in the temperate interior mountains of British Columbia. Wildlife Society Bulletin 33: 1288-1302.

SWARTZ, S.M., K.S. BREUER, AND D.J. WILLIS. 2008. Aeromechanics in aeroecology: flight biology in the aerosphere. Integrative and Comparative Biology 48: 85-98.

TELFER, E.S. 1970. Winter habitat selection by moose and white-tailed deer. Journal of Wildlife Management 34: 553-559.

U.S. FisH AND WiLdlife SERVICE. 2016. Bald and Golden Eagles: Population demographics and estimation of sustainable take in the United States, 2016 update. Division of Migratory Bird Management, Washington D.C., USA.

Unsworth, J.W., L. KUCK, E.O. GARTON, AND B.R. ButTERFIELD. 1998. Elk habitat selection on the Clearwater national forest, Idaho. Journal of Wildlife Management: 1255-1263. 
WATSON, J. 1991. The Golden Eagle and pastoralism across Europe. In Curtis, D.J., E.M. Bignal, and M.A. Curtis (eds). Birds and Pastoral Agriculture in Europe 56-57. Argyll and Joint Nature Conservation Committee, Peterborough.

-----. 2010. The Golden Eagle. Second Ed. T. and A.D. Poyser, London, U.K.

Watson, J.W., A.A. DufF, AND R.W. DAVIES. 2014. Home range and resource selection by GPS-monitored adult golden eagles in the Columbia Plateau Ecoregion: Implications for wind power development. Journal of Wildlife Management 78: 1012-1021.

Weston, E.D., D.P Whitfield, J.M. Travis, And X. LAmbin, 2013. When do young birds disperse? Tests from studies of golden eagles in Scotland. BioMed Central Ecology 13: 1.

Whitfield, D.P., A.H. Fielding, M.J. Gregory, A.G. Gordon, D.R. McLeOd, ANd P.E. HAWORTH. 2007. Complex effects of habitat loss on Golden Eagles Aquila chrysaetos. Ibis 149: 26-36.

WORTON, B.J. 1989. Kernel methods for estimating the utilization distribution in home-range studies. Ecology 70: 164-168.

XiAn, G., C.G. HoMER, AND C.L. AldRIDGE. 2012. Effects of land cover and regional climate variations on long-term spatiotemporal changes in sagebrush ecosystems. GIScience and Remote Sensing 49: 378-396.

YACKEL AdAms, A.A., S.K. SKAGEN, AND R. KNIGHT. 2000. Functions of perch relocations in a communal night roost of wintering bald eagles. Canadian Journal of Zoology 78: 809816. 
Table 1. Commission for Environmental Cooperation (CEC) land cover classes, and the reclassified variables used in analyses of winter habitat associations of first-year Golden Eagles from Denali National Park and Preserve, Alaska. Percent land cover per individual winter range is in Appendix A.1 SI Table 3.

ORIGINAL LAND COVER CLASS

Temperate or sub-polar needleleaf forest

Sub-polar taiga needleleaf forest

Tropical or sub-tropical broadleaf evergreen forest Tropical or sub-tropical broadleaf deciduous forest Temperate or sub-polar broadleaf deciduous forest Mixed forest

Tropical or sub-tropical shrubland Temperate or sub-polar shrubland Tropical or sub-tropical grassland Temperate or sub-polar grassland Sub-polar or polar shrubland-lichen-moss Sub-polar or polar grassland-lichen-moss Sub-polar or polar barren-lichen-moss

Wetland

Cropland

Barren land

Urban and built-up

Water

Snow and ice
RECLASSIFIED

Coniferous Forest

Coniferous Forest

Broadleaf Forest

Broadleaf Forest

Broadleaf Forest

Mixed Forest

Shrub

Shrub

Grassland

Grassland

Shrub

Grassland

Other

Other

Cropland

Other

Other

Other

Other
7 
Table 2. Models used to describe variables that influence winter home range (HR) size (a; KDE 95\% isopleth) and winter core use area (CUA) size (b; KDE 50\% isopleth) of first-year Golden Eagles from Denali National Park and Preserve, Alaska. Models are listed in rank order from the most to least supported (Akaike's information criterion adjusted for small sample size (AICc) weight $\geq$ 0). Physiography model variables include Mean Elevation of HR or CUA, latitude of centroid of HR or CUA, \% of HR or CUA made up of TPI category "canyon", \% of HR or CUA made up of TPI category "steep slope”, Mean TRI of HR or CUA. Land Cover model variables include \% cover of broadleaf forest within HR or CUA, \% cover of coniferous forest within HR or CUA, \% cover of cropland within HR or CUA, \% cover of grassland within HR or CUA, \% cover of shrub within HR or CUA. 
AICc

$\mathrm{AICc}$

Model

(A) Home Range

Orographic Updraft 1

Natal Range Characteristics

Broadleaf Forest

Orographic Updraft 2

Combined Forest

Coniferous Forest

Lagomorph Prey

Grassland Ungulate

Latitude

Physiography

Land Cover

Combined Full

$\%$ of HR made up of TPI category "steep slope"

$\%$ of HR made up of TPI categories "steep slope" + "canyon"

40.39

41.10

41.12

Mean TRI of HR

$\%$ cover of coniferous forest + broadleaf forest within HR

$\%$ cover of coniferous forest within HR

$\%$ cover of shrub within HR

$\%$ cover of grassland within HR

Latitude of centroid of HR

Full Physiography model

Full Land Cover model

Full Physiography Model + Full Land Cover model
42.70

44.79

47.04

47.13

47.48

49.48

55.83

56.26

369.96

$\triangle \mathrm{AICc}$

weight

Likelihood

\section{(B) Core Use Area}

Natal Range Characteristics

Orographic Updraft 1

Broadleaf Forest

Orographic Updraft 2

Combined Forest

Coniferous Forest

Grassland Ungulate

Lagomorph Prey

Latitude

Physiography Model

Land Cover Model

Combined Full Model

$\%$ of CUA made up of TPI categories "steep slope" + "canyon"

$\%$ of CUA made up of TPI category "steep slope"

40.76

41.49

$\%$ cover broadleaf forest within CUA

43.32

Mean TRI of CUA

43.82

$\%$ cover of coniferous forest + broadleaf forest within CUA

46.63

$\%$ cover of coniferous forest within CUA

$\%$ Grassland

$\%$ cover of shrub within CUA

48.71

48.80

0.00

0.34

0.71

0.24

$0.72 \quad 0.24$

0.70

2.30

0.11

0.70

4.39

0.04

0.32

\subsection{5}

0.01

0.11

\subsection{3}

7.08

0.01

0.04

0.03

9.08

0.01

0.03

15.44

0.00

0.01

15.86

0.00

0.00

329.56

0.00

0.00

0.00

0.00

Latitude of centroid of CUA

48.85

$$
0.00
$$

0.43

1.00

$\begin{array}{lll}0.73 & 0.30 & 0.69\end{array}$

$\begin{array}{lll}2.57 & 0.12 & 0.28\end{array}$

$\begin{array}{lll}3.06 & 0.09 & 0.22\end{array}$

$\begin{array}{lll}5.87 & 0.02 & 0.05\end{array}$

$\begin{array}{lll}7.95 & 0.01 & 0.02\end{array}$

Full Physiography model

50.74

8.04

0.01

0.02

Full Land Cover model

54.51

8.09

0.01

0.02

9.98

0.00

0.01

58.44

13.75

0.00

0.00

Full Physiography Model + Full Land Cover model

373.78

0.00

0.00

333.02

0.00

0.00 
Table 3. Model averaged effect sizes and standard errors for fixed effects describing response of size of winter home range (HR) size (A; KDE 95\% isopleth) and winter core use area (CUA) size (B; KDE 50\% isopleth) of first-year Golden Eagles from Denali National Park and Preserve, Alaska. (1997-1999). Effects measured using linear mixed effects models.

\begin{tabular}{|c|c|c|c|}
\hline MODEL DESCRIPTION & PARAMETER & VALUE & $\mathrm{SE}$ \\
\hline \multirow[t]{12}{*}{ (A) Variation in HR Size } & Intercept & 9.225 & 3.816 \\
\hline & \% Steep Slope & 7.485 & 36.630 \\
\hline & $\%$ Canyon & -0.047 & 1.439 \\
\hline & $\%$ Broadleaf Forest & -1.105 & 2.195 \\
\hline & mean TRI & 0.565 & 3.695 \\
\hline & $\%$ combined Forest & -0.062 & 0.361 \\
\hline & $\%$ Coniferous Forest & -0.009 & 0.146 \\
\hline & $\%$ Shrub & 0.009 & 0.128 \\
\hline & $\%$ Grassland & 0.006 & 0.106 \\
\hline & Centroid Latitude & -0.001 & 0.020 \\
\hline & Elevation Range & 0.000 & 0.007 \\
\hline & Cropland & 0.000 & 0.042 \\
\hline \multirow[t]{12}{*}{ (B) Variation in CUA Size } & Intercept & 7.713 & 3.678 \\
\hline & $\%$ Canyon & -0.930 & 3.845 \\
\hline & $\%$ Steep Slope & 12.513 & 48.415 \\
\hline & $\%$ Broadleaf Forest & -0.447 & 1.314 \\
\hline & mean TRI & 0.584 & 3.269 \\
\hline & $\%$ combined Forest & -0.030 & 0.234 \\
\hline & $\%$ Coniferous Forest & -0.003 & 0.094 \\
\hline & $\%$ Grassland & 0.004 & 0.083 \\
\hline & $\%$ Shrub & 0.003 & 0.085 \\
\hline & Centroid Latitude & -0.001 & 0.019 \\
\hline & Elevation Range & 0.000 & 0.016 \\
\hline & Cropland & 0.000 & 0.032 \\
\hline
\end{tabular}


Fig 1. Telemetry data from winter home ranges of first-year Golden Eagles tracked from nests in Denali National Park and Preserve, Alaska in 1997 and 1999. Panels are a) Individual winter season Argos telemetry locations; and b) winter home range of one individual (2688) estimated with Brownian Bridge Movement Models (BBMM; 95 \% isopleth), Kernel Density Estimates (KDE; $95 \%$ isopleth) and Minimum Convex Polygon (MCP). The 95\% KDE home range of Individual 2688 also is shown in map panel a.
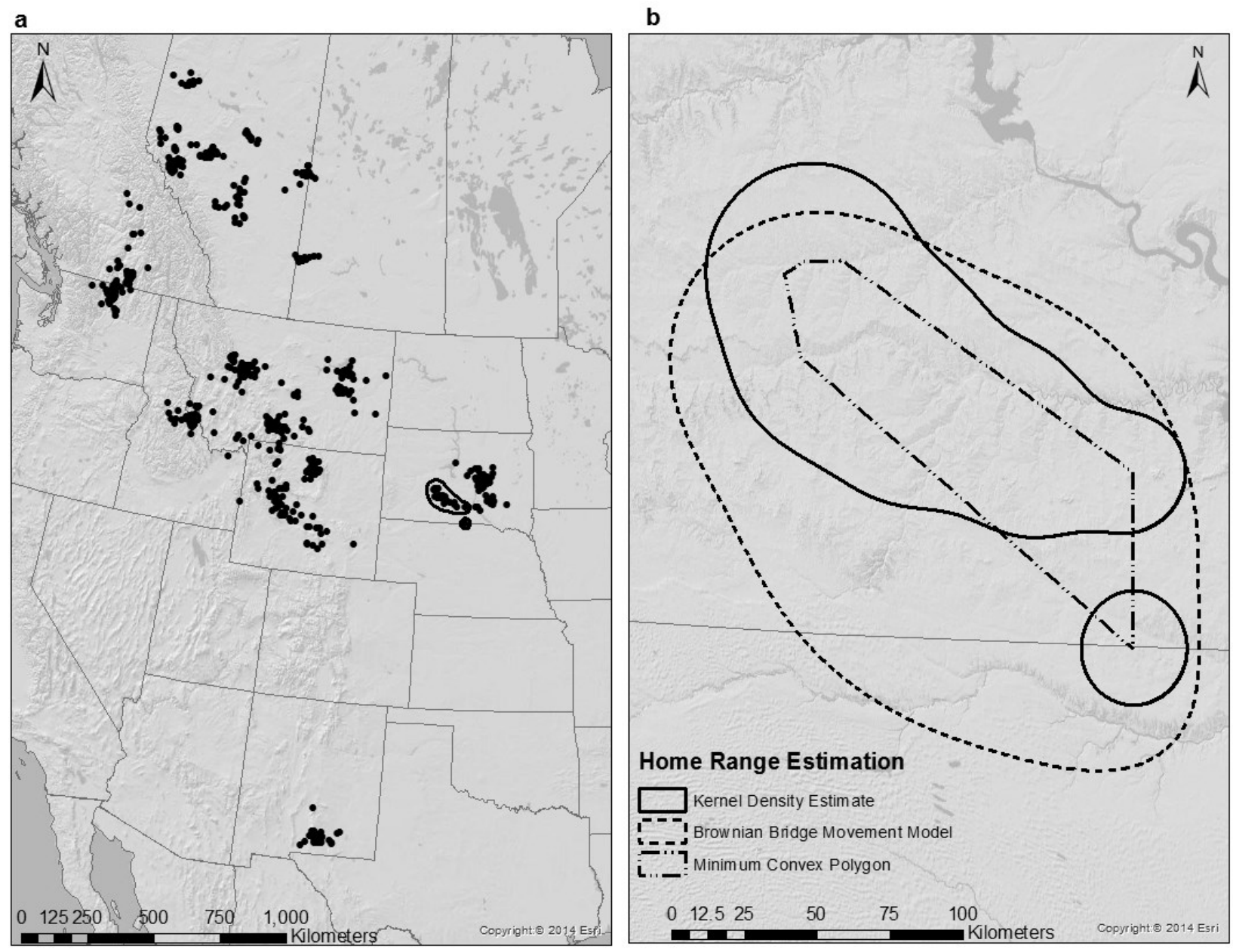
Fig 2. Average proportion of seven land cover classes (described in Table 1) within a) winter home ranges (KDE 95\% isopleth) and b) winter core use areas (KDE 50\% isopleth) for first-year Golden Eagles from Denali National Park and Preserve, Alaska (1997-1999).
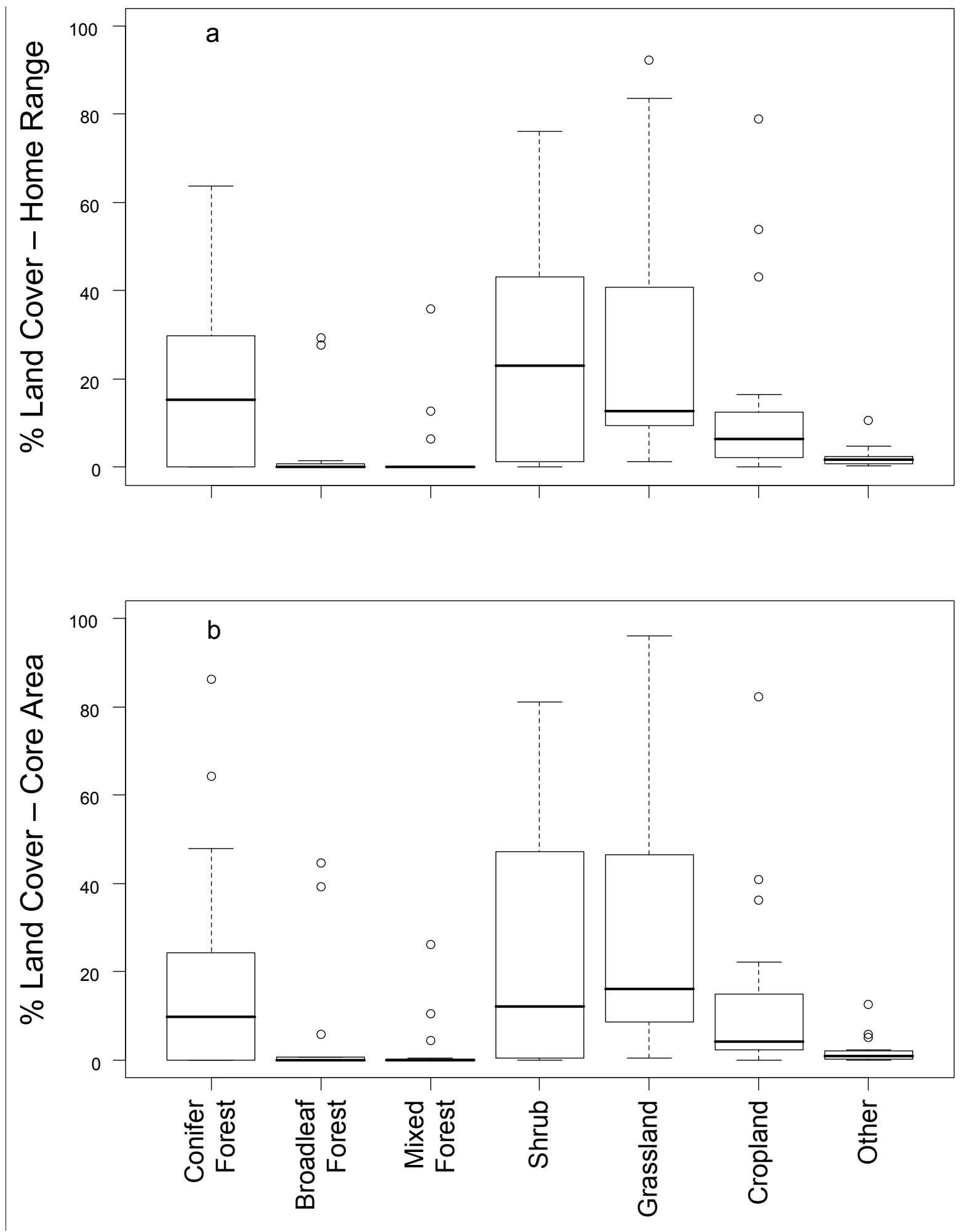
Fig 3. Model averaged results of relationship between key habitat variables and size of winter home ranges (HR; 95\% KDE isopleth) and core use areas (CUA; 50\% KDE isopleth) of firstyear Golden Eagles from Denali National Park and Preserve, Alaska, (1997 - 1999). Results suggested that a) HR size increased as the proportion of TPI steep slopes increased; b) CUA size decreased as the proportion of broadleaf forest land cover increased; and c) CUA size increased as the mean TRI increased.
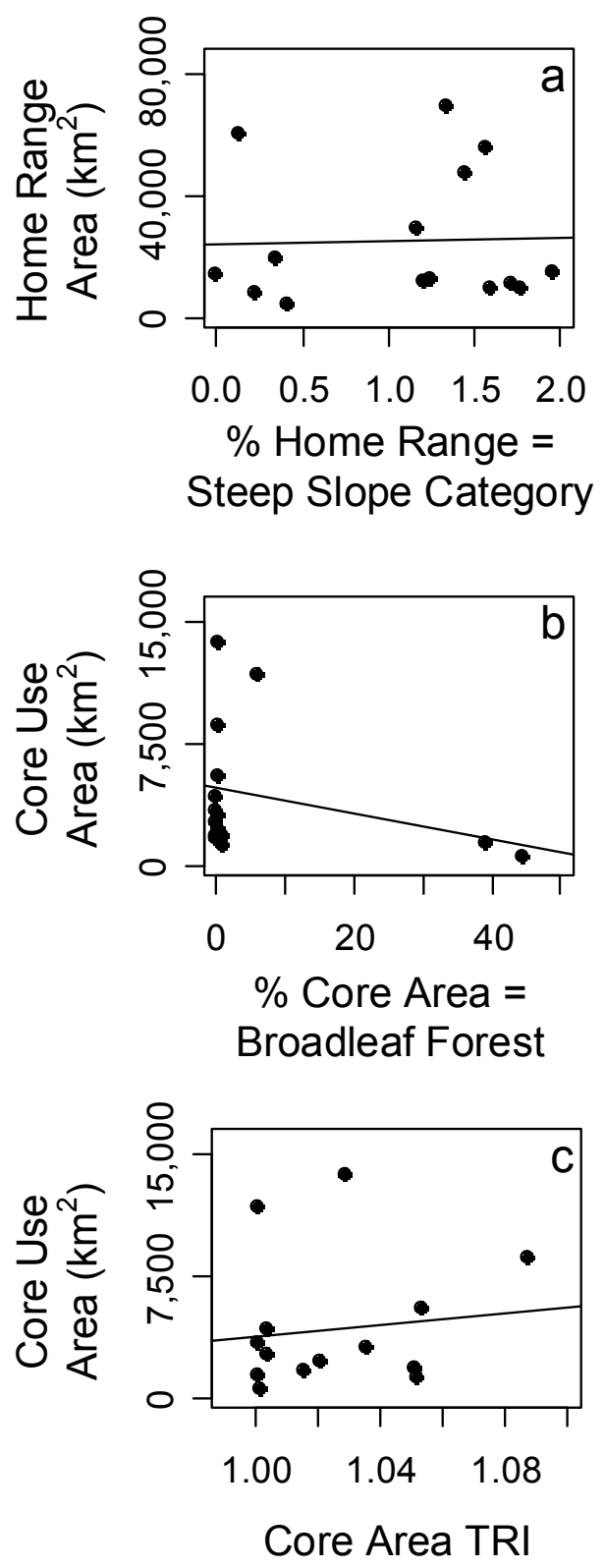


\section{APPENDIX A.1}

\section{SUPPLEMENTARY INFORMATION}

SI Table 1. Argos satellite locations by location-quality class before and after Douglas Argos accuracy filtering, and only filtered winter season locations used in analyses, obtained from radio-tagged first-year Golden Eagles born in Denali.

\begin{tabular}{|c|c|c|c|c|c|c|}
\hline \multirow[t]{2}{*}{$\begin{array}{l}\text { ARGOS LOCATION- } \\
\text { QUALITY CLASS }\end{array}$} & \multicolumn{2}{|c|}{$\begin{array}{l}\text { ALL ARGOS } \\
\text { LOCATIONS }\end{array}$} & $\begin{array}{c}\text { BEST F } \\
\text { LOCA } \\
\text { DUTY }\end{array}$ & $\begin{array}{l}\text { RED } \\
\text { PER } \\
\text { LE }\end{array}$ & \multicolumn{2}{|c|}{ WINTER LOCATIONS } \\
\hline & $n$ & $(\%)$ & $n$ & $(\%)$ & $n$ & $(\%)$ \\
\hline 3 & 102 & 1.2 & 87 & 5.5 & 34 & 4.4 \\
\hline 2 & 320 & 3.7 & 234 & 14.7 & 96 & 12.5 \\
\hline 1 & 1213 & 14.1 & 568 & 35.7 & 249 & 32.4 \\
\hline 0 & 4312 & 50.3 & 559 & 35.1 & 335 & 43.6 \\
\hline A & 907 & 10.6 & 50 & 3.1 & 23 & 3.0 \\
\hline B & 1176 & 13.7 & 82 & 5.2 & 27 & 3.5 \\
\hline $\mathrm{Z}$ & 544 & 6.3 & 12 & 0.8 & 5 & 0.7 \\
\hline Total & 8574 & 100.0 & 1592 & 100.0 & 769 & 100.0 \\
\hline
\end{tabular}


SI Table 2. Area $\left(\mathrm{km}^{2}\right)$ of winter home ranges (95\% isopleth) and CUAs (50\% isopleth) for (a) female and (b) male Golden Eagles telemetered in their first-year from Denali National Park and Preserve using three estimation methods (Brownian bridge movement model (BBMM), kernel density estimate (KDE), and minimum convex polygon (MCP)). An asterisk (*) in the "BBMM" columns indicates that we were unable to calculate the home range for these individuals An asterisk $\left(^{*}\right)$ in the "winter end" column denotes a radio failure, and $\left({ }^{\mathrm{D}}\right)$ denotes mortality before departing winter range.

\section{SI Table 2a. FeMALES}

\begin{tabular}{|c|c|c|c|c|c|c|c|c|c|c|}
\hline ID & $\begin{array}{c}\text { BIRD } \\
\text { YR }\end{array}$ & KDE 95 & KDE 50 & BBMM 95 & BBMM 50 & MCP & $\begin{array}{c}\text { WINTER } \\
\text { START }\end{array}$ & $\begin{array}{c}\text { WINTER } \\
\text { END }\end{array}$ & DAYS & LOCATIONS \\
\hline 2632 & 1 & 9865 & 1865 & 33022 & 4922 & 11221 & 2 Nov 97 & 15 Apr 98 & 165 & 51 \\
\hline 2634 & 1 & 13887 & 3081 & 24419 & 5414 & 10838 & 26 Oct 97 & 21 Apr $98^{*}$ & 178 & 57 \\
\hline 2635 & 1 & 14895 & 2240 & 26016 & 3730 & 14032 & 24 Oct 97 & 25 Apr 98 & 184 & 56 \\
\hline 2647 & 1 & 69478 & 13701 & $*$ & $*$ & 47765 & 5 Nov 97 & 7 May 98 & 184 & 56 \\
\hline 2670 & 1 & 4429 & 595 & 16325 & 2690 & 3630 & 29 Nov 99 & 18 Apr 00 & 142 & 53 \\
\hline 2681 & 1 & 60471 & 11773 & $*$ & $*$ & 29281 & 28 Dec 99 & 25 Mar 00 & 89 & 34 \\
\hline 2685 & 1 & 11399 & 1761 & 25084 & 4229 & 12195 & 30 Oct 99 & 10 Apr 00 & 164 & 63 \\
\hline 2697 & 1 & 29371 & 4178 & $*$ & $*$ & 30981 & 11 Nov 99 & 8 May 00 & 180 & 60 \\
\hline \multicolumn{2}{|c|}{ TOTALS } & $\begin{array}{r}26724 \\
\pm 24769\end{array}$ & $\begin{array}{c}4899 \\
\pm 4974\end{array}$ & $\begin{array}{l}24973 \\
\pm 5937\end{array}$ & $\begin{array}{c}4197 \\
\pm 1060\end{array}$ & $\begin{array}{c}19993 \\
\pm 14654\end{array}$ & $\begin{array}{c}11 \mathrm{Nov} \\
\pm 22 \mathrm{~d}\end{array}$ & $\begin{array}{l}19 \mathrm{Apr} \\
\pm 14 \mathrm{~d}\end{array}$ & $\begin{array}{c}161 \\
\pm 32 \mathrm{~d}\end{array}$ & $\begin{array}{c}54 \\
\pm 9\end{array}$ \\
\hline
\end{tabular}

\begin{tabular}{|c|c|c|c|c|c|c|c|c|c|c|}
\hline & $\begin{array}{l}\text { I Tab } \\
\text { BIRD }\end{array}$ & b. Males & & & & & WINTER & WINTER & & \\
\hline ID & YR & KDE 95 & KDE 50 & BBMM 95 & BBMM 50 & $\mathrm{MCP}$ & START & END & DAYS & LOCATIONS \\
\hline 2636 & 1 & 56051 & 5569 & 54103 & 6146 & 72086 & 2 Nov 97 & 15 Apr 98 & 165 & 53 \\
\hline 2641 & 1 & 9401 & 1371 & $*$ & $*$ & 8460 & 12 Nov 97 & 18 Apr 98 & 180 & 56 \\
\hline 2646 & 1 & 47545 & 8664 & 33819 & 6543 & 25145 & 23 Oct 97 & $24 \mathrm{Feb} 98^{\mathrm{D}}$ & 125 & 37 \\
\hline 2688 & 1 & 13017 & 2696 & 24676 & 5105 & 5848 & 2 Jan 00 & 4 Apr 00 & 94 & 29 \\
\hline 2689 & 1 & 12010 & 1719 & 18574 & 3423 & 11940 & 17 Nov 99 & 26 Apr 00 & 162 & 54 \\
\hline 2692 & 1 & 19126 & 3341 & 23612 & 5168 & 20207 & 4 Nov 99 & 30 Apr 00 & 179 & 73 \\
\hline 2699 & 1 & 7915 & 1449 & 15666 & 2811 & 4170 & 6 Nov 99 & 10 Feb 00 & 97 & 33 \\
\hline $\mathrm{TO}^{-}$ & & $\begin{array}{c}23581 \\
\pm 19750\end{array}$ & $\begin{array}{c}3544 \\
\pm 2693\end{array}$ & $\begin{array}{c}28408 \\
\pm 14039\end{array}$ & $\begin{array}{c}4866 \\
\pm 1477\end{array}$ & $\begin{array}{c}21122 \\
\pm 23733\end{array}$ & $\begin{array}{l}13 \text { Nov } \\
\pm 23 \mathrm{~d}\end{array}$ & $\begin{array}{l}1 \mathrm{Apr} \\
\pm 31 \mathrm{~d}\end{array}$ & $\begin{array}{c}143 \\
\pm 37 \mathrm{~d}\end{array}$ & $\begin{array}{c}48 \\
\pm 16\end{array}$ \\
\hline
\end{tabular}


SI Table 3. Winter land cover per home range (KDE 95\% isopleth) and core use area (KDE 50\% isopleth). Land cover variables were derived from the 2005 CEC North American land cover dataset (CEC 2013). CEC land cover categories were simplified and grouped according to text and Table 1 for analyses. Land cover values shown are percent cover per individual home range.

\begin{tabular}{|c|c|c|c|c|c|c|c|c|}
\hline BIRD ID & $\begin{array}{l}\text { AREA } \\
\left(\mathrm{km}^{2}\right)\end{array}$ & $\begin{array}{c}\text { CONIFEROUS } \\
\text { FOREST } \\
\end{array}$ & $\begin{array}{c}\text { BROADLEAF } \\
\text { FOREST }\end{array}$ & $\begin{array}{l}\text { MIXED } \\
\text { FOREST } \\
\end{array}$ & SHRUB & GRASSLAND & CROPLAND & OTHER \\
\hline \multicolumn{9}{|c|}{ (A) Home Range } \\
\hline 2632 & 9865 & 63.81 & 1.49 & 12.76 & 7.60 & 3.79 & 0.02 & 10.54 \\
\hline 2634 & 13887 & 25.10 & 0.02 & 0.00 & 24.29 & 41.58 & 8.09 & 0.93 \\
\hline 2635 & 14895 & 18.81 & 0.03 & 0.00 & 50.51 & 23.49 & 6.26 & 0.89 \\
\hline 2636 & 56051 & 21.75 & 0.07 & 0.00 & 28.60 & 40.26 & 7.78 & 1.54 \\
\hline 2641 & 9401 & 63.75 & 0.81 & 0.02 & 23.07 & 8.07 & 0.80 & 3.48 \\
\hline 2646 & 47545 & 45.84 & 0.02 & 0.00 & 37.55 & 12.83 & 3.29 & 0.47 \\
\hline 2647 & 69478 & 12.37 & 0.74 & 0.00 & 69.93 & 11.99 & 2.38 & 2.60 \\
\hline 2670 & 4429 & 15.42 & 29.35 & 35.87 & 1.14 & 1.18 & 16.48 & 0.56 \\
\hline 2681 & 60471 & 0.00 & 0.01 & 0.05 & 0.09 & 18.77 & 78.91 & 2.17 \\
\hline 2685 & 11399 & 34.37 & 0.15 & 0.01 & 48.58 & 12.53 & 1.91 & 2.44 \\
\hline 2688 & 13017 & 0.01 & 0.00 & 0.00 & 0.01 & 92.17 & 6.33 & 1.48 \\
\hline 2689 & 12010 & 12.50 & 0.04 & 0.00 & 76.17 & 10.73 & 0.10 & 0.47 \\
\hline 2692 & 19126 & 0.02 & 0.04 & 0.00 & 0.00 & 55.06 & 43.08 & 1.80 \\
\hline 2697 & 29371 & 0.16 & 0.00 & 0.00 & 5.24 & 83.72 & 8.49 & 2.38 \\
\hline 2699 & 7915 & 0.27 & 27.78 & 6.45 & 1.32 & 5.39 & 53.91 & 4.89 \\
\hline TOTALS & $\begin{array}{r}25257 \\
\pm 21830 \\
\end{array}$ & $\begin{array}{r}20.95 \\
\pm 22.11 \\
\end{array}$ & $\begin{array}{c}4.04 \\
\pm 9.97 \\
\end{array}$ & $\begin{array}{r}3.68 \\
\pm 9.59 \\
\end{array}$ & $\begin{array}{c}24.94 \\
\pm 26.34 \\
\end{array}$ & $\begin{array}{c}28.10 \\
\pm 28.83 \\
\end{array}$ & $\begin{array}{r}15.86 \\
\pm 23.59 \\
\end{array}$ & $\begin{array}{r}2.44 \\
\pm 2.55 \\
\end{array}$ \\
\hline \multicolumn{9}{|c|}{ (B) Core Use Area } \\
\hline 2632 & 1865 & 64.30 & 0.74 & 10.43 & 8.65 & 3.29 & 0.00 & 12.59 \\
\hline 2634 & 3081 & 17.11 & 0.05 & 0.00 & 21.42 & 53.08 & 7.81 & 0.52 \\
\hline 2635 & 2240 & 9.88 & 0.04 & 0.00 & 66.06 & 17.35 & 6.60 & 0.08 \\
\hline 2636 & 5569 & 28.19 & 0.04 & 0.00 & 25.55 & 40.08 & 4.31 & 1.83 \\
\hline 2641 & 1308 & 86.24 & 0.81 & 0.02 & 12.21 & 0.58 & 0.07 & 0.06 \\
\hline 2646 & 8664 & 47.91 & 0.08 & 0.00 & 36.97 & 11.56 & 2.98 & 0.49 \\
\hline 2647 & 13701 & 15.43 & 0.03 & 0.00 & 58.68 & 16.21 & 4.50 & 5.15 \\
\hline 2670 & 595 & 5.55 & 44.56 & 26.25 & 0.18 & 0.38 & 22.25 & 0.83 \\
\hline 2681 & 11773 & 0.10 & 5.89 & 0.37 & 0.42 & 8.66 & 82.32 & 2.24 \\
\hline 2685 & 1761 & 20.55 & 0.00 & 0.00 & 57.71 & 16.76 & 3.71 & 1.27 \\
\hline 2688 & 2696 & 0.00 & 0.00 & 0.00 & 0.01 & 96.23 & 2.78 & 0.98 \\
\hline 2689 & 1719 & 7.65 & 0.00 & 0.00 & 81.06 & 11.17 & 0.00 & 0.12 \\
\hline 2692 & 3341 & 0.00 & 0.00 & 0.00 & 0.00 & 63.62 & 36.25 & 0.13 \\
\hline 2697 & 4178 & 0.01 & 0.00 & 0.00 & 2.06 & 94.94 & 1.98 & 1.02 \\
\hline 2699 & 1449 & 0.09 & 39.30 & 4.45 & 0.59 & 8.67 & 41.00 & 5.90 \\
\hline TOTALS & $\begin{array}{c}4263 \\
\pm 4000\end{array}$ & $\begin{array}{c}20.20 \\
\pm 26.30\end{array}$ & $\begin{aligned} & 6.10 \\
\pm & 14.66\end{aligned}$ & $\begin{array}{c}2.77 \\
\pm 7.08\end{array}$ & $\begin{array}{c}24.77 \\
\pm 28.30\end{array}$ & $\begin{array}{c}29.51 \\
\pm 32.68\end{array}$ & $\begin{array}{c}14.44 \\
\pm 22.86\end{array}$ & $\begin{array}{c}2.21 \\
\pm 3.38\end{array}$ \\
\hline
\end{tabular}




\section{Chapter 3}

\section{LAND COVER CHANGES IN HOME RANGES OF MIGRATORY GOLDEN EAGLES FROM ALASKA}

Formatted in the style of Journal of Raptor Research 


\section{ABSTRACT}

Land cover is being altered in numerous direct and indirect ways from both anthropogenic and natural forces. The effects of these changes may be especially relevant to species that make long distance movements between two often dramatically different landscapes. To characterize how habitat alteration may influence a long distance migratory species, we studied how land cover changed over an 11 year period within summer and winter areas used by Golden Eagles (Aquila chrysaetos). The eagles we studied, spent winter in western North America and summer in Alaska and northwest Canada. Land cover within areas used in summer at northern latitudes was predominantly shrublands. Land cover within winter eagle use areas at southern latitudes was comprised mostly of grasslands. At both spatial scales we studies, we found greater differences in percent land cover in winter use areas than in summer use areas. From 2001 to 2011, on winter range we detected losses in percent cover in Deciduous Forest, gains in Evergreen Forest and Water, and both gains and losses in Croplands and Urban cover. Over the same interval, on summer range we detected gains in percent cover of Evergreen Forest and Grasslands, and losses in Barren ground cover and Snow/Ice cover. Previous work has shown that long term declines in reproductive output of Golden Eagles in Denali is not well explained by conditions on breeding grounds. This work provides potential insight into what may be indirectly influencing these declines and may also assist with conservation of other migratory and non-migratory eagles that use these same locations by providing understanding on how land cover in these areas has changed.

Keywords: Aquila chrysaetos, Denali, first-year, Golden Eagle, land cover change, seasonal 
Both natural and anthropogenic forces are modifying habitats globally (McBean et al. 2005, Parmesan 2006, Raynolds et al. 2014) with substantial direct and indirect consequences for ecosystems (Walter et al. 2002, Parry et al. 2007, Moritz et al. 2008, Both et al. 2010). Anthropogenic forces are directly affecting ecosystems with land cover and land use alterations, and they are affecting habitats indirectly by influencing natural systems and ecosystem processes (Walther et al. 2002, Parmesan 2006). Documented transformations in habitat attributed to anthropogenic influence include altered vegetative structure and shifts in vegetation and vertebrate species distribution and abundance (Root et al. 2003, Parmesan and Yohe 2003, Sturm et al. 2005, Moritz et al. 2008). These changes impact the phenology of plants, insects, and vertebrates that are important as food for many herbivores and predators (altered synchrony; Inouye et al. 2000, Visser and Both 2005, Both et al. 2010). Climate change is also increasing the spread of introduced species and pathogens as well as modifying wildfire regimens (Dale et al. 2001, Brooks et al. 2014, Van Hemert et al. 2014).

Land cover is a potential proxy for ecosystem-level changes (Lambin and Strahler 1994, Turner et al. 2007, Tapia et al. 2017). North American land cover transformation, driven by a suite of bio-physical habitat parameters, is exacerbated and accelerated by climate change, particularly at northern latitudes (Serreze and Francis 2006, Screen and Simmonds 2010). These bio-physical changes are especially prominent at northern latitudes, where warmer temperatures and a longer growing season (Kozlov and Berlina 2002, Linderholm 2006) have resulted in an expansion of woody shrubs in previously shrub-free elevational and latitudinal zones (Sturm et al. 2005).

As vegetative structure is altered, available resources in those habitats, such as food and cover, are transformed. There are cascading effects for the communities of organisms which rely on those resources, and these effects potentially can influence population dynamics, species distributions and interactions, food web structure, biodiversity, and ecosystem processes (Logan et al. 2003, Convey and Smith 2006, Parmesan and Yohe 2003, Grosbois et al. 2008, Harms et a. 2017). Such changes in vegetative structure may be especially relevant to species that are long distance migrants and who rely on multiple, often dramatically different, landscapes during breeding, non-breeding and migration seasons (Both et al. 2010, Newton 2004, 2010). 
There are many ways to measure how land cover change could affect wildlife. One way would be to track different individuals to measure land cover in different time periods, and then to evaluate changes in land cover types used. While informative, this method requires long term tracking, detailed seasonal land cover data and large sample sizes that allow separation of individual and temporal variability. A second, more simple way is to evaluate land cover change over time within areas used by animals at one of those times. This approach requires fewer data and yet still may provide insight into how wildlife may be influenced by land cover change.

To understand how changing land cover may affect a long distance migratory apex predator, we evaluated land cover change over time in historical home ranges of first-year migratory Golden Eagles (Aquila chrysaetos) hatched in interior Alaska and tracked 20 years ago. These eagles migrate thousands of kilometers between summer and winter ranges (McIntyre et al. 2008) and thus the land cover they encounter in those two seasons should be distinct and subject to dramatically different, sometimes climate-driven, pressures. We focused on three research questions: 1) Has there been change over time in the land cover characteristics of areas Golden Eagles once used? 2) Which land cover characteristics have changed most rapidly within those historical Golden Eagle use areas? 3) Within historical eagle use areas, is land cover change greater within summer ranges or winter ranges?

\section{METHODS}

Golden Eagles tracked in this study hatched in a $2100 \mathrm{~km}^{2}$ study area centered at $63^{\circ}$ $35.8^{\prime} \mathrm{N}, 149^{\circ} 38.2^{\prime} \mathrm{W}$, in the northern foothills of the Alaska Range in Denali National Park and Preserve (Denali; Fig 1). Nestling eagles from Denali fledged in July to August and initiated migration in September or October (McIntyre and Collopy 2006). They arrived on wintering grounds approximately in late October to early January, stayed through February to May, and then they summered in Alaska, Yukon and Northwest Territories between mid-May and September (McIntyre et al. 2008, Chapter 2 of this thesis).

Summer range for Denali's radio-tagged first-year Golden Eagles encompassed portions of Alaska and western Yukon Territories (Fig 1; see also McIntyre et al. 2008). General 
descriptions of land cover at northern latitudes within and surrounding summer eagle ranges is predominantly high alpine, tundra and boreal forest (Goward et al. 1987, NASA LP DAAC, 2013). Topography varies greatly in summer ranges, with rugged, glaciated, mountainous terrain interspersed with vast flat areas and transitioning to coastal plain north of the Brooks Range (Gesch et al. 2002). Summer diet of breeding and nestling eagles in Denali is composed primarily of snowshoe hare (Lepis americanus), ptarmigan (Lagopus spp), and Arctic ground squirrel (Spermophillis parryii) (McIntyre et al. 2006). Summer diet of Golden Eagles elsewhere at northern latitudes is similar depending on availability, and also includes waterfowl (Brodeur et al. 1996).

The winter range of the sample of radio-tagged eagles spanned a large portion of western North America from northern Alberta to southern New Mexico (Fig 1) (see McIntyre et al. 2008). Topography also varies considerably over eagle winter ranges, with rugged, mountainous terrain in the Rocky Mountains and expansive flat areas in the Great Plains (Goward et al. 1987, Gesch et al. 2002, NASA LP DAAC, 2013). During winter, diet for this species includes carrion from wild or domestic large mammals such as ungulates (Marr and Knight 1983, Watson 2010), and small or medium-sized mammals (including Lepus spp and Marmota spp), and mediumsized birds (Phasianus colchicus and Tetraonidae; Kochert et al. 2002, Watson 2010).

Data Collection. McIntyre et al. (2008) radio-tagged nestlings in late July and early August in 1997 and 1999. Eagles $>56$ d of age were fitted with a 95g satellite Platform Terminal Transmitter (PTTs; Microwave Telemetry, Columbia, Maryland, U.S.A.). These PTTs used the Argos satellite tracking system to record locations (McIntyre et al. 2008). Duty cycles for the transmitters were $8 \mathrm{hr}$ on and $72 \mathrm{hr}$ off in 1997, and $8 \mathrm{hr}$ on and $48 \mathrm{hr}$ off in 1999 (McIntyre et al. 2008).

Data Processing and Management. To reduce error associated with the Argos telemetry locations, we applied the Douglas Argos Filter (DAF; Douglas et al. 2012) using the DAF filter parameters from McIntyre et al. (2008). Filter application reduced auxiliary-class location fixes (0, A, B, Z; up to $12 \mathrm{~km}$ error; Argos 1996). The resulting locations were comprised of higher proportion of standard class location fixes (3, 2, 1; from 125m error; Argos 1996). We further 
manually filtered telemetry data, removing implausible movement spikes (e.g., three sequential points where the first and last locations were close in proximity but the middle point was $>200$ $\mathrm{km}$ away with an atypically acute internal turning angle). The unfiltered telemetry data collected on individuals used in these analyses were comprised of $18.5 \%$ standard-class and $81.5 \%$ auxiliary-class Argos location quality class fixes. After accuracy filtering the telemetry data used in these analyses were comprised of $48.9 \%$ standard-class and $51.1 \%$ auxiliary-class fixes (Appendix B.1 SI Table 1).

We focused analyses on winter and summer of the first-year of data collection for each bird. We calculated start and end dates of the winter and summer season based on the following criteria. We defined arrival on each seasonal range as data points that had $<200 \mathrm{~km}$ between consecutive telemetry fixes and that were not in the direction of migration (primarily in a southeast direction in autumn, northwest in spring; McIntyre et al. 2008). Conversely, we defined the end of each season as distances between consecutive telemetry locations $>200 \mathrm{~km}$ with movements that occurred in the direction of migration (primarily northwest in spring, southeast in autumn). For individuals that did not survive or had transmitter failure during the season, we used the last date of recorded data as the season end date. For these analyses, we only considered birds for which we had sufficient telemetry data for reasonable space use estimation while having a minimum of data ( $>30$ days of data and $>13$ telemetry locations), in a single non-migratory season (summer and winter). From this telemetry selection criteria, dates on winter range for individuals in this study ranged from 23 October - $25 \mathrm{March}$, and dates on summer range spanned 3 May - 20September.

Space Use, Golden Eagle Home Range and Core Use Estimation. We used kernel density estimation (KDE) to model winter and summer space use of first-year Golden Eagles (Worton 1989). We calculated KDEs in the Geospatial Modeling Environment (Spatial Ecology LLC, Beyer 2012) within R (3.1.3) and ArcMap (10.2.2).

As we used a subset of radio-tagged individuals with sufficient seasonal telemetry data for home range analysis, and we used a liberal $200 \mathrm{~km}$ movement threshold to define the start and end of the winter period (see above). The resulting arrival and departure dates used in this 
study differ slightly from those previously reported for these eagles that had been defined with a more conservative threshold by McIntyre et al. (2008). To account for the possible inclusion of migration locations in our seasonal range dataset, we performed our analysis on two different home range isopleths (95\% and 50\%). The more liberal 95\% isopleth estimates (hereafter home ranges) likely contain a small number of points that others might consider migratory. The more conservative $50 \%$ isopleth estimates (hereafter core use areas) do not contain points collected during migration and are tightly constrained estimates of space use. We used a Mann-Whitney U-test to compare area of home ranges and core use areas between summer and winter and between sexes by each season, summer and winter.

Land Cover Habitat Associations Over Time. We used ArcMap 10.2.2 to associate winter home ranges and core use areas with land cover and land use data. For each winter and summer home range and core use area, we extracted land cover and land use data from the Moderate Resolution Imaging Spectroradiometer (MODIS) $500 \mathrm{~m}$ land cover dataset (MCD12Q1; Friedl et al. 2010, NASA LP DAAC 2013). MODIS multiple-pass annual average imagery provide the most comprehensive, highest resolution, and longest temporal scale dataset available for locations of our eagle home ranges which fell in both Canada and the USA. Other long term datasets with higher resolution data stop at the US-Canada border. We used annual average land use and land cover data collected at five year intervals $(2001,2006,2011)$. The 2001 land cover data used were closest to the time of telemetry data collection $(1997-2000)$ and describe habitat associations for first-year Golden Eagles, while the other two time stamps were used to elucidate change in those areas after eagles had used them.

To simplify interpretation of change in land cover and land use, we reduced the number of land cover classes from twelve to nine by combining similar classes (Table 1). To do this, we combined the classes named Evergreen Needleleaf Trees and Evergreen Broadleaf Trees into a combined Evergreen Forest category. We also combined the classes named Deciduous Broadleaf Trees and Deciduous Needleleaf Trees into a combined Deciduous Forest category and we combined the categories named Cereal Crops and Broadleaf Crops, into a combined Croplands category. The land cover category Urban comprised a small portion $(\bar{x}<0.9 \%)$ of eagle ranges 
but it was not combined into another category because we wanted to be able to distinguish urban land cover from both croplands and non-anthropogenic categories.

The telemetry data and KDEs, especially those from Alaska, tended to include areas over open water. Although Golden Eagles usually avoid large expanses of open water (Watson et al. 1992, Watson 2010), we did not exclude these locations from our analyses because water at northern latitudes and the Rocky Mountain West may be frozen during some or all of the time eagles are present in both winter and summer season.

Data Analyses. To understand if land cover has changed within areas Golden Eagles used historically, we used descriptive statistics (sample means and standard deviations) to characterize land cover habitat associations from each time stamp at two spatial scales (home ranges and core use areas). Statistics were calculated as percent cover per individual range and separately by season (summer and winter) and spatial scale (home range and core use area).

We used a Mann-Whitney U-test with sequential Bonferroni correction (Rice 1989) to adjust the critical value to compare percent land cover of each category among the three years within seasonal home ranges and core use areas. We chose critical values based on $\mathrm{k}=9$ tests because Rice (1989) states that there is no minimum number of tests for a sequential Bonferroni correction and determining the number is difficult and depends on the question presented. Comparing among the three years of land cover data resulted in three temporal comparisons (2001-2006, 2006-2011, and 2001-2011). Using multiple time intervals allows a more detailed description of the change over time than does measuring change between only two time periods (Gillanders et al. 2008). We performed this analysis separately between each time period for each season (summer and winter) and for each spatial scale (home ranges and core use areas). There was no Urban land cover within summer core use areas at any time and so we only performed $\mathrm{k}=8$ tests for summer core use areas. To describe the differences in percent cover across time intervals, we calculated percent change in land cover variables of eagle use areas that were statistically significant. 
Due to the importance of snow cover and its effects on water availability (Barnett et al. 2005, Stewart et al. 2005), vegetation structure and land cover, we were especially interested in snow cover change. In winter eagle ranges in western North America, snow fall and snow cover are prominent drivers of water availability and drought potential in all seasons (Stewart et al. 2005). In summer eagle use areas at northern latitudes, snow cover not only is important in driving water availability and drought potential, but it also has an important role in energy reflection of UV radiation, albedo effect, and accelerated warming known as Arctic amplification (Serreze and Francis 2006, Screen and Simmonds 2010). With less energy reflected from snow cover, more is absorbed, thus rapidly increasing near surface air and soil temperatures and in turn amplifying warming effects at nearly twice the rate as other latitudes (Serreze and Francis 2006, Screen and Simmonds 2010). To examine if snow and ice cover within eagle use areas changed over time, we separately evaluated Snow/Ice cover for change in both summer and winter ranges between time stamps using a Mann-Whitney U-test.

\section{RESULTS}

Space Use. Winter Range. Winter distribution of this sample of Golden Eagles reported by McIntyre et al. (2008) included much of the Rocky Mountain region of central North America, from northern Alberta to southern New Mexico (Figure 1). We had sufficient data ( $>$ $30 \mathrm{~d}$ on range with $>13$ telemetry locations) to model 15 individual winter use areas (female $=8$, male $=7 ; \mathrm{n}=7$ from 1997 and $\mathrm{n}=8$ from 1999). For additional details on winter eagle ranges, including arrival and departure dates, see Chapter 2 of this thesis.

Summer Range. Summer distribution of this sample of Golden Eagles reported by McIntyre et al. (2008) included much of northern, central, and eastern Alaska, into northern and western Yukon Territories, reaching into the northwest-most portion of Northwest Territories (Figure 1). We had sufficient data ( $>30 \mathrm{~d}$ on range with $>13$ telemetry locations) to model ten individual summer use areas (female $=6$, male $=4 ; n=4$ from 1997, and $n=6$ from 1999) (Appendix B.1 SI Table 2). Females arrived to summer ranges, on average, on 21 May $\pm 16 \mathrm{~d}$ (3 May - 7 June). Males arrived, on average, on 23 May \pm 10 d (12 May - 3 June). Females 
departed summer ranges, on average, on 9 August $\pm 30 \mathrm{~d}$ (31 July - 20 Sept). Males departed, on average, on 19 August \pm 29 d (11 July -18 Sept).

Golden Eagle Home Range and Core Use Estimation. Winter Range. Winter home range size of Golden Eagles varied from 4429 to $69478 \mathrm{~km}^{2}$ and was similar between the sexes (see Chapter 2, this thesis). Winter core use area size varied from 595 to $13701 \mathrm{~km}^{2}$ and also did not vary among the sexes. See Chapter 2 of this thesis for additional details and statistical comparisons on winter eagle ranges.

Summer Range. Summer eagle home ranges were larger than winter home ranges on average $(p=0.001)$, and varied in size from 20990 to $224376 \mathrm{~km}^{2}\left(\bar{x}=101238 \pm 74922 \mathrm{~km}^{2}\right)$. Summer home ranges of males were larger than those of females (females $\bar{x}=55706 \pm 31623$ $\mathrm{km}^{2}$; males $\bar{x}=169537 \pm 69334 \mathrm{~km}^{2} ; p=0.038$ ). Summer core use areas were larger than winter core use areas on average $(p=0.001)$, and for all individuals in this study varied from 3190 to $38652 \mathrm{~km}^{2}\left(\bar{x}=17567 \pm 13165 \mathrm{~km}^{2}\right)$. Summer core use areas were on average larger for males (females $\bar{x}=15567 \pm 13165 \mathrm{~km}^{2}$; males $\bar{x}=28492 \pm 13281 \mathrm{~km}^{2} ; p=0.038$ ).

\section{Land Cover Habitat Associations Over Time. Winter Home Ranges and Core Use} Areas. Land cover within winter home ranges and core areas in 2001, nearest to when eagles were present, and in other years when eagles are not present, averaged about 50\% Grasslands (Table 2). The only other land cover types that composed $>10 \%$ of winter home ranges were Evergreen Forest and Croplands (although Croplands comprised slightly less percent cover in core use areas in 2011). All other land cover categories comprised, on average, small percentages of core use areas or of home ranges, although variability among individual birds was high (Appendix B.1 SI Table 3).

Summer Home Range and Core Use Areas. Land cover within eagle summer home ranges and core use areas was different from that in winter. Land cover within summer eagle home ranges consistently averaged approximately $50 \%$ Shrublands, with $>10 \%$ average land cover comprised of Grasslands and Evergreen Forest (core use areas were similar except there tended to be less Evergreen forest). All other land cover categories comprised, on average, small 
percentages of core use areas or of home ranges in summer, although variability among individual birds was high (Appendix B.1 SI Table 3). Alaska and northern Canada are sparsely populated and the land cover category Urban did not appear in any individual summer core use area at any time.

Land Cover Change. Winter Home Range. Change in land cover variables within historical eagle winter home ranges was most prevalent across the longer interval between 2001 and 2011. During this period, there were statistically significant differences in five of the nine categories of land cover within home ranges (Table 3). Over this longer period Deciduous Forest and Croplands decreased substantially in percent cover (30.1\% and $37.1 \%$ loss respectively), while Evergreen Forest (29.3\% gain) and Water increased (67.1\% gain; Table 2, Table 3). Change in percent cover of category Urban had statistically significant differences across this longer time interval, although it only comprised very small percentages $(<0.3 \%)$ of winter home ranges. During the period 2006 and 2011, two land cover categories changed significantly, both increasing in percent land cover (Evergreen Forest 15.0\% gain; Water 101.5\% gain: Table 2, Table 3). Comparisons across the earliest time interval (2001-2006) showed significant decreases in percent cover of the land cover categories Croplands (22.2\% loss), Deciduous Forest (18.9\% loss), and increases in the category Evergreen Forest (12.5\% gain).

Winter Core Use Area. Change in land cover variables on winter core use areas was most prevalent across the longer time interval from 2001 to 2011. During this period there were statistically significant differences in four of the nine land cover categories within core use areas (Table 2, Table 3). From 2001 - 2011 statistically significant changes in land cover were detected in categories Deciduous Forest (26.7\% loss) and Croplands (36.7\% loss), Evergreen Forest 34.2\% gain) and Water (116.8\% gain; Table 2, Table 3). During the period 2001 to 2006, there were no land cover categories with statistically significant differences (Table 3). During the period 2006 to 2011, percent cover of Croplands decreased by 27.9\%, while Evergreen Forest and Water increased (by 15.5\%, and 237.5\% respectively; Table 2, Table 3).

Summer Home Range. Change in land cover variables within summer home ranges was most prevalent between the 2001 and 2006 imagery. During this period there were statistically 
significant differences in two of the nine land cover categories (Table 3). Evergreen Forest increased in percent cover by $23.0 \%$, while the land cover category Snow/Ice decreased by 17.8\%; Table 2). During the period 2006 - 2011, there were no statistically significant changes in land cover. Across the longer interval from 2001 - 2011, we detected only a statistically significant change in the land cover category Barren ( $82.5 \%$ loss; Table 3$)$.

Summer Core Use Area. Change in land cover variables in summer core use areas was generally small. Comparing $2001-2011$ data, we detected statistically significant decreases in percent cover of the land cover categories Snow/Ice (22.3\% loss) and Barren (84.4\% loss; Table 2; Table 3). During the period 2006 - 2011, only the land cover category Grasslands changed significantly (14.8\% gain; Table 2, Table 3). During the period $2001-2006$, the land cover category Snow/Ice decreased significantly (25.2\% loss; Table 2, Table 3). All other land cover categories did not statistically significantly change within summer core use areas across the time frame studied (Table 3).

\section{DISCUSSION}

Land Cover Within Historical Eagle Use Areas. There was high among-individual variability of land cover composition in both summer and winter eagle use areas. In some cases the dominant land cover type in an individual's seasonal use area was not a prevalent land cover type when averaged across individuals. For example, while on average Shrublands were not prevalent in winter use areas, they were the dominant land cover type for one individual's historical winter use areas (Shrublands comprised $89.3 \%$ of the home range and $99.8 \%$ of the core area; both calculated from 2011 land cover data). Likewise, summer use areas included individual outliers in land cover composition. For example, for one individual land cover category Water comprised $25.0 \%$ of the summer home range and $39.2 \%$ of the core use area (calculated from the 2001 land cover data). When averaged across individuals, summer use percent land cover category Water comprised $<8.0 \%$.

Land Cover Change Over Time. We detected more prevalent change in land cover composition on eagle winter range than we did on summer range. Although there are numerous 
drivers of land cover change, our results were intriguing as much of the published literature suggests that due to climate change, the bio-physical characteristics of habitats at northern latitudes, are changing more rapidly than at southern latitudes (McBean et al. 2005, Serreze and Francis 2006, Screen and Simmonds 2010). This is largely because snow and ice cover at northern latitudes is an especially important driver of potential land cover change over extended time frames. As climate changes, growing season length and number of frost free days at northern latitudes are increasing (Kozlov and Berlina 2002, Linderholm 2006), and there are an increasing number of rain events in winter affecting snowpack and water availability (Regonda et al. 2005). Changes in precipitation regimes are affecting changes in land cover. These shifting parameters have substantial effects on bio-physical systems including increasing soil temperatures and modifying water availability (Hinzman et al. 2003), in turn altering the phenology and distribution of plant species (Cleland et al. 2007). Terrestrial permafrost, snow cover, glaciation, and sea ice have all shown marked declines at northern latitudes (Regonda et al. 2005, McBean 2005, Parry et al. 2007). The effects of decreasing snow and ice cover are especially important aspects of Arctic amplification at northern latitudes in which the albedo effect of snow and ice on UV radiation reflection is reduced (Serreze and Francis 2006, Screen and Simmonds 2010).

We observed several changes in land cover parameters over the 11 year time frame of the study that were likely driven by natural processes. Water availability, and thus potential water and snow and ice cover, in winter eagle use areas of western North America is driven by annually and spatially variable winter precipitation (Barnett et al. 2005, Stewart et al. 2005). Natural processes such as the El Niño and La Niña oscillations affect winter precipitation and thus potential annual average water and snow and ice cover throughout this region (Holmgren et al. 2001, Hamlet et al. 2005). Likewise, in summer eagle use areas, snow and ice land cover are critically important variables in albedo effect on Arctic amplification and changes in these land cover classes creates accelerated potential for land cover change. The patterns we detected in snow and ice cover in summer use areas were consistent with those reported in other studies at northern latitudes (Regonda et al. 2005, McBean et al. 2005, Parry et al. 2007, Lindsay et al. 2016). 
Another natural change in land cover reported in other studies includes spatially variable alterations in shrublands land cover. Throughout much of western North America shrublands cover is decreasing at temperate latitudes (Anderson and Inouye 2001, Knick et al. 2003, Xian et al. 2012), and increasing at northern latitudes (Sturm et al. 2005). This is especially prominent in the western US near winter eagle ranges in sagebrush habitat (Anderson and Inouye 2001, Knick et al. 2003, Xian et al. 2012). At northern latitudes shrub cover is encroaching into areas where they were previously not found, including expansion poleward, into meadows, and into higher elevations (Sturm et al. 2005, Roland and Stehn 2013). We were therefore surprised that, we did not detect change in the MODIS data for the land cover category Shrublands in either summer or winter eagle use areas. We suspect this may be due to the relatively short temporal scale and resolution of our study.

Several of the changes we observed are likely driven by anthropogenic forces such as energy development and agriculture. Changes in cover of the category Croplands in winter use areas likely are driven by food and commodity pricing (Lobell et al. 2011) and agricultural management practices (e.g., USDA Farm Service Agency Conservation Reserve Programs; Delisle and Savidge 1997). Likewise, during the time frame studied, human population in the western US, and thus potential urban development, has increased by $13.8 \%$ in and surrounding winter eagle use areas (US Census Bureau 2000 and 2010 intercensal census; Mackun et al. 2011). While population has also increased in Alaska during this time (Mackun et al. 2011), similar changes from urbanization and agricultural forces were not as prevalent within and surrounding summer eagle use areas compared to winter eagle use areas.

There are non-biological explanations for our observation that land cover in eagle use areas is changing more in southern than northern latitudes in our study area. Our land cover results show the effect of latitudinal range of eagle use areas. Space use in winter spanned a much greater latitudinal range $\left(32^{\circ} 5.6^{\prime} \mathrm{N}\right.$ to $54^{\circ} 33.2^{\prime} \mathrm{N}$ ) than did space use in summer (from $59^{\circ}$ $52.6^{\prime} \mathrm{N}$ to $\left.70^{\circ} 48.9^{\prime} \mathrm{N}\right)$. Likewise, land cover in winter use areas is subject to large-scale changes in land cover classifications caused by fire (McKenzie et al. 2004), drought (Wan et al. 2004), and agricultural practices (Karlen et al. 1994) that are less prevalent and have different effects in summer use areas. 
It is also possible that the differences we observed in change in land cover between summer and winter use areas are a reflection of the scale of land cover data that we used and the time span in which we attempted to measure change. Although they were the best data available to us, the $500 \mathrm{~m}$ resolution and the relatively short temporal extent of the MODIS land cover data may not accurately reflect small scale changes in land cover at the scale of eagle home ranges. Other studies which analyzed land cover change with higher resolution land cover data have been able to detect small yet significant changes (Xiubin 1996, Lindsay et al. 2016, Tapia et al. 2017).

Conclusion. Golden Eagles in Denali have shown long-term declines in nesting rates and fledgling production while territory occupancy has remained steady (McIntyre and Schmidt 2012). These declines are not well explained by conditions on the breeding grounds and previous work has suggested that they may be caused by changes or deterioration of winter habitat (McIntyre and Schmidt 2012). Even across a relatively short time span from, 2001 to 2011, our results show statistically significant changes in land cover in areas used by first-year eagles, especially on wintering grounds. Migratory adult Golden Eagles also use similar areas of western North America in winter (Harmata 2002, McIntyre 2012, Domenech et al. 2015). Work in other systems has shown the relevance of carry over effects on avian demography (Webster 2002, Boulet and Norris 2006, Both et al. 2010, Newton 2004, 2010). Additional studies focused on winter behavior and movements of breeding age eagles could build on the results we report here to identify the mechanisms for these declines.

\section{ACKNOWLEDGMENTS}

This research was funded by Denali National Park and Preserve and the US Geological Survey. Eagles were captured and banded under USGS banding permit 22035. The Oregon State University Animal Care and Use Committee approved the capture, handling, and attachment protocols (AUF no. 1962). Technical and analytical assistance were provided by M. Braham, T. Miller, and A. Duerr with additional assistance from members of the Katzner lab group. We would like to thank M. Priebe for thoughtful revisions. 


\section{LITERATURE CITED}

ANDERSON, J.E., AND R.S. INOUYE. 2001. Landscape-scale changes in plant species abundance and biodiversity of a sagebrush steppe over 45 years. Ecological Monographs, 71:531556.

ARGOS. 1996. User's Manual. [Online.] CLS/Service Argos, Toulouse, France. Available at www.argos-system.rog/manual/.

BARnetT, T.P., J.C. AdAM, AND D.P. LETTENMAIER. 2005. Potential impacts of a warming climate on water availability in snow-dominated regions. Nature 438: 303-309.

Beyer, H. L. 2012. Geospatial Modelling EnVironment (Software Version 0.7. 2.1). http://www.spatialecology.com/gme. (last accessed 17 May 2016).

Both, C., C.A. Van Turnhout, R.G. Bijlsma, H. Siepel, A.J. Van Strien, And R.P. Foppen, 2010. Avian population consequences of climate change are most severe for longdistance migrants in seasonal habitats. Proceedings of the Royal Society of London B: Biological Sciences 277: 1259-1266.

BOULET, M., AND D.R. NORRIS. 2006. Introduction: the past and present of migratory connectivity. Ornithological Monographs: 1-13.

Brodeur, S., R. Decarie, D.M. Bird, AND M. Fuller. 1996. Complete migration cycle of Golden Eagles breeding in northern Quebec. Condor: 293-299.

Brooks, D. R., E.P. Hoberg, W.A. Boeger, S.L. Gardner, K. E. Galbreath, D. Herczeg, H.H. MEJÍA-MAdRID, S.E. RÁCZ, AND A.T. DursahinHAN. 2014. Finding Them Before They Find Us: Informatics, Parasites, and Environments in Accelerating Climate Change. Comparative Parasitology 81: 155-164. 
Cleland, E. E., I. Chuine, A. Menzel, H.A. Mooney, And M.D. Schwartz. 2007. Shifting plant phenology in response to global change. Trends in Ecology and Evolution, 22: 357365.

Convey, P., AND R.I.L. SMith. 2006. Responses of terrestrial Antarctic ecosystems to climate change. Plant Ecology 182:1-10.

Dale, V.H., L.A. Joyce, S. McNulty, R.P. Neilson, M.P. Ayres, M.D. Flannigan, C.J. Peterson, AND D. Simberloff. 2001. Climate change and forest disturbances: climate change can affect forests by altering the frequency, intensity, duration, and timing of fire, drought, introduced species, insect and pathogen outbreaks, hurricanes, windstorms, ice storms, or landslides. BioScience 51: 723-734.

DELISLE, J.M., AND J.A. SAVIDGE, J.A. 1997. Avian use and vegetation characteristics of Conservation Reserve Program fields. The Journal of Wildlife Management: 318-325.

Douglas, D.C., R. WeinzIERL, S.C. DAVIDSON, R. KAYs, M. WiKelskiI, AND G. Bohrer. 2012. Moderating Argos location errors in animal tracking data. Methods in Ecology and Evolution 3: 999-1007.

Friedl, M.A., D. Sulla-Menashe, B. Tan, A. Schneider, N. Ramankutty, A. Sibley, And X. HUANG. 2010. MODIS Collection 5 global land cover: Algorithm refinements and characterization of new datasets. Remote Sensing of Environment 114: 168-182.

Gesch, D., M. Imoen, S. Greenlee, C. Nelson, M. Steuck, AND D. Tyeler. 2002. The national elevation dataset. Photogrammetric Engineering and Remote Sensing 68: 5-32.

Gillanders, S.N., N.C. CoOps, M.A. Wulder, S.E. Gergel, And T. NElson. 2008. Multitemporal remote sensing of landscape dynamics and pattern change: describing natural and anthropogenic trends. Progress in Physical Geography 32: 503-528. 
Goward S.N., D. Dye, A. Kerber, And V. KalB. 1987. Comparison of North and South American biomes from AVHRR observations. Geocarto International 2: 27-39.

Grosbois, V., O Gimenez, J.M. Gaillard, R. Pradel, C. Barbraud, J. Clobert, A.P. MOLLER, AND H. WeIMERSKIRCH. 2008. Assessing the impact of climate variation on survival in vertebrate populations. Biological Reviews 83: 357-399.

Hamlet, A.F., P.W. Mote, M.P. Clark, And D.P. LetTenmaier. 2005. Effects of temperature and precipitation variability on snowpack trends in the western United States. Journal of Climate 18: 4545-4

HARMATA, A.R. 2002. Encounters of golden eagles banded in the Rocky Mountain West. Journal of Field Ornithology, 73: 23-32.561.

Harms, T.M., K.T. Murphy, X. LyU, S.S. Patterson, K.E. KinkeAd, S.J. Dinsmore, And P.W. FRESE. 2017. Using landscape habitat associations to prioritize areas of conservation action for terrestrial birds.Public Library of Science 12. e0173041.

Hinzman, L.D., N.D. Bettez, W.R. Bolton, F.S. Chapin, M.B. Dyurgerov, C.L. Fastie, B. Griffith, R.D. Hollister, A. Hope, H.P. Huntington. And A.M. Jensen. 2005. Evidence and implications of recent climate change in northern Alaska and other arctic regions. Climatic Change 72: 251-298.

Holmgren, M., M. Scheffer, E. EzCurRA, J.R. GutiÉRreZ, And G.M. MOHREN. 2001. El Niño effects on the dynamics of terrestrial ecosystems. Trends in Ecology \& Evolution, 16(2), 89-94.

InOUYe D.W., B. BARR, K.B. Armitage, B.D. InOuYe BD. 2000. Climate change is affecting altitudinal migrants and hibernating species. Proceedings of the National Academy of Science USA 97:1630- 33 
Karlen, D.L., G.E. VArvel, D.G. Bullock, And R.M. Cruse. 1994. Crop rotations for the 21st century. Advances in Agronomy 53: 1-45.

Knick, S.T, D.S. Dobkin, J.T. Rotenberry, M.A. Schroeder, W.M. VAnder Haegen, ANd C. VAN RIPER III. 2003. Teetering on the edge or too late? Conservation and research issues for avifauna of sagebrush habitats. Condor 105: 611-634.

Kochert, M.N., K. Steenhof, C.L. MCIntyre, And E.H. Craig. 2002. Golden Eagle (Aquila chrysaetos). Number 684 in The Birds of North America. A. Poole and G. Gill, editors. The Birds of North America, Incorporated. Philadelphia, Pennsylvania.

Kozlov, M.V., AND N.G. BerlinA. 2002. Decline in length of the summer season on the Kola Peninsula Russia. Climatic Change 54: 387- 398.

LAMBIN, E F., AND A.H. STRAHLER. 1994. Indicators of land-cover change for change-vector analysis in multitemporal space at coarse spatial scales. International Journal of Remote Sensing 15: 2099-2119.

LINDERHOLM, H.W. 2006. Growing season changes in the last century. Agricultural and Forest Meteorology 137: 1-14.

Lindsay, C., J. ZhU, A.E. Miller, P. KirChner, And T.L. Wilson. 2015. Deriving snow cover metrics for Alaska from MODIS. Remote Sensing, 7: 12961-12985.

Lobell, D. B., Schlenker, W., And Costa-Roberts, J. 2011. Climate trends and global crop production since 1980. Science 333: 616-620.

LogAn, J.A., J. REgniere, J. AND J.A. POWELL. 2003. Assessing the impacts of global warming on forest pest dynamics. Frontiers in Ecology and the Environment, 1: 130-137. 
MaCKUn, P.J., S. Wilson, T.R. FisCheTtI, AND J. GowOROWSKA. 2011. Population distribution and change: 2000 to 2010. US Department of Commerce, Economics and Statistics Administration, US Census Bureau.

MARR, N.V., AND R.L. KNIGHT. 1983. Food habits of golden eagles in eastern Washington. Murrelet 64: 73-77.

McBean, G., G. Alekseev, D. Chen, E. Foerland, J. Fyfe, P.Y. Groisman, R. King, H. Melling, R. Vose, AND P.H. Whitfield. 2005. Chapter 2: Arctic Climate: past and present. Arctic Climate Impact Assessment.

MCINTYRe, C.L., AND M.W. Collopy. 2006. Postfledging dependence period of migratory golden eagles (Aquila chrysaetos) in Denali National Park and Preserve, Alaska. The Auk 123: 877-884.

------, D.C. Douglas, M.W. Collopy. 2008. Movements of Golden Eagles (Aquila chrysaetos) from Interior Alaska during Their First-year of Independence. Auk 125: 214-224.

------. 2012. Quantifying Sources of Mortality and Wintering Ranges of Golden Eagles from Interior Alaska Using Banding and Satellite Tracking. Journal of Raptor Research 46:129-134.

------, AND J.H. SCHMIDT. 2012. Ecological and environmental correlates of territory occupancy and breeding performance of migratory Golden Eagles Aquila chrysaetos in interior Alaska. Ibis 154: 124-135.

McKenzie, D., Z.E. Gedalof, D.L. Peterson, and P. Mote. 2004. Climatic change, wildfire, and conservation. Conservation Biology 18: 890-902.

Moritz, C., J.L. PAtTon, C.J. Conroy, J.L. PARRA, G.C. White, AND S.R. Beissinger, 2008. Impact of a century of climate change on small-mammal communities in Yosemite National Park, USA. Science, 322: 261-264. 
NASA LP DAAC. 2013. MODIS Terra + Aqua Land Cover Type 5 Yearly L3 Global 500m NASA EOSDIS Land Processes DAAC, USGS Earth Resources Observation and Science (EROS) Center, Sioux Falls, South Dakota (https://pdaac.usgs.gov), accessed January 24, 2017, at https://pdaac.usgs.gov/data_access/reverb.

NEWTON, I. 2004. Population limitation in migrants. Ibis, 146: 197-226.

-----. 2010. The migration ecology of birds. Academic Press.

PARMESAn, C., G. YOHE. 2003. A globally coherent fingerprint of climate change impacts across natural systems. Nature 421: 37- 42 .

-----. 2006. Ecological and evolutionary responses to recent climate change. Annual Review of Ecology Evolution and Systematics 37: 637-669.

PARRY, M.L. Editor. 2007. Climate Change 2007: Impacts, adaptation and vulnerability: contribution of Working Group II to the fourth assessment report of the Intergovernmental Panel on Climate Change 4. Cambridge University Press.

Raynolds, M.K., D.A. Walker, K.J. Ambrosius, J. Brown, K.R. Everett, M. Kanevskiy, G.P. Kofinas, V.E. Romanovsky, Y. WhUR, P.J. WebBer. 2014. Cumulative geoecological effects of 62 years of infrastructure and climate change in ice-rich permafrost landscapes, Prudhoe Bay Oilfield, Alaska. Global Change Biology 20: 12111224.

Regonda, S.K., B Rajagopalan, M. Clark, AND J. Pitlick. 2005. Seasonal cycle shifts in hydroclimatology over the western United States. Journal of Climate, 18: 372-384.

RICE, W. R. 1989. Analyzing tables of statistical tests. Evolution, 43: 223-225. 
ROLAND, C.A., AND S.E. STEHN. 2013. Denali repeat photography project reveals dramatic changes: a drier, woodier, and more densely vegetated park. Alaska Park Science, 12, 6465.

Root, T.L., J.T. Price, K.R. Hall, S.H. Schneider, C. Rosenzweig, And J.A. Pounds. 2003. Fingerprints of global warming on wild animals and plants. Nature, 421: 57-60.

SCREEN, J.A., I. SIMMONDS. 2010. The central role of diminishing sea ice in recent Arctic temperature amplification. Nature 464:1334-1337

SERREZE, M.C., AND J.A. Francis. 2006. The Arctic amplification debate. Climatic Change 76: 241-264.

StewART, I.T., D.R. CAYAN, AND M.D. DETTINGER. 2005. Changes toward earlier streamflow timing across western North America. Journal of Climate, 18: 1136-1155.

Sturm M., J. Schimel, G. Mechaelson, J.M. WelKer, S.F. Oberbauer, G.E. Liston, J. FAHNESTOCK, AND V.E. ROMANOVSKY. 2005. Winter biological processes could help convert Arctic tundra to shrubland. BioScience 55: 17-26

TAPiA, L., A. Regos, A. GIL-CARRERA, AND J. Dominguez. 2017. Unravelling the response of diurnal raptors to land use change in a highly dynamic landscape in northwestern Spain: an approach based on satellite earth observation data. European Journal of Wildlife Research 63: 40.

TuRner, B.L., E.F. LAMBIN, AND A. REENBERG, A. 2007. The emergence of land change science for global environmental change and sustainability. Proceedings of the National Academy of Sciences, 104: 20666-20671.

VAn Hemert, C., J.M. Pierce, C.M. Handel. 2014. Wildlife health in a rapidly changing north: focus on avian disease. Frontiers in Ecology and the Environment. 12: 548-556. 
VISSER M.E., C. BOTH. 2005. Shifts in phenology due to global climate change: the need for a yardstick. Proceedings of the Royal Society of London B: Biological Sciences 272: 25612569.

Walther, G.R., E. Post, P. Convey, A. Menzel, C. Parmesan, T.J. Beebee, J.M. Fromentin, O. Hoegh-GuldBerg, AND F. BAIRLEIN. 2002. Ecological responses to recent climate change. Nature, 416: 389-395.

WAN, Z., P. WANG, AND X. LI. 2004. Using MODIS land surface temperature and normalized difference vegetation index products for monitoring drought in the southern Great Plains, USA. International Journal of Remote Sensing 25: 61-72.

WAtson, J., S.R. RAE, AND R. StILlman. 1992. Nesting density and breeding success of golden eagles in relation to food supply in Scotland. Journal of Animal Ecology, 543-550.

-----. 2010. The Golden Eagle. Second Ed. T. and A.D. Poyser, London, U.K.

Webster, M.S., P.P. Marra, S.M. Haig, S. Bensch, And R.T. HolmeS. 2002. Links between worlds: Unravelling migratory connectivity. Trends in Ecology and Evolution. 17: 76-83.

WORTON, B.J. 1989. Kernel methods for estimating the utilization distribution in home-range studies. Ecology 70: 164-168.

Xian, G., C.G. Homer, AND C.L. Aldridge. 2012. Effects of land cover and regional climate variations on long-term spatiotemporal changes in sagebrush ecosystems. GIScience and Remote Sensing 49: 378-396.

XiUBIN, L. 1996. A review of the international researches on land use/land cover change [J]. Acta Geographica Sinica 6. 
Table 1. MODIS annual land cover data (Terra + Aqua Type 5 Yearly L3 Global 500m SIN Grid MCD12Q1) Land Cover Classification: Type 5 Plant Functional Type (PFT) scheme and combined categories used in analyses of land cover change within seasonal home ranges of migratory first-year Golden Eagles hatched in Denali.

\begin{tabular}{ll}
\multicolumn{2}{c}{ MODIS LAND COVER } \\
\hline CLASSIFICATION & COMBINED \\
& CATEGORIES \\
\hline Barren or Sparse Vegetation & Barren \\
Cereal Crops & Croplands \\
Broadleaf Crops & Croplands \\
Deciduous Needleleaf Trees & Deciduous Forest \\
Deciduous Broadleaf Trees & Deciduous Forest \\
Evergreen Needleleaf Trees & Evergreen Forest \\
Evergreen Broadleaf Trees & Evergreen Forest \\
Grass & Grasslands \\
Shrub & Shrublands \\
Snow and Ice & Snow/Ice \\
Urban and Built-up & Urban \\
Water & Water \\
\hline Total 12 & \multicolumn{1}{c}{9} \\
\hline
\end{tabular}


Table 2. Average percent land cover categories \pm standard deviation within areas used by first-year Golden Eagles hatched in Denali, Alaska, on winter and summer home ranges and core use areas. Cover was estimated from MODIS imagery from 2001, 2006 and 2011. Land cover classes are as in Table 1.

\section{WINTER HOME RANGES}

\begin{tabular}{lccc}
\hline LAND COVER & 2001 & 2006 & 2011 \\
\hline Barren & $0.5 \pm 1.5$ & $0.2 \pm 0.3$ & $0.1 \pm 0.2$ \\
Croplands & $16.4 \pm 24.4$ & $12.7 \pm 21.8$ & $10.3 \pm 19.1$ \\
Deciduous Forest & $4.6 \pm 10.1$ & $3.7 \pm 8.7$ & $3.2 \pm 7.9$ \\
Evergreen Forest & $21.9 \pm 25.7$ & $24.6 \pm 28.1$ & $28.3 \pm 30.6$ \\
Grasslands & $47.9 \pm 33.9$ & $51.6 \pm 35.4$ & $50.5 \pm 35.3$ \\
Shrublands & $8.0 \pm 20.8$ & $7.0 \pm 22.5$ & $6.5 \pm 22.9$ \\
Snow/Ice & $0.0 \pm 0.0$ & $0.0 \pm 0.1$ & $0.0 \pm 0.0$ \\
Urban & $0.2 \pm 0.3$ & $0.2 \pm 0.3$ & $0.2 \pm 0.3$ \\
Water & $0.5 \pm 8.3$ & $0.5 \pm 0.6$ & $0.9 \pm 1.1$ \\
\hline
\end{tabular}

\section{WINTER CORE USE AREAS}

\begin{tabular}{lccc}
\hline LAND COVER & 2001 & 2006 & 2011 \\
\hline Barren & $0.4 \pm 1.4$ & $0.1 \pm 0.3$ & $0.0 \pm 0.1$ \\
Croplands & $14.6 \pm 24.4$ & $12.3 \pm 21.8$ & $8.8 \pm 16.6$ \\
Deciduous Forest & $5.7 \pm 13.9$ & $4.70 \pm 11.4$ & $4.1 \pm 10.5$ \\
Evergreen Forest & $20.3 \pm 29.0$ & $23.6 \pm 31.1$ & $27.2 \pm 32.9$ \\
Grasslands & $49.7 \pm 37.5$ & $51.7 \pm 37.4$ & $52.1 \pm 38.0$ \\
Shrublands & $8.8 \pm 22.9$ & $7.3 \pm 23.3$ & $7.0 \pm 24.5$ \\
Snow/Ice & $0.0 \pm 0.0$ & $0.0 \pm 0.1$ & $0.0 \pm 0.0$ \\
Urban & $0.2 \pm 0.4$ & $0.2 \pm 0.4$ & $0.1 \pm 0.3$ \\
Water & $0.3 \pm 0.5$ & $0.2 \pm 03$ & $0.6 \pm 1.0$ \\
\hline
\end{tabular}

\section{SUMMER HOME RANGES}

\begin{tabular}{ccc}
\hline 2001 & 2006 & 2011 \\
\hline $1.5 \pm 0.9$ & $1.3 \pm 1.1$ & $0.3 \pm 0.2$ \\
$0.0 \pm 0.0$ & $0.0 \pm 0.0$ & $0.01 \pm 0.0$ \\
$1.2 \pm 1.0$ & $1.4 \pm 1.4$ & $1.0 \pm 1.0$ \\
$10.4 \pm 9.1$ & $12.8 \pm 10.4$ & $12.9 \pm 10.7$ \\
$25.5 \pm 7.4$ & $21.8 \pm 7.5$ & $23.1 \pm 7.2$ \\
$48.0 \pm 14.2$ & $50.9 \pm 16.4$ & $50.4 \pm 15.6$ \\
$3.8 \pm 4.1$ & $3.1 \pm 4.1$ & $2.7 \pm 4.4$ \\
$0.0 \pm 0.0$ & $0.0 \pm 0.00$ & $0.6 \pm 1.8$ \\
$9.7 \pm 8.3$ & $9.2 \pm 8.7$ & $9.1 \pm 8.6$ \\
\hline
\end{tabular}

\begin{tabular}{ccc}
\multicolumn{3}{c}{ SUMMER CORE USE AREAS } \\
\hline 2001 & 2006 & 2011 \\
\hline $1.7 \pm 1.5$ & $1.2 \pm 1.4$ & $0.3 \pm 0.3$ \\
$0.0 \pm 0.0$ & $0.0 \pm 0.0$ & $0.0 \pm 0.0$ \\
$0.8 \pm 0.9$ & $0.9 \pm 1.1$ & $0.8 \pm 0.8$ \\
$5.5 \pm 6.1$ & $8.6 \pm 8.9$ & $8.4 \pm 8.8$ \\
$26.7 \pm 10.7$ & $21.1 \pm 8.9$ & $24.2 \pm 9.7$ \\
$54.1 \pm 16.5$ & $57.5 \pm 18.9$ & $55.8 \pm 18.0$ \\
$4.3 \pm 6.8$ & $3.2 \pm 5.4$ & $3.3 \pm 5.9$ \\
$0.0 \pm 0.0$ & $0.0 \pm 0.0$ & $0.0 \pm 0.0$ \\
$7.9 \pm 12.0$ & $7.5 \pm 12.1$ & $7.12 \pm 12.8$ \\
\hline
\end{tabular}


Table 3. Changes in percent land cover within areas used by first-year Golden Eagles hatched in Denali, Alaska, on winter and summer home ranges and core use areas. Results shown are from Mann-Whitney $U$-test $(V, p)$ with sequential Bonferroni correction adjusted critical value (Rice 1989) across three time intervals (2001 - 2006, 2006 - 2011, and 2001 - 2011). Land cover classes are as in Table 1. Within summer core use areas the land cover category Urban did not appear.

a. WINTER HOME RANGES

\begin{tabular}{lcccccc}
\hline & \multicolumn{2}{c}{$2001-2006$} & \multicolumn{2}{c}{$2006-2011$} & \multicolumn{2}{c}{$2001-2011$} \\
\cline { 2 - 7 } LAND COVER & $V$ & $p$ & $V$ & $p$ & $V$ & $p$ \\
\hline Barren & 61 & 0.616 & 76 & 0.149 & 78 & 0.025 \\
Croplands & 107 & $\mathbf{0 . 0 0 5} *$ & 104 & 0.010 & 105 & $\mathbf{0 . 0 0 8 *}$ \\
Deciduous Forest & 105 & $\mathbf{0 . 0 0 2 *}$ & 81 & 0.014 & 100 & $\mathbf{0 . 0 0 3 *}$ \\
Evergreen Forest & 9 & $\mathbf{0 . 0 0 7} *$ & 0 & $\mathbf{0 . 0 0 2 *}$ & 6 & $\mathbf{0 . 0 0 4}$ \\
Grasslands & 29 & 0.083 & 104 & 0.010 & 54 & 0.762 \\
Shrublands & 72 & 0.233 & 88 & 0.028 & 84 & 0.052 \\
Snow/Ice & 54 & 0.068 & 30 & 0.839 & 58 & 0.029 \\
Urban & 48 & 0.041 & 3 & 0.371 & 55 & $\mathbf{0 . 0 0 6 *}$ \\
Water & 57 & 0.170 & 0 & $\mathbf{0 . 0 0 3 *}$ & 0 & $\mathbf{0 . 0 0 3 *}$ \\
\hline
\end{tabular}

\section{c. WINTER CORE USE AREAS}

\begin{tabular}{lcccccc}
\hline & \multicolumn{2}{c}{$2001-2006$} & \multicolumn{2}{c}{$2006-2011$} & \multicolumn{2}{c}{$2001-2011$} \\
\cline { 2 - 7 } LAND COVER & $V$ & $p$ & $V$ & $p$ & $V$ & $p$ \\
\hline Barren & 34 & 0.541 & 31 & 0.080 & 47 & 0.053 \\
Croplands & 105 & 0.008 & 114 & $\mathbf{0 . 0 0 1 *}$ & 108 & $\mathbf{0 . 0 0 4 *}$ \\
Deciduous Forest & 64 & 0.055 & 81 & 0.012 & 87 & $\mathbf{0 . 0 0 4}$ \\
Evergreen Forest & 10 & 0.008 & 6 & $\mathbf{0 . 0 0 6 *}$ & 7 & $\mathbf{0 . 0 0 5 *}$ \\
Grasslands & 37 & 0.208 & 67 & 0.720 & 50 & 0.600 \\
Shrublands & 76 & 0.149 & 75 & 0.043 & 76 & 0.149 \\
Snow/Ice & 14 & 1.000 & 12 & 0.281 & 18 & 0.142 \\
Urban & 36 & 0.014 & 1 & 1.000 & 36 & 0.014 \\
Water & 48 & 0.1973 & 0 & $\mathbf{0 . 0 0 6 *}$ & 1 & $\mathbf{0 . 0 0 5 *}$ \\
\hline
\end{tabular}

b.

\begin{tabular}{cccccc}
\hline \multicolumn{2}{c}{$2001-2006$} & \multicolumn{2}{c}{$2006-2011$} & \multicolumn{2}{c}{$2001-2011$} \\
\hline$V$ & $p$ & $V$ & $p$ & $V$ & $p$ \\
\hline 43 & 0.131 & 53 & 0.006 & 55 & $\mathbf{0 . 0 0 2 *}$ \\
25 & 0.363 & 6 & 0.107 & 15 & 0.726 \\
31 & 0.770 & 46 & 0.064 & 41 & 0.193 \\
0 & $\mathbf{0 . 0 0 2 *}$ & 23 & 0.695 & 4 & 0.014 \\
50 & 0.020 & 8 & 0.049 & 46 & 0.064 \\
16 & 0.275 & 29 & 0.922 & 14 & 0.193 \\
55 & $\mathbf{0 . 0 0 2} *$ & 21 & 0.906 & 47 & 0.049 \\
1 & 1.000 & 1 & 1.000 & 1 & 1.000 \\
45 & 0.084 & 33 & 0.625 & 50 & 0.020 \\
\hline
\end{tabular}

d.

SUMMER CORE USE AREAS

\begin{tabular}{cccccc}
\hline \multicolumn{2}{c}{$2001-2006$} & \multicolumn{2}{c}{$2006-2011$} & \multicolumn{2}{c}{$2001-2011$} \\
\hline$V$ & $p$ & $V$ & $p$ & $V$ & $p$ \\
\hline 47 & 0.049 & 44 & 0.013 & 55 & $\mathbf{0 . 0 0 2 *}$ \\
14 & 0.529 & 14 & 0.529 & 10 & 0.590 \\
16 & 0.477 & 31.0 & 0.343 & 19.0 & 0.722 \\
0 & 0.009 & 33 & 0.236 & 3 & 0.024 \\
47 & 0.049 & 1 & $\mathbf{0 . 0 0 4}$ & 33 & 0.625 \\
15 & 0.232 & 52 & 0.010 & 17 & 0.322 \\
55 & $\mathbf{0 . 0 0 2 *}$ & 13 & 0.933 & 55.0 & $\mathbf{0 . 0 0 2 *}$ \\
- & - & - & - & - & - \\
37 & 0.097 & 29 & 0.922 & 44.0 & 0.106 \\
\hline
\end{tabular}


Fig 1. First-year Golden Eagle core use areas (KDE 50\% isopleth) across summer $(\mathrm{n}=10)$ and winter seasons $(n=15)$, displayed over a shaded relief base map. Summer ranges are those in Alaska, U.S.A., Yukon Territory and Northwest Territories, Canada. Winter ranges are those that occur from central Alberta, Canada, to New Mexico, U.S.A., and from Washington State to South Dakota, U.S.A. The eagles' natal area of Denali National Park and Preserve is shown in cross hatch in central Alaska. Map projected to North America Equal Area Conic projection. 
Fig 1.

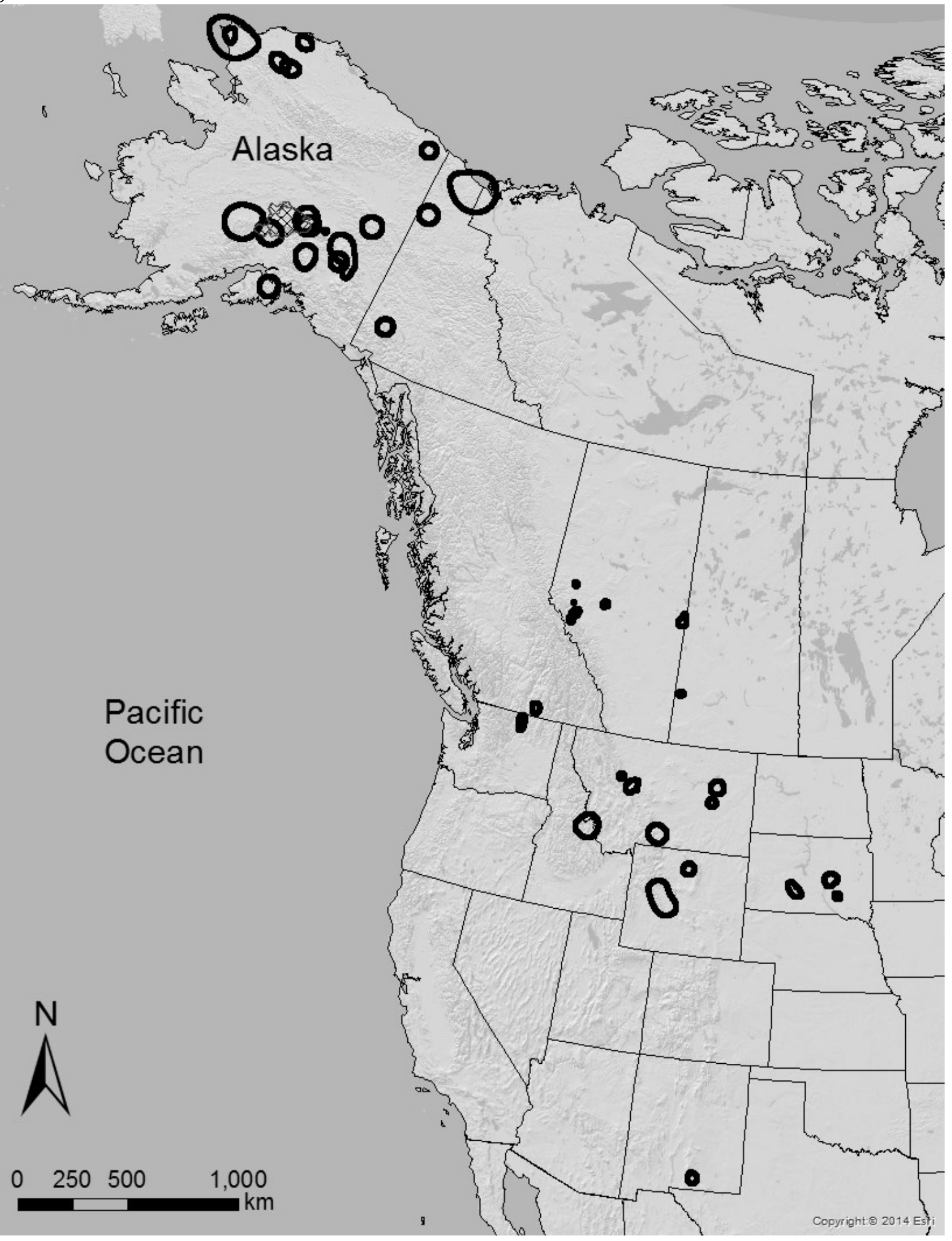


APPENDIX B.1

SUPPLEMENTARY INFORMATIOION

SI Table 1. Number of Argos satellite locations by location-quality class. Before and after Douglas Argos accuracy filtering, and only filtered non-migratory summer and winter season locations used in this study, obtained from radio-tagged first-year Golden Eagles from Denali.

\begin{tabular}{lcccccc} 
ARGOS LOCATION- & \multicolumn{2}{c}{ AlL ARGOS } & \multicolumn{2}{c}{ BEST FILTERED LOCATION } & \multicolumn{2}{c}{ NON-MiGRATORY } \\
QUALITY CLASS & \multicolumn{2}{c}{ LOCATIONS } & \multicolumn{2}{c}{ PER DUTY CYCLE } & \multicolumn{2}{c}{ LOCATIONS USED } \\
& $n$ & $(\%)$ & $n$ & $(\%)$ & $n$ & $(\%)$ \\
\hline 3 & 168 & 1.1 & 142 & 5.2 & 50 & 4.7 \\
2 & 538 & 3.6 & 390 & 14.2 & 137 & 12.9 \\
1 & 2041 & 13.7 & 945 & 34.5 & 334 & 31.4 \\
0 & 7639 & 51.4 & 978 & 35.7 & 433 & 40.7 \\
A & 1502 & 10.1 & 96 & 3.5 & 42 & 3.9 \\
B & 2046 & 13.8 & 170 & 6.2 & 42 & 3.9 \\
Z & 935 & 6.3 & 22 & 0.8 & 27 & 2.5 \\
\hline Total & 14869 & 100.0 & 2743 & 100.0 & 1065 & 100.0 \\
\hline
\end{tabular}


SI Table 2. Summary statistics for individual seasons used to calculate summer KDEs for (a) male and (b) female first-year Golden Eagles hatched in Denali. Data shown are individuals (ID), area of space used $\left(\mathrm{km}^{2}\right)$ for summer home range size (KDE95) and summer core use area size (KDE50), season start and end date, number of days on summer range, and number of telemetry location fixes. A single asterisk (*) in season end date column denotes a radio failure, and $\left({ }^{\mathrm{D}}\right)$ denotes mortality before departing summer range. For summary statistics on winter space use see Chapter 2 of this thesis.

\begin{tabular}{lcccccc} 
a & MALE & \multicolumn{1}{l}{ KDE50 } & $\begin{array}{c}\text { SEASON } \\
\text { START }\end{array}$ & $\begin{array}{c}\text { SEASON } \\
\text { END }\end{array}$ & DAYS & LOCATIONS \\
\hline 2636 & 68080.0 & 9175.8 & 12May1998 & 18Sept1998* & 130 & 43 \\
2689 & 196987.0 & 38651.9 & 3June2000 & 11July2000 & 39 & 17 \\
2692 & 224375.5 & 30732.9 & 20May2000 & 20Aug2000 & 93 & 31 \\
2657 & 188704.2 & 35405.9 & 28May1998 & 28Aug1998 & 93 & 26 \\
\hline AVERAGE & 169536.7 & 28491.6 & 23-May & 19-Aug & 75 & 29.3 \\
SD & \pm 69334.2 & \pm 13281.1 & $\pm 10 \mathrm{~d}$ & $\pm 29 \mathrm{~d}$ & $\pm 31 \mathrm{~d}$ & \pm 10.8 \\
\hline
\end{tabular}

\section{b FEMALE}

\begin{tabular}{lcccccc}
\hline ID & KDE95 & KDE50 & $\begin{array}{c}\text { SEASON } \\
\text { START }\end{array}$ & $\begin{array}{c}\text { SEASON } \\
\text { END }\end{array}$ & DAYS & LOCATIONS \\
\hline 2632 & 41272.0 & 6717.3 & 17May1998 & 27June1998 & 42 & 13 \\
2635 & 20990.1 & 3190.1 & 7June1998 & 20Sept1998 & 106 & 35 \\
2670 & 75279.7 & 15775.6 & 24May2000 & 31July2000 & 69 & 25 \\
2681 & 58740.4 & 7951.6 & 3May2000 & 4Aug2000 & 94 & 33 \\
2685 & 106672.9 & 21389.4 & 9May2000 & 31July2000 & 84 & 35 \\
2697 & 31280.2 & 6681.1 & 6June2000 & 2Sept2000 & 89 & 35 \\
\hline AVERAGE & 55705.89 & 10284.18 & 21-May & 9-Aug & 81 & 29.3 \\
SD & \pm 31623.1 & \pm 6855.0 & $\pm 14 d$ & $\pm 30 d$ & $\pm 23 \mathrm{~d}$ & \pm 8.9 \\
\hline
\end{tabular}


SI Table 3. Percent land cover categories \pm standard deviation by individual on winter and summer home ranges and core use areas for first-year Golden Eagles at three time stamps (2001, 2006, 2011), reported in percent cover by combined MODIS land cover category as in Table 1.

2001 SUMMER HOME RANGE

\begin{tabular}{cccccccccc}
\hline & Barren & Croplands & $\begin{array}{c}\text { Deciduous } \\
\text { Forest }\end{array}$ & $\begin{array}{c}\text { Evergreen } \\
\text { Forest }\end{array}$ & Grasslands & Shrublands & Snow/Ice & Urban & Water \\
\hline 2632 & 0.8 & 0.0 & 1.7 & 23.6 & 34.8 & 37.6 & 0.1 & 0.0 & 1.4 \\
2635 & 0.8 & 0.0 & 0.0 & 0.0 & 32.9 & 47.9 & 0.4 & 0.0 & 18.0 \\
2670 & 2.8 & 0.0 & 2.2 & 16.4 & 30.0 & 38.0 & 6.8 & 0.0 & 3.8 \\
2681 & 1.8 & 0.0 & 1.2 & 9.8 & 30.5 & 47.7 & 5.9 & 0.0 & 3.0 \\
2685 & 2.8 & 0.0 & 2.8 & 20.7 & 23.7 & 27.3 & 11.9 & 0.1 & 10.7 \\
2697 & 0.4 & 0.0 & 0.0 & 0.0 & 18.7 & 68.1 & 0.8 & 0.0 & 12.0 \\
2636 & 2.3 & 0.0 & 0.5 & 3.7 & 19.3 & 69.5 & 2.6 & 0.0 & 2.1 \\
2689 & 2.3 & 0.0 & 2.0 & 18.0 & 31.0 & 34.6 & 7.7 & 0.0 & 4.3 \\
2692 & 1.0 & 0.0 & 1.5 & 11.4 & 21.0 & 49.4 & 1.0 & 0.0 & 14.8 \\
2657 & 0.6 & 0.0 & 0.1 & 0.1 & 12.6 & 59.9 & 0.3 & 0.0 & 26.5 \\
\hline & $1.5 \pm 0.9$ & $0.0 \pm 0.0$ & $1.2 \pm 1.0$ & $10.4 \pm 9.1$ & $25.5 \pm 7.4$ & $48.0 \pm 14.2$ & $3.8 \pm 4.1$ & $0.0 \pm 0.0$ & $9.6 \pm 8.3$
\end{tabular}

2006 SUMMER HOME RANGE

\begin{tabular}{cccccccccc}
\hline & Barren & Croplands & $\begin{array}{c}\text { Deciduous } \\
\text { Forest }\end{array}$ & $\begin{array}{c}\text { Evergreen } \\
\text { Forest }\end{array}$ & Grasslands & Shrublands & Snow/Ice & Urban & Water \\
\hline 2632 & 0.3 & 0.0 & 1.5 & 24.4 & 27.0 & 46.2 & 0.0 & 0.0 & 0.6 \\
2635 & 0.1 & 0.0 & 0.1 & 0.2 & 27.3 & 53.1 & 0.0 & 0.0 & 19.2 \\
2670 & 2.1 & 0.0 & 4.4 & 21.9 & 25.6 & 36.9 & 5.7 & 0.0 & 3.3 \\
2681 & 1.8 & 0.0 & 1.1 & 14.2 & 26.6 & 49.2 & 5.0 & 0.0 & 2.2 \\
2685 & 2.1 & 0.0 & 3.0 & 23.7 & 24.9 & 25.2 & 11.5 & 0.1 & 9.5 \\
2697 & 0.2 & 0.0 & 0.0 & 0.0 & 9.7 & 78.1 & 0.0 & 0.0 & 11.9 \\
2636 & 3.3 & 0.0 & 0.5 & 6.2 & 20.1 & 67.9 & 0.8 & 0.0 & 1.3 \\
2689 & 2.1 & 0.0 & 1.8 & 23.2 & 29.0 & 33.4 & 7.3 & 0.0 & 3.2 \\
2692 & 0.9 & 0.0 & 1.1 & 13.7 & 20.4 & 49.6 & 0.5 & 0.0 & 13.8 \\
2657 & 0.5 & 0.0 & 0.0 & 0.1 & 7.6 & 65.2 & 0.0 & 0.0 & 26.5 \\
\hline & $1.3 \pm 1.1$ & $0.0 \pm 0.0$ & $1.3 \pm 1.4$ & $12.8 \pm 10.4$ & $21.8 \pm 7.5$ & $50.5 \pm 16.4$ & $3.1 \pm 4.1$ & $0.0 \pm 0.0$ & $9.2 \pm 8.7$
\end{tabular}

2011 SUMMER HOME RANGE

\begin{tabular}{cccccccccc}
\hline & Barren & Croplands & $\begin{array}{c}\text { Deciduous } \\
\text { Forest }\end{array}$ & $\begin{array}{c}\text { Evergreen } \\
\text { Forest }\end{array}$ & Grasslands & Shrublands & Snow/Ice & Urban & Water \\
\hline 2632 & 0.4 & 0.0 & 1.1 & 23.9 & 27.3 & 45.9 & 0.1 & 0.0 & 1.4 \\
2635 & 0.0 & 0.0 & 0.1 & 0.0 & 28.4 & 53.0 & 0.0 & 0.0 & 18.4 \\
2670 & 0.0 & 0.0 & 2.8 & 23.1 & 27.3 & 37.6 & 0.5 & 5.8 & 2.9 \\
2681 & 0.4 & 0.0 & 0.8 & 15.1 & 27.8 & 48.9 & 4.9 & 0.0 & 2.1 \\
2685 & 0.7 & 0.0 & 2.5 & 24.3 & 24.7 & 25.5 & 12.5 & 0.1 & 9.7 \\
2697 & 0.0 & 0.0 & 0.0 & 0.0 & 12.2 & 75.8 & 0.0 & 0.0 & 11.9 \\
2636 & 0.4 & 0.0 & 0.3 & 5.4 & 25.6 & 66.8 & 0.4 & 0.0 & 1.1 \\
2689 & 0.5 & 0.0 & 1.3 & 23.8 & 29.1 & 34.3 & 7.8 & 0.0 & 3.1 \\
2692 & 0.3 & 0.0 & 1.4 & 13.3 & 19.2 & 51.1 & 0.7 & 0.0 & 14.0 \\
2657 & 0.0 & 0.0 & 0.0 & 0.0 & 8.8 & 64.7 & 0.0 & 0.0 & 26.4 \\
\hline & $0.3 \pm 0.2$ & $0.0 \pm 0.0$ & $1.0 \pm 1.0$ & $12.9 \pm 10.7$ & $23.1 \pm 7.2$ & $50.4 \pm 15.6$ & $2.7 \pm 4.4$ & $0.6 \pm 1.8$ & $9.1 \pm 8.6$
\end{tabular}


2001 SUMMER CORE USE AREA

\begin{tabular}{cccccccccc}
\hline & Barren & Croplands & $\begin{array}{c}\text { Deciduous } \\
\text { Forest }\end{array}$ & $\begin{array}{c}\text { Evergreen } \\
\text { Forest }\end{array}$ & Grasslands & Shrublands & Snow/Ice & Urban & Water \\
\hline 2632 & 0.2 & 0.0 & 0.9 & 12.5 & 36.2 & 49.5 & 0.0 & 0.0 & 0.7 \\
2635 & 1.9 & 0.0 & 0.0 & 0.0 & 45.4 & 50.2 & 0.2 & 0.0 & 2.3 \\
2670 & 4.1 & 0.0 & 1.7 & 6.6 & 27.0 & 38.8 & 15.9 & 0.0 & 5.8 \\
2681 & 0.8 & 0.0 & 0.1 & 2.0 & 28.9 & 63.9 & 3.6 & 0.0 & 0.8 \\
2685 & 3.7 & 0.1 & 2.0 & 14.7 & 23.5 & 29.0 & 17.9 & 0.0 & 9.1 \\
2697 & 0.0 & 0.0 & 0.0 & 0.0 & 19.8 & 80.1 & 0.1 & 0.0 & 0.0 \\
2636 & 2.6 & 0.0 & 0.7 & 5.1 & 22.9 & 65.5 & 1.0 & 0.0 & 2.2 \\
2689 & 2.7 & 0.0 & 2.1 & 14.0 & 30.4 & 43.5 & 4.4 & 0.0 & 2.9 \\
2692 & 1.0 & 0.0 & 0.4 & 0.5 & 7.0 & 75.2 & 0.1 & 0.0 & 15.8 \\
2657 & 0.3 & 0.0 & 0.0 & 0.0 & 15.5 & 44.8 & 0.3 & 0.0 & 39.2 \\
\hline & $1.7 \pm 1.5$ & $0.0 \pm 0.0$ & $0.8 \pm 0.9$ & $5.5 \pm 6.1$ & $25.6 \pm 10.7$ & $54.1 \pm 16.5$ & $4.3 \pm 6.8$ & $0.0 \pm 0.0$ & $7.9 \pm 12.0$
\end{tabular}

2006 SUMMER CORE USE AREA

\begin{tabular}{cccccccccc}
\hline & Barren & Croplands & $\begin{array}{c}\text { Deciduous } \\
\text { Forest }\end{array}$ & $\begin{array}{c}\text { Evergreen } \\
\text { Forest }\end{array}$ & Grasslands & Shrublands & Snow/Ice & Urban & Water \\
\hline 2632 & 0.0 & 0.0 & 0.7 & 19.0 & 22.1 & 58.1 & 0.0 & 0.0 & 0.1 \\
2635 & 0.1 & 0.0 & 0.3 & 0.4 & 34.8 & 59.9 & 0.0 & 0.0 & 4.5 \\
2670 & 2.3 & 0.0 & 3.5 & 10.6 & 26.5 & 38.6 & 13.1 & 0.0 & 5.5 \\
2681 & 0.6 & 0.0 & 0.4 & 3.6 & 20.3 & 73.0 & 1.9 & 0.0 & 0.2 \\
2685 & 3.1 & 0.1 & 2.3 & 19.4 & 27.6 & 27.6 & 13.3 & 0.0 & 6.6 \\
2697 & 0.0 & 0.0 & 0.0 & 0.0 & 9.8 & 90.2 & 0.0 & 0.0 & 0.0 \\
2636 & 3.5 & 0.0 & 0.8 & 10.3 & 22.9 & 61.5 & 0.2 & 0.0 & 0.8 \\
2689 & 2.4 & 0.0 & 1.1 & 22.2 & 27.9 & 40.3 & 3.9 & 0.0 & 2.2 \\
2692 & 0.2 & 0.0 & 0.1 & 0.6 & 9.3 & 74.2 & 0.0 & 0.0 & 15.6 \\
2657 & 0.0 & 0.0 & 0.0 & 0.0 & 9.6 & 51.1 & 0.0 & 0.0 & 39.1 \\
\hline & $1.2 \pm 1.4$ & $0.0 \pm 0.0$ & $0.9 \pm 1.1$ & $8.6 \pm 8.9$ & $21.07 \pm 8.9$ & $57.5 \pm 18.9$ & $3.2 \pm 5.4$ & $0.0 \pm 0.0$ & $7.5 \pm 12.1$
\end{tabular}

2011 SUMMER CORE USE AREA

\begin{tabular}{cccccccccc}
\hline & Barren & Croplands & $\begin{array}{c}\text { Deciduous } \\
\text { Forest }\end{array}$ & $\begin{array}{c}\text { Evergreen } \\
\text { Forest }\end{array}$ & $\begin{array}{c}\text { Grassland } \\
\text { s }\end{array}$ & Shrublands & Snow/Ice & Urban & Water \\
\hline 2632 & 0.0 & 0.0 & 0.6 & 17.4 & 25.6 & 55.9 & 0.0 & 0.0 & 0.5 \\
2635 & 0.0 & 0.0 & 0.2 & 0.0 & 37.2 & 59.8 & 0.0 & 0.0 & 2.7 \\
2670 & 0.6 & 0.0 & 2.2 & 13.3 & 28.8 & 38.4 & 13.3 & 0.0 & 3.3 \\
2681 & 0.2 & 0.0 & 0.1 & 3.5 & 27.2 & 67.7 & 1.1 & 0.0 & 0.1 \\
2685 & 0.9 & 0.0 & 1.8 & 19.5 & 29.6 & 26.2 & 15.1 & 0.0 & 6.8 \\
2697 & 0.0 & 0.0 & 0.0 & 0.0 & 13.7 & 86.3 & 0.0 & 0.0 & 0.0 \\
2636 & 0.3 & 0.0 & 0.7 & 8.4 & 29.7 & 60.4 & 0.1 & 0.0 & 0.4 \\
2689 & 0.4 & 0.0 & 1.3 & 21.5 & 31.0 & 39.7 & 3.8 & 0.0 & 2.0 \\
2692 & 0.1 & 0.0 & 1.2 & 0.2 & 8.1 & 74.3 & 0.0 & 0.0 & 16.0 \\
2657 & 0.0 & 0.0 & 0.0 & 0.0 & 11.0 & 49.7 & 0.0 & 0.0 & 39.2 \\
\hline & $0.3 \pm 0.3$ & $0.0 \pm 0.0$ & $0.8 \pm 0.8$ & $8.4 \pm 8.8$ & $24.2 \pm 9.7$ & $55.9 \pm 18.0$ & $3.3 \pm 5.9$ & $0.0 \pm 0.0$ & $7.1 \pm 12.3$
\end{tabular}


2001 WINTER HOME RANGE

\begin{tabular}{cccccccccc}
\hline & Barren & Croplands & $\begin{array}{c}\text { Deciduous } \\
\text { Forest }\end{array}$ & $\begin{array}{c}\text { Evergreen } \\
\text { Forest }\end{array}$ & Grasslands & Shrublands & Snow/Ice & Urban & Water \\
\hline 2632 & 0.4 & 0.2 & 6.6 & 72.7 & 14.8 & 4.2 & 0.1 & 0.1 & 1.0 \\
2634 & 0.0 & 9.7 & 0.5 & 23.4 & 64.2 & 1.7 & 0.0 & 0.4 & 0.1 \\
2635 & 0.8 & 3.7 & 0.1 & 8.7 & 71.6 & 14.9 & 0.0 & 0.1 & 0.0 \\
2647 & 0.5 & 2.9 & 0.2 & 4.9 & 86.6 & 4.5 & 0.1 & 0.0 & 0.2 \\
2670 & 0.0 & 15.8 & 32.1 & 45.2 & 5.0 & 1.7 & 0.0 & 0.2 & 0.1 \\
2681 & 0.0 & 8.6 & 0.0 & 0.0 & 91.4 & 0.0 & 0.0 & 0.0 & 0.0 \\
2685 & 0.0 & 7.1 & 0.9 & 40.5 & 47.6 & 2.3 & 0.0 & 0.9 & 0.8 \\
2697 & 0.1 & 2.3 & 0.0 & 0.1 & 95.3 & 0.2 & 0.0 & 0.0 & 2.0 \\
2636 & 0.1 & 6.3 & 0.3 & 13.5 & 76.4 & 3.1 & 0.0 & 0.3 & 0.1 \\
2641 & 0.0 & 7.4 & 1.7 & 67.3 & 19.1 & 2.3 & 0.0 & 0.7 & 1.7 \\
2646 & 0.0 & 5.2 & 0.6 & 45.2 & 46.1 & 2.5 & 0.1 & 0.1 & 0.2 \\
2688 & 0.0 & 29.2 & 0.0 & 0.0 & 70.7 & 0.0 & 0.0 & 0.0 & 0.0 \\
2689 & 5.9 & 0.3 & 0.5 & 5.1 & 6.1 & 81.9 & 0.0 & 0.1 & 0.0 \\
2692 & 0.2 & 80.6 & 0.0 & 0.1 & 18.1 & 0.0 & 0.0 & 0.0 & 1.0 \\
2699 & 0.1 & 66.3 & 25.7 & 1.3 & 5.0 & 0.6 & 0.0 & 0.0 & 1.0 \\
\hline & $0.5 \pm 1.5$ & $16.4 \pm 24.4$ & $4.6 \pm 10.1$ & $21.9 \pm 25.7$ & $47.9 \pm 33.8$ & $8.0 \pm 20.8$ & $0.0 \pm 0.0$ & $0.2 \pm 0.3$ & $0.5 \pm 0.6$
\end{tabular}

2006 WINTER HOME RANGE

\begin{tabular}{cccccccccc}
\hline & Barren & Croplands & $\begin{array}{c}\text { Deciduous } \\
\text { Forest }\end{array}$ & $\begin{array}{c}\text { Evergreen } \\
\text { Forest }\end{array}$ & Grasslands & Shrublands & Snow/Ice & Urban & Water \\
\hline 2632 & 0.5 & 0.1 & 4.3 & 79.0 & 13.8 & 1.8 & 0.0 & 0.1 & 0.4 \\
2634 & 0.0 & 4.8 & 0.2 & 27.2 & 66.5 & 0.8 & 0.0 & 0.4 & 0.1 \\
2635 & 0.0 & 2.7 & 0.1 & 13.2 & 87.9 & 3.2 & 0.0 & 0.1 & 0.0 \\
2647 & 0.2 & 2.3 & 0.2 & 6.3 & 89.9 & 0.9 & 0.0 & 0.0 & 0.2 \\
2670 & 0.0 & 10.6 & 25.6 & 49.9 & 10.0 & 3.6 & 0.0 & 0.2 & 0.2 \\
2681 & 0.0 & 19.2 & 0.0 & 0.0 & 80.8 & 0.0 & 0.0 & 0.0 & 0.0 \\
2685 & 0.0 & 4.9 & 0.2 & 45.8 & 46.8 & 0.6 & 0.0 & 0.9 & 0.8 \\
2697 & 0.5 & 0.9 & 0.0 & 0.0 & 96.9 & 0.1 & 0.0 & 0.0 & 1.5 \\
2636 & 0.0 & 4.3 & 0.3 & 16.0 & 77.9 & 1.2 & 0.0 & 0.3 & 0.1 \\
2641 & 0.0 & 5.6 & 0.6 & 73.3 & 17.4 & 0.7 & 0.0 & 0.6 & 1.7 \\
2646 & 0.0 & 3.0 & 0.3 & 52.0 & 44.1 & 0.5 & 0.0 & 0.1 & 0.1 \\
2688 & 0.0 & 2.6 & 0.0 & 0.0 & 97.4 & 0.0 & 0.0 & 0.0 & 0.0 \\
2689 & 0.8 & 0.3 & 0.0 & 3.9 & 6.8 & 88.0 & 0.0 & 0.1 & 0.0 \\
2692 & 0.4 & 68.9 & 0.0 & 0.1 & 29.5 & 0.0 & 0.0 & 0.0 & 0.7 \\
2699 & 0.1 & 61.0 & 24.3 & 2.3 & 7.8 & 3.4 & 0.2 & 0.0 & 1.0 \\
\hline & $0.2 \pm 0.3$ & $12.7 \pm 21.8$ & $3.7 \pm 8.7$ & $24.6 \pm 28.1$ & $51.6 \pm 35.4$ & $7.0 \pm 22.5$ & $0.0 \pm 0.1$ & $0.2 \pm 0.3$ & $0.4 \pm 0.6$
\end{tabular}


2011 WINTER HOME RANGE

\begin{tabular}{cccccccccc}
\hline & Barren & Croplands & $\begin{array}{c}\text { Deciduous } \\
\text { Forest }\end{array}$ & $\begin{array}{c}\text { Evergreen } \\
\text { Forest }\end{array}$ & Grasslands & Shrublands & Snow/Ice & Urban & Water \\
\hline 2632 & 0.1 & 0.0 & 2.0 & 81.2 & 11.3 & 1.9 & 0.0 & 0.1 & 3.2 \\
2634 & 0.0 & 1.9 & 0.1 & 32.7 & 64.6 & 0.1 & 0.0 & 0.4 & 0.2 \\
2635 & 0.8 & 2.0 & 0.0 & 13.3 & 82.8 & 0.9 & 0.0 & 0.1 & 0.0 \\
2647 & 0.3 & 0.9 & 0.1 & 9.2 & 88.7 & 0.5 & 0.0 & 0.0 & 0.3 \\
2670 & 0.0 & 6.5 & 23.2 & 59.4 & 9.0 & 1.3 & 0.0 & 0.2 & 0.4 \\
2681 & 0.0 & 21.6 & 0.0 & 0.0 & 78.4 & 0.0 & 0.0 & 0.0 & 0.0 \\
2685 & 0.0 & 1.4 & 0.1 & 54.7 & 41.1 & 0.4 & 0.0 & 0.9 & 1.5 \\
2697 & 0.1 & 1.0 & 0.0 & 0.1 & 96.4 & 0.0 & 0.0 & 0.0 & 2.2 \\
2636 & 0.0 & 2.4 & 0.1 & 19.3 & 77.5 & 0.3 & 0.0 & 0.3 & 0.2 \\
2641 & 0.0 & 1.3 & 0.3 & 81.8 & 12.6 & 0.3 & 0.0 & 0.6 & 3.0 \\
2646 & 0.0 & 2.0 & 0.1 & 59.3 & 38.0 & 0.1 & 0.0 & 0.1 & 0.5 \\
2688 & 0.0 & 2.3 & 0.0 & 0.0 & 97.7 & 0.0 & 0.0 & 0.0 & 0.0 \\
2689 & 0.0 & 0.6 & 0.2 & 5.1 & 4.7 & 89.3 & 0.0 & 0.1 & 0.0 \\
2692 & 0.3 & 51.8 & 0.0 & 0.1 & 46.9 & 0.0 & 0.0 & 0.0 & 1.0 \\
2699 & 0.1 & 58.8 & 22.2 & 8.0 & 7.4 & 2.3 & 0.0 & 0.0 & 1.2 \\
\hline & $0.1 \pm 0.2$ & $10.3 \pm 19.1$ & $3.2 \pm 7.9$ & $28.3 \pm 30.6$ & $50.5 \pm 35.3$ & $6.5 \pm 22.9$ & $0.0 \pm 0.0$ & $0.2 \pm 0.3$ & $0.9 \pm 1.1$
\end{tabular}

2001 WINTER CORE USE AREA

Barren Croplands Deciduous Evergreen Grasslands Shrublands Snow/Ice Urban Water

\begin{tabular}{|c|c|c|c|c|c|c|c|c|c|}
\hline & & & Forest & Forest & & & & & \\
\hline 2632 & 0.5 & 0.5 & 5.7 & 71.8 & 14.4 & 5.0 & 0.1 & 0.2 & 1.7 \\
\hline 2634 & 0.1 & 10.8 & 0.4 & 13.8 & 73.1 & 1.6 & 0.0 & 0.1 & 0.1 \\
\hline 2635 & 0.3 & 2.3 & 0.0 & 3.1 & 76.5 & 17.7 & 0.0 & 0.0 & 0.0 \\
\hline 2647 & 0.2 & 2.0 & 0.1 & 3.3 & 86.5 & 7.5 & 0.2 & 0.1 & 0.2 \\
\hline 2670 & 0.0 & 19.0 & 49.3 & 24.0 & 6.5 & 0.9 & 0.0 & 0.0 & 0.3 \\
\hline 2681 & 0.0 & 8.5 & 0.0 & 0.0 & 91.5 & 0.0 & 0.0 & 0.0 & 0.0 \\
\hline 2685 & 0.0 & 12.5 & 0.8 & 25.6 & 56.8 & 2.5 & 0.0 & 1.6 & 0.2 \\
\hline 2697 & 0.1 & 0.1 & 0.0 & 0.1 & 98.9 & 0.0 & 0.1 & 0.0 & 0.8 \\
\hline 2636 & 0.0 & 5.1 & 0.4 & 18.2 & 74.1 & 1.9 & 0.0 & 0.1 & 0.2 \\
\hline 2641 & 0.0 & 2.6 & 1.2 & 92.9 & 2.3 & 0.9 & 0.0 & 0.1 & 0.0 \\
\hline 2646 & 0.0 & 5.3 & 0.4 & 48.7 & 42.9 & 2.4 & 0.0 & 0.1 & 0.1 \\
\hline 2688 & 0.0 & 6.5 & 0.0 & 0.0 & 93.5 & 0.0 & 0.0 & 0.0 & 0.0 \\
\hline 2689 & 5.3 & 0.0 & 0.1 & 1.4 & 3.2 & 90.0 & 0.0 & 0.0 & 0.0 \\
\hline 2692 & 0.0 & 84.3 & 0.0 & 0.1 & 15.4 & 0.1 & 0.0 & 0.0 & 0.0 \\
\hline \multirow[t]{2}{*}{2699} & 0.0 & 59.9 & 27.1 & 1.3 & 10.0 & 0.9 & 0.0 & 0.0 & 0.7 \\
\hline & $0.4 \pm 1.4$ & $14.6 \pm 24.4$ & $5.7 \pm 13.9$ & $20.3 \pm 29.0$ & $49.7 \pm 37.5$ & $8.8 \pm 22.9$ & $0.0 \pm 0.0$ & $0.2 \pm 0.4$ & $0.3 \pm 0.5$ \\
\hline
\end{tabular}


2006 WINTER CORE USE AREA

\begin{tabular}{cccccccccc}
\hline & Barren & Croplands & $\begin{array}{c}\text { Deciduous } \\
\text { Forest }\end{array}$ & $\begin{array}{c}\text { Evergreen } \\
\text { Forest }\end{array}$ & Grasslands & $\begin{array}{c}\text { Shrubland } \\
\text { s }\end{array}$ & Snow/Ice & Urban & Water \\
\hline 2632 & 1.0 & 0.1 & 4.0 & 79.6 & 12.0 & 2.4 & 0.0 & 0.2 & 0.7 \\
2634 & 0.0 & 5.2 & 0.2 & 18.9 & 74.3 & 1.2 & 0.0 & 0.1 & 0.1 \\
2635 & 0.0 & 2.1 & 0.1 & 4.5 & 90.7 & 2.6 & 0.0 & 0.0 & 0.0 \\
2647 & 0.1 & 1.7 & 0.1 & 6.5 & 90.6 & 0.6 & 0.2 & 0.1 & 0.2 \\
2670 & 0.0 & 17.3 & 35.6 & 31.3 & 12.1 & 3.3 & 0.0 & 0.0 & 0.4 \\
2681 & 0.0 & 16.1 & 0.0 & 0.0 & 83.9 & 0.0 & 0.0 & 0.0 & 0.0 \\
2685 & 0.0 & 9.2 & 0.4 & 34.3 & 53.6 & 0.8 & 0.0 & 1.6 & 0.2 \\
2697 & 0.4 & 0.0 & 0.0 & 0.0 & 99.2 & 0.0 & 0.0 & 0.0 & 0.4 \\
2636 & 0.0 & 2.8 & 0.2 & 22.4 & 73.0 & 1.4 & 0.0 & 0.1 & 0.1 \\
2641 & 0.0 & 0.5 & 0.3 & 95.5 & 3.3 & 0.2 & 0.0 & 0.1 & 0.1 \\
2646 & 0.0 & 2.7 & 0.2 & 57.7 & 38.9 & 0.3 & 0.0 & 0.0 & 0.1 \\
2688 & 0.0 & 0.1 & 0.0 & 0.0 & 99.9 & 0.0 & 0.0 & 0.0 & 0.0 \\
2689 & 0.1 & 0.1 & 0.0 & 0.7 & 7.8 & 91.3 & 0.0 & 0.0 & 0.0 \\
2692 & 0.0 & 74.6 & 0.0 & 0.0 & 25.2 & 0.0 & 0.0 & 0.0 & 0.0 \\
2699 & 0.1 & 51.3 & 29.3 & 2.1 & 11.2 & 5.1 & 0.2 & 0.0 & 0.7 \\
\hline & $0.1 \pm 0.3$ & $12.2 \pm 21.8$ & $4.7 \pm 11.4$ & $23.6 \pm 31.1$ & $51.7 \pm 37.4$ & $7.3 \pm 23.3$ & $0.0 \pm 0.1$ & $0.1 \pm 0.4$ & $0.2 \pm 0.2$
\end{tabular}

2011 WINTER CORE USE AREA

\begin{tabular}{cccccccccc}
\hline & Barren & Croplands & $\begin{array}{c}\text { Deciduous } \\
\text { Forest }\end{array}$ & $\begin{array}{c}\text { Evergreen } \\
\text { Forest }\end{array}$ & Grasslands & $\begin{array}{c}\text { Shrubland } \\
\text { s }\end{array}$ & Snow/Ice & Urban & Water \\
\hline 2632 & 0.2 & 0.0 & 2.0 & 82.2 & 9.8 & 1.6 & 0.0 & 0.2 & 4.0 \\
2634 & 0.0 & 1.5 & 0.1 & 22.7 & 75.2 & 0.1 & 0.0 & 0.1 & 0.2 \\
2635 & 0.0 & 1.4 & 0.0 & 5.6 & 92.3 & 0.7 & 0.0 & 0.0 & 0.0 \\
2647 & 0.1 & 0.6 & 0.0 & 8.8 & 89.8 & 0.3 & 0.1 & 0.1 & 0.2 \\
2670 & 0.0 & 8.2 & 34.3 & 42.2 & 12.2 & 2.7 & 0.0 & 0.0 & 0.4 \\
2681 & 0.0 & 15.1 & 0.0 & 0.0 & 84.9 & 0.0 & 0.0 & 0.0 & 0.0 \\
2685 & 0.0 & 3.3 & 0.2 & 49.9 & 44.5 & 0.2 & 0.0 & 1.3 & 0.5 \\
2697 & 0.1 & 0.0 & 0.0 & 0.0 & 98.6 & 0.0 & 0.0 & 0.0 & 1.2 \\
2636 & 0.0 & 2.4 & 0.0 & 20.9 & 76.1 & 0.2 & 0.0 & 0.1 & 0.3 \\
2641 & 0.0 & 0.1 & 0.2 & 98.0 & 0.5 & 0.0 & 0.0 & 0.1 & 1.1 \\
2646 & 0.0 & 2.4 & 0.0 & 67.0 & 30.1 & 0.1 & 0.0 & 0.0 & 0.3 \\
2688 & 0.0 & 0.2 & 0.0 & 0.0 & 99.8 & 0.0 & 0.0 & 0.0 & 0.0 \\
2689 & 0.0 & 0.2 & 0.0 & 1.4 & 2.9 & 95.5 & 0.0 & 0.0 & 0.0 \\
2692 & 0.0 & 48.9 & 0.0 & 0.1 & 51.1 & 0.0 & 0.0 & 0.0 & 0.0 \\
2699 & 0.1 & 48.0 & 24.9 & 9.5 & 13.2 & 3.3 & 0.0 & 0.0 & 1.0 \\
\hline & $0.0 \pm 0.1$ & $8.8 \pm 16.36$ & $4.1 \pm 10.5$ & $27.2 \pm 32.9$ & $52.1 \pm 38.0$ & $7.0 \pm 24.5$ & $0.0 \pm 0.0$ & $0.1 \pm 0.3$ & $0.6 \pm 1.0$
\end{tabular}




\section{APPENDIX A.2}

\section{SUPPLEMENTARY INFORMATION}

SI Fig. 1. Maps showing home ranges of pre-adult Golden Eagles from Alaska. Home ranges were estimated with Kernel Density Estimate (KDE), Brownian Bridge Movement Model (BBMM), and Minimum Convex Polygon (MCP). Home ranges calculated at 95\% isopleth (KDE95, BBMM95), and core use areas calculated at 50\% isopleth (KDE50, BBMM50). Each displayed 1:2,200,000 scale. We were unable to calculate BBMMs for four individuals. KDEs were used for subsequent analyses.
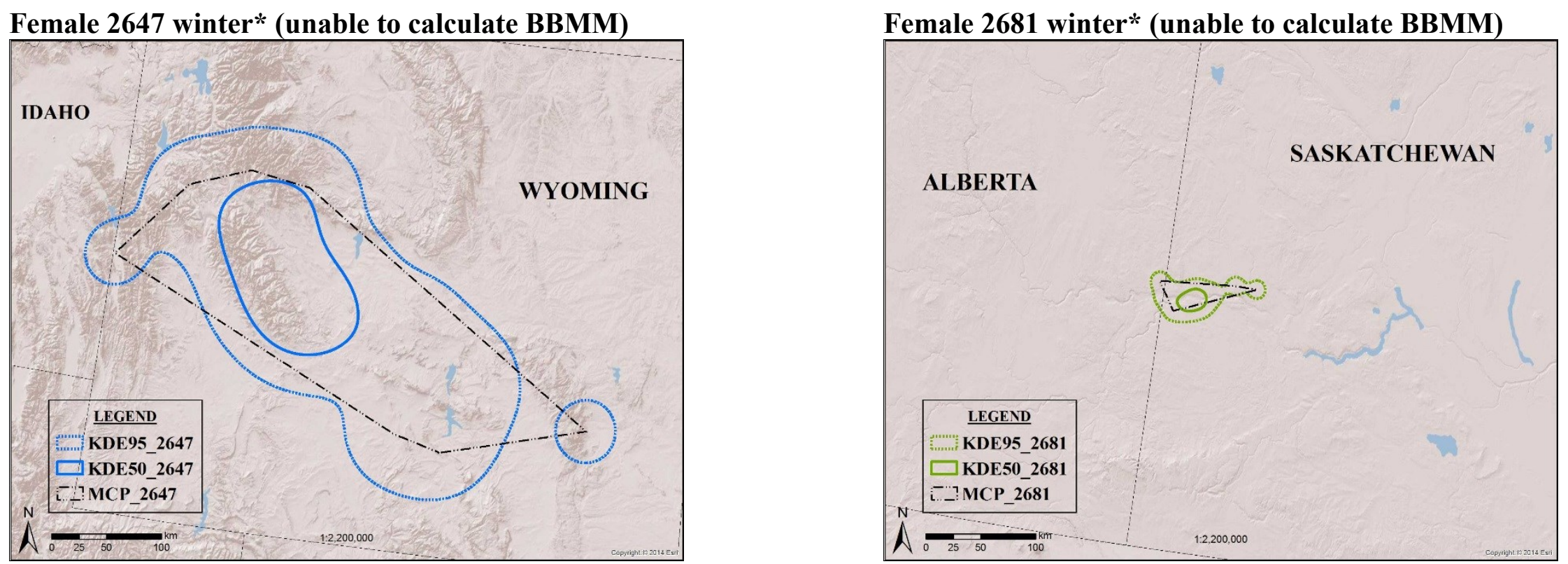


\section{Female 2697 winter* (unable to calculate BBMM)}

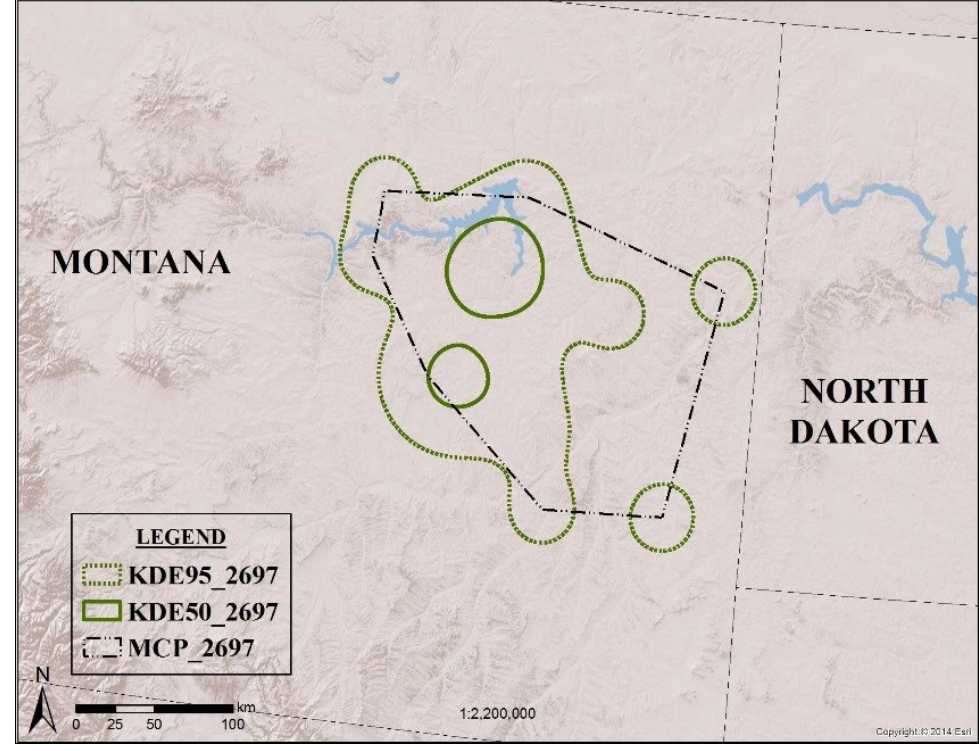

\section{Female 2632 winter}

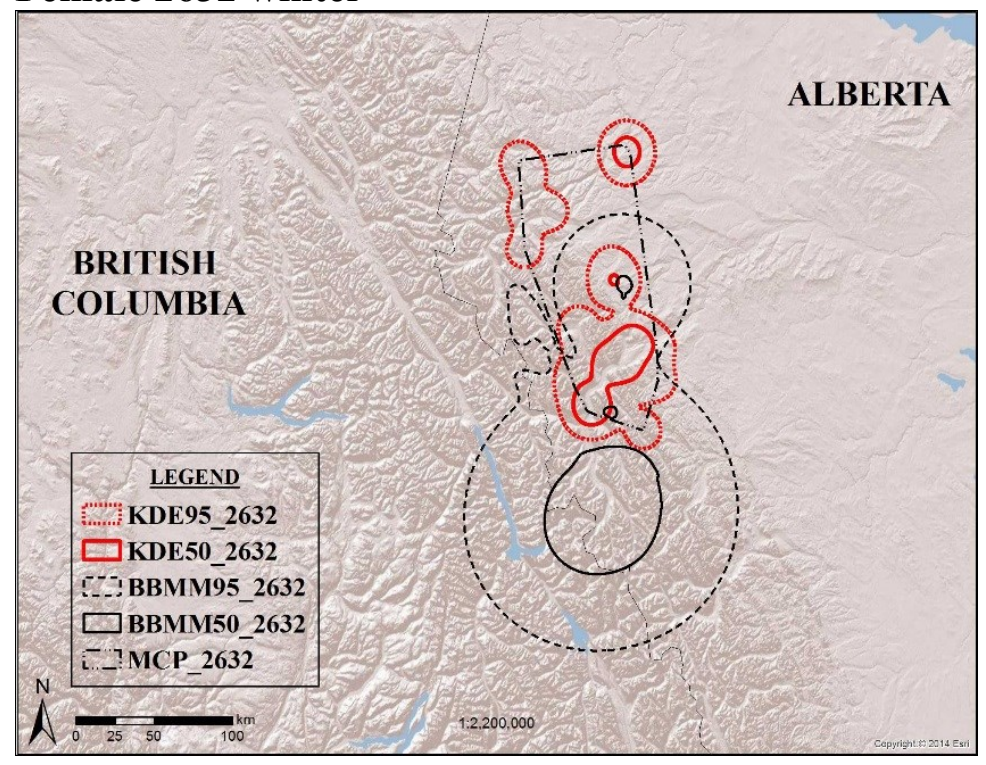

Male 2641 winter* (unable to calculate BBMM)

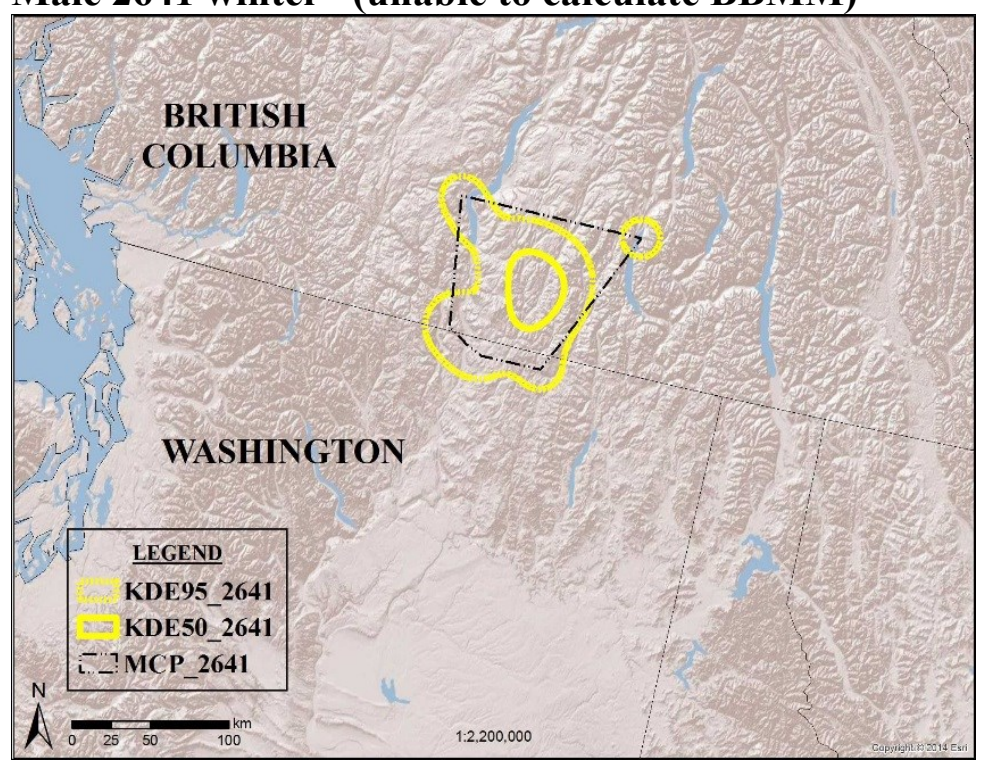

Female 2634 winter

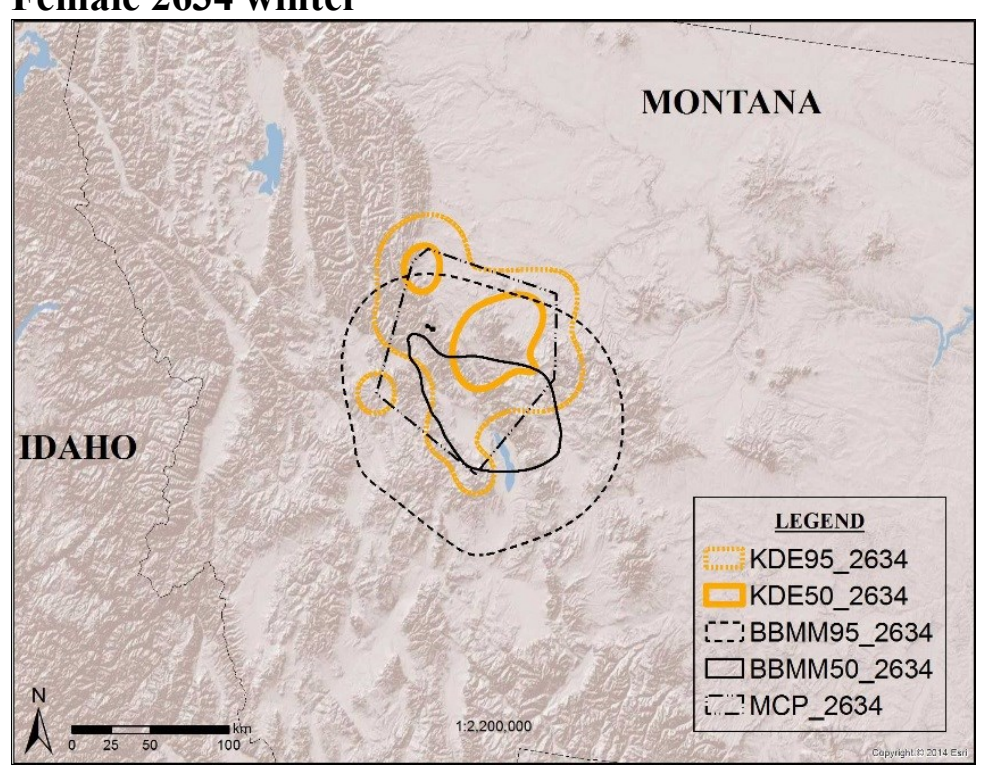




\section{Female 2635 winter}

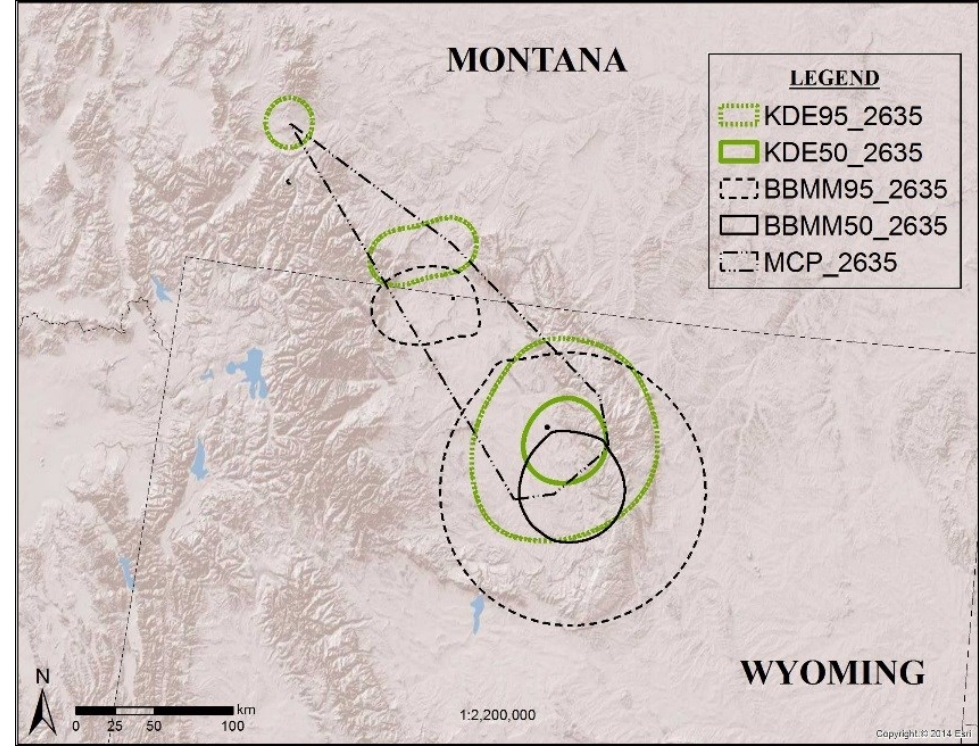

\section{Female 2685 winter}

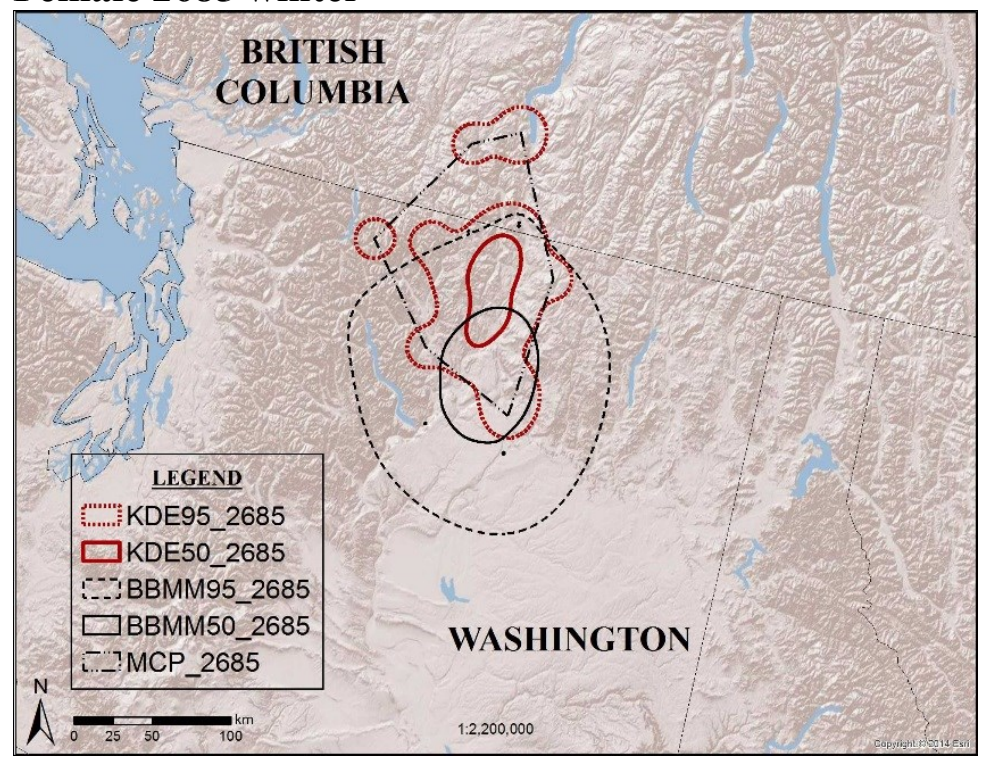

\section{Female 2670 winter}

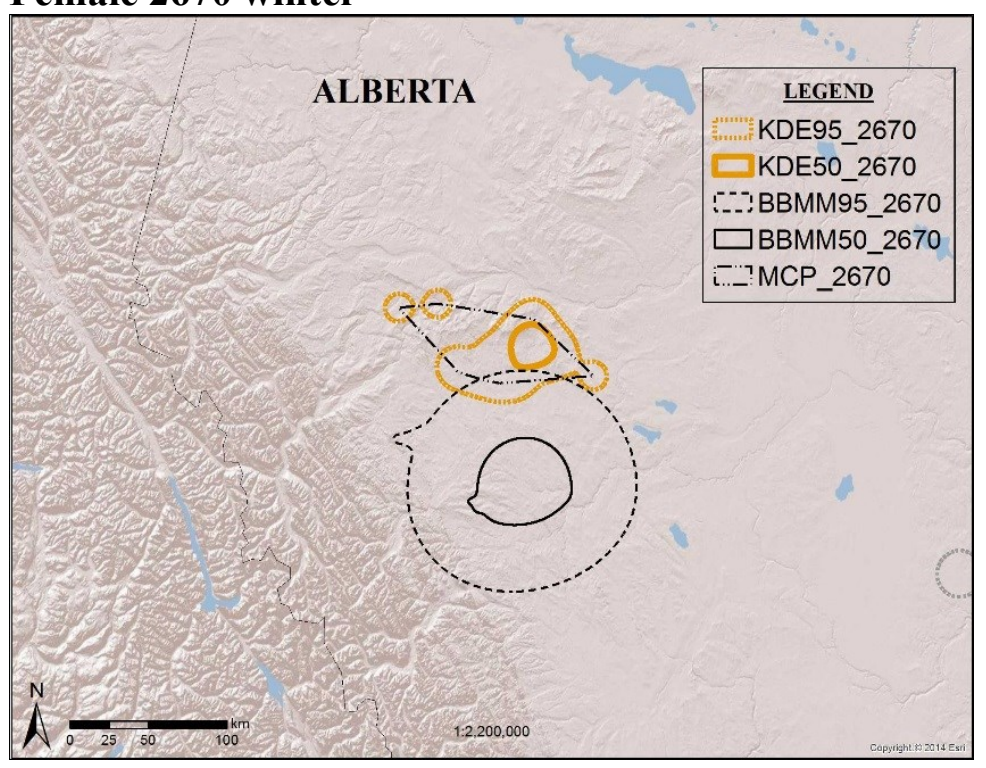

\section{Male 2636 winter}

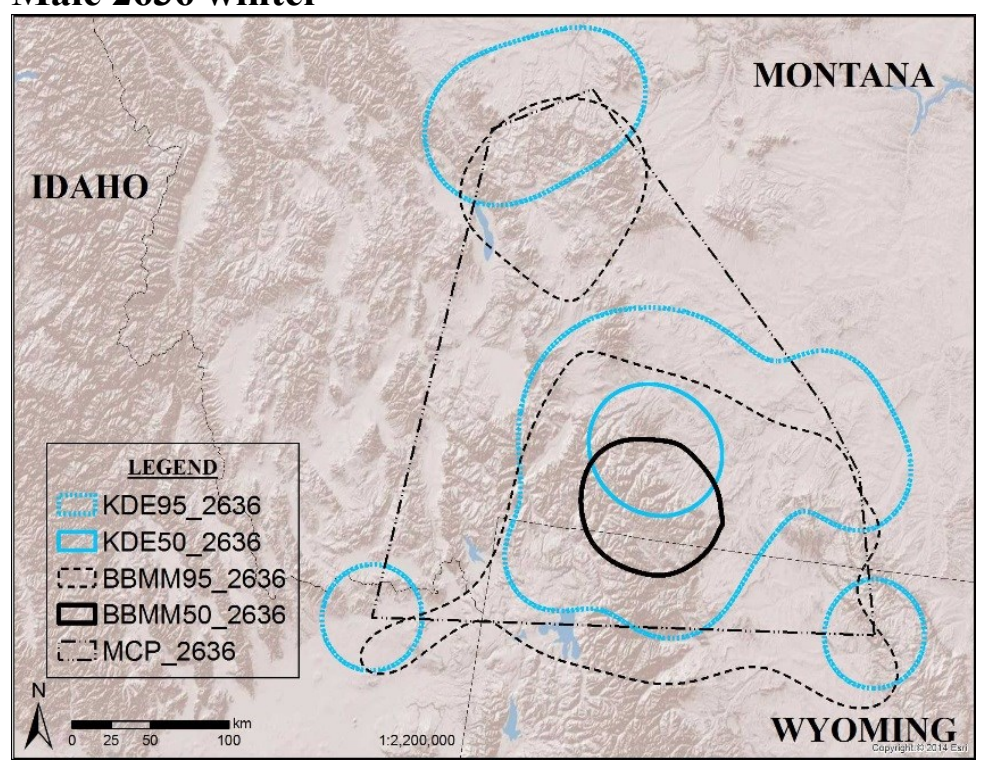




\section{Male 2646 winter}

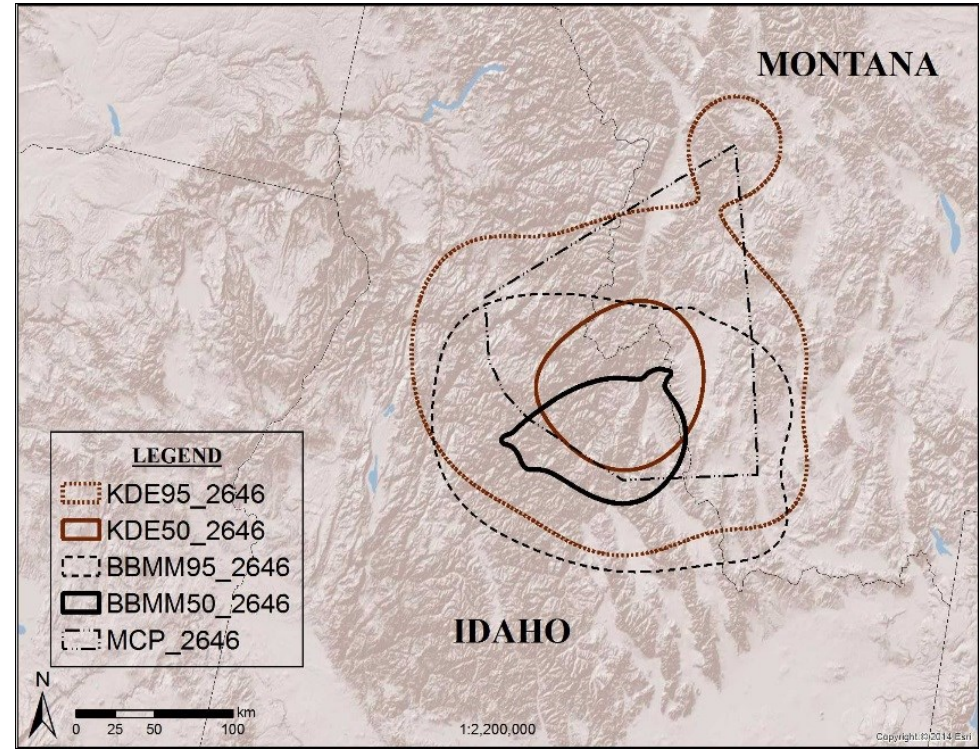

\section{Male 2689 winter}

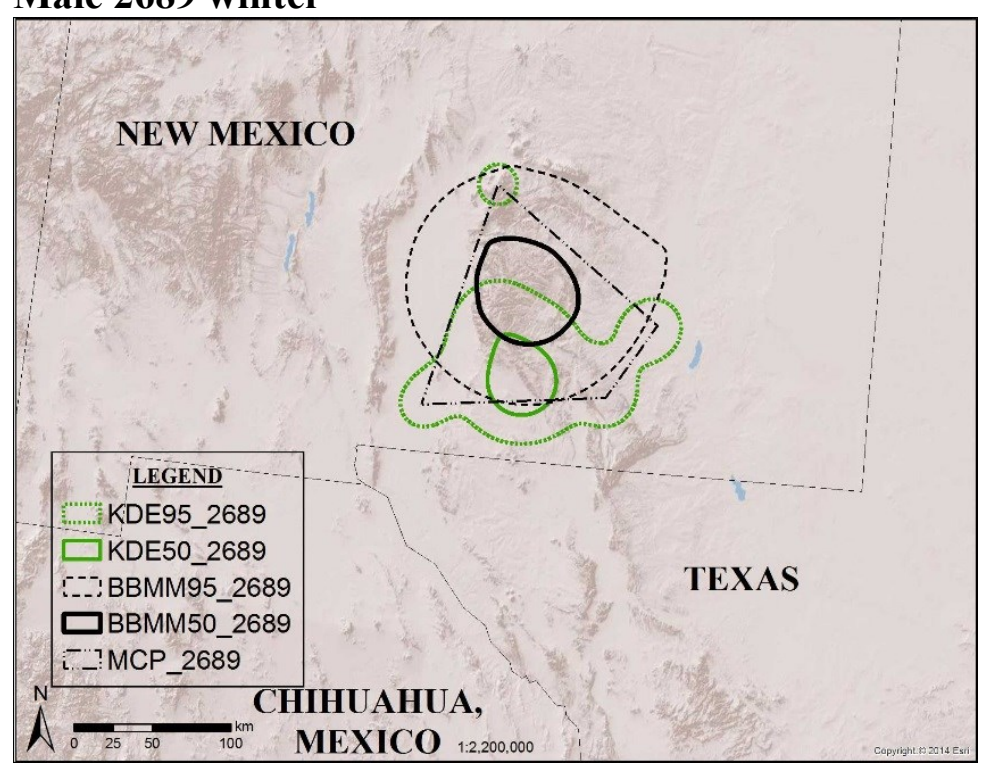

\section{Male 2688 winter}

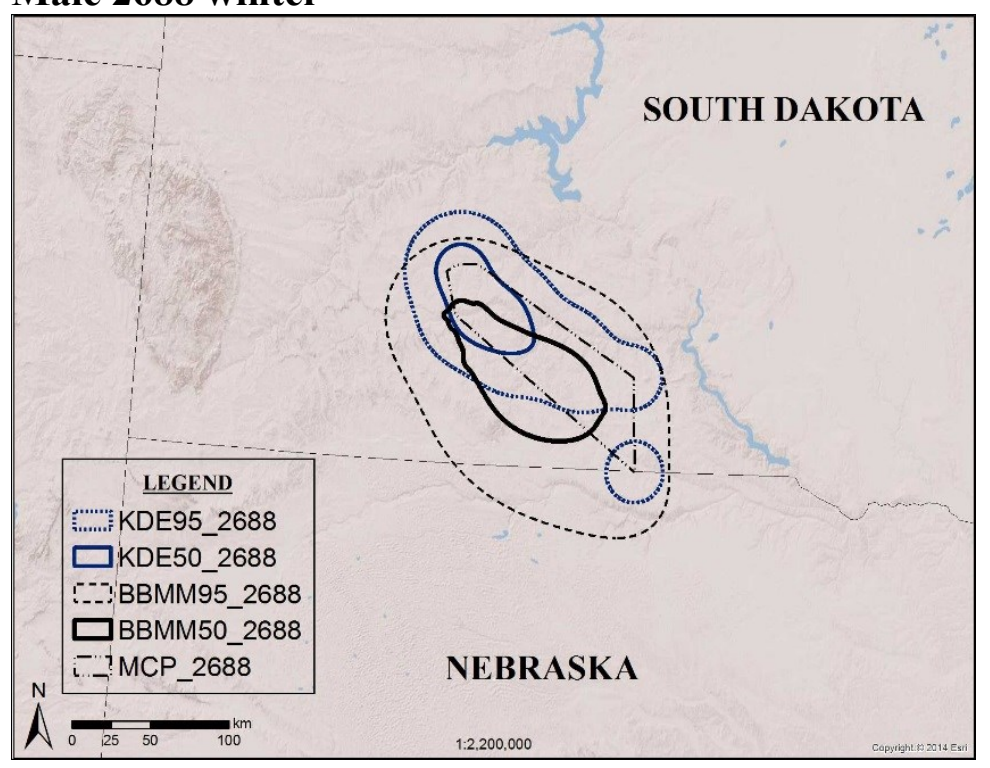

Male 2692 winter

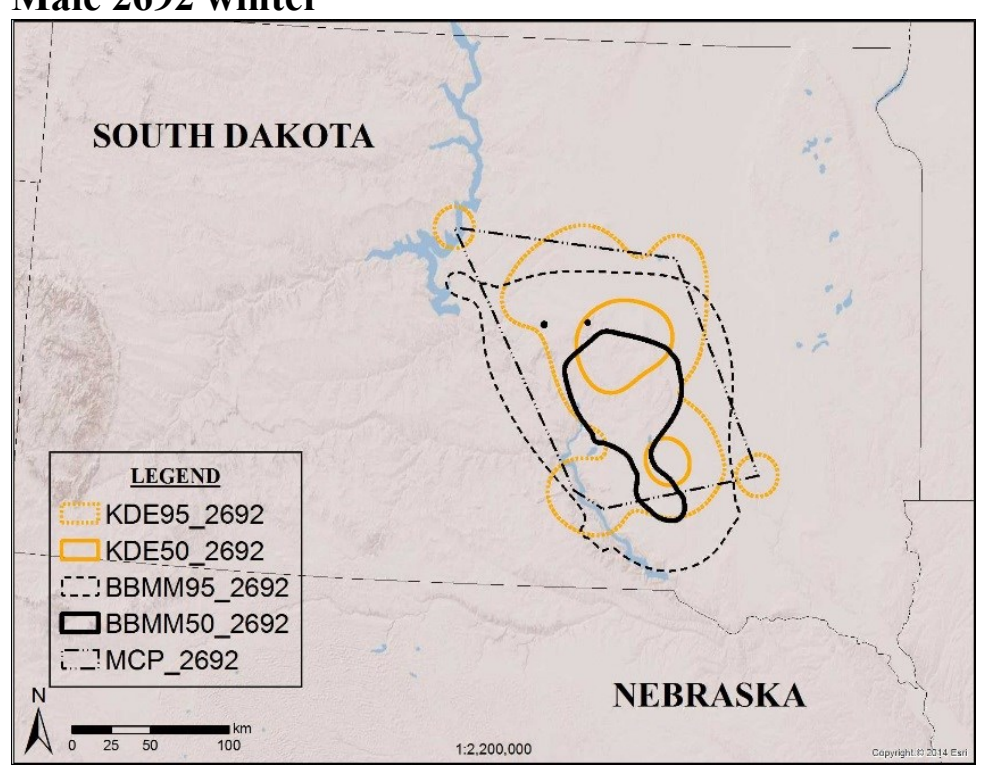


Male 2699 winter

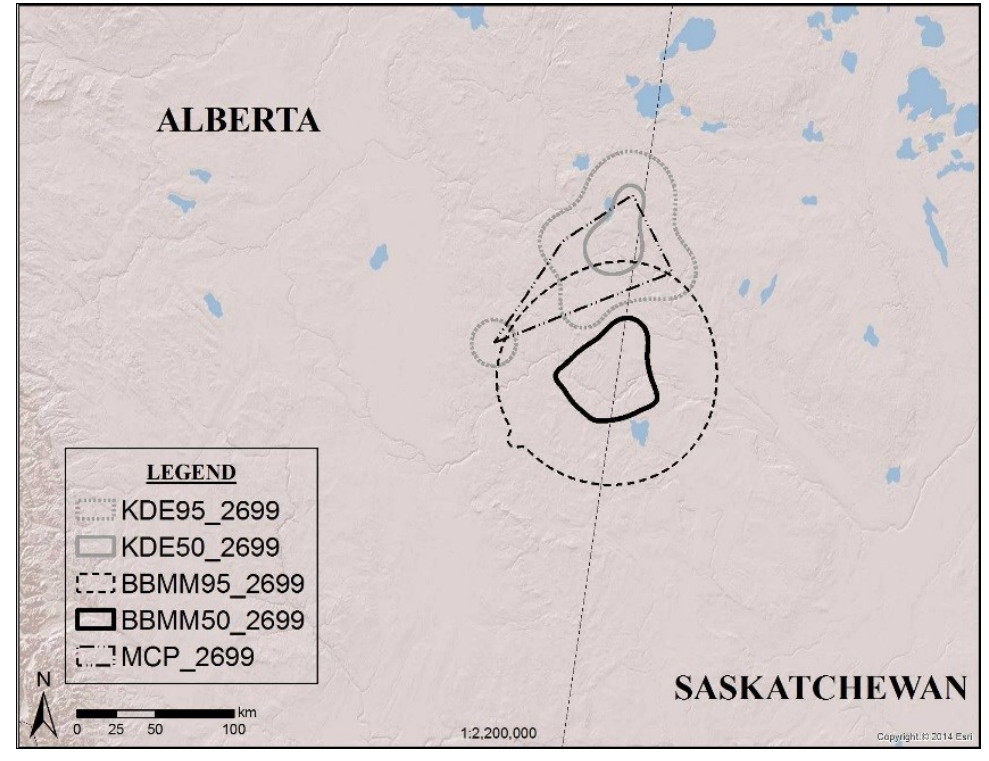




\section{APPENDIX B.2}

\section{SUPPLEMENTARY INFORAMTION}

SI Fig. 2. Space use estimation for pre-adult Golden Eagles summer use areas derived from Kernel Density Estimate (KDE), Home ranges calculated at 95\% isopleth (KDE95), and core use areas calculated at 50\% isopleth (KDE50). Denali National Park and

Preserve is displayed for reference. Each displayed 1:5,000,000 scale. Maps projected in Alaska Albers for display purposes.

\section{Female 2632 summer}

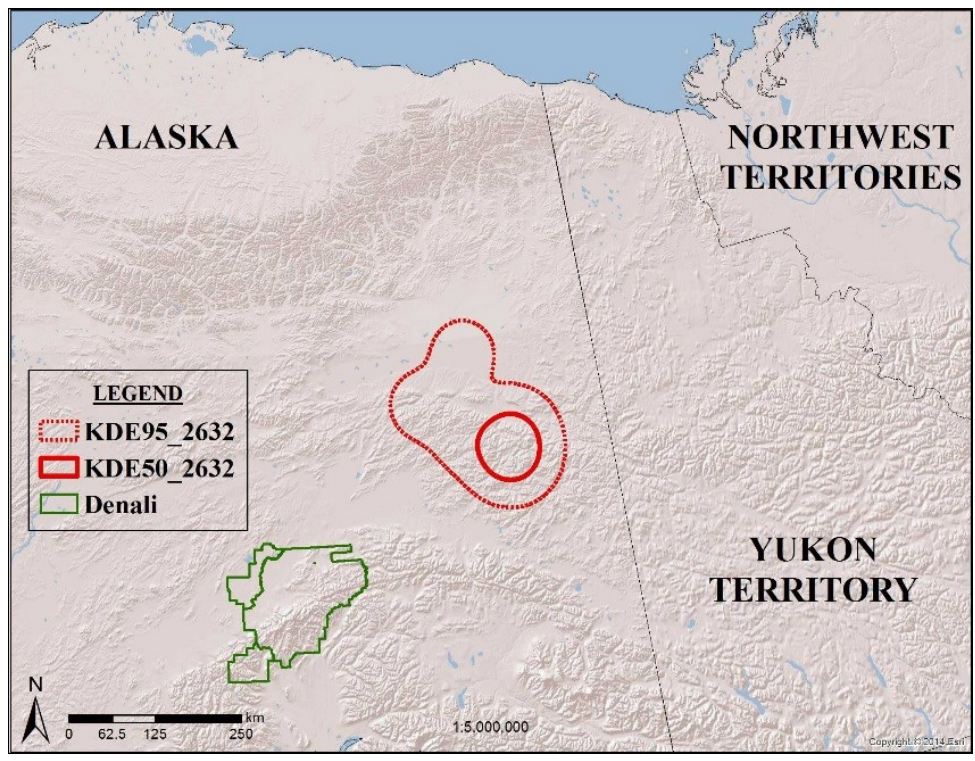

Female 2635 summer

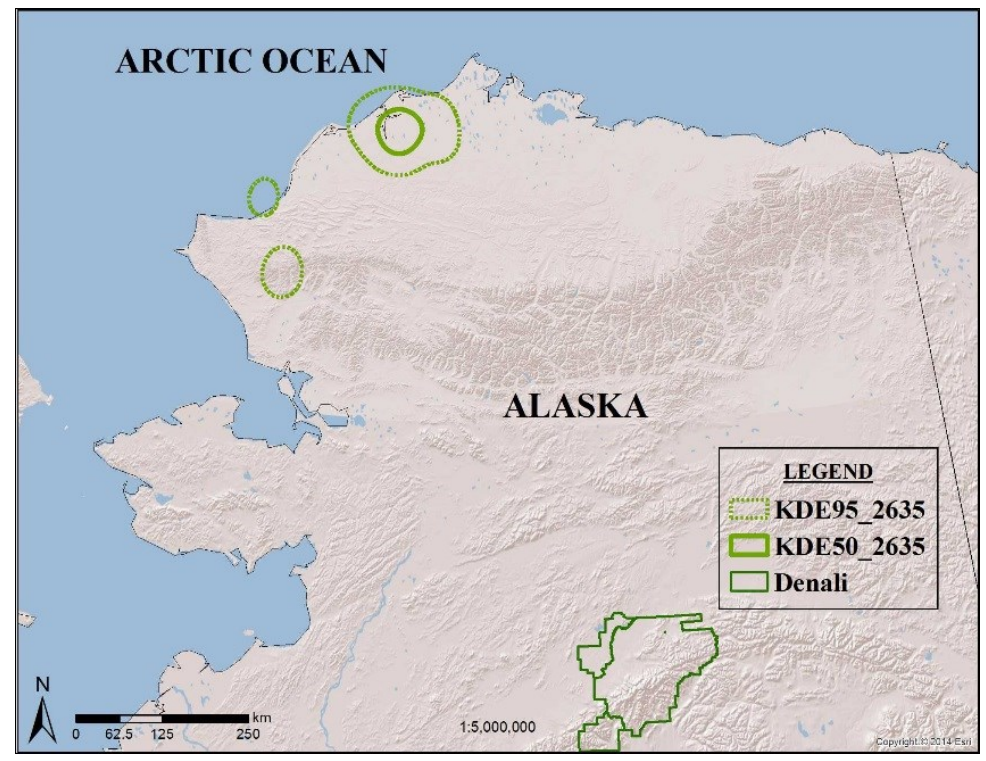




\section{Female 2670 summer}

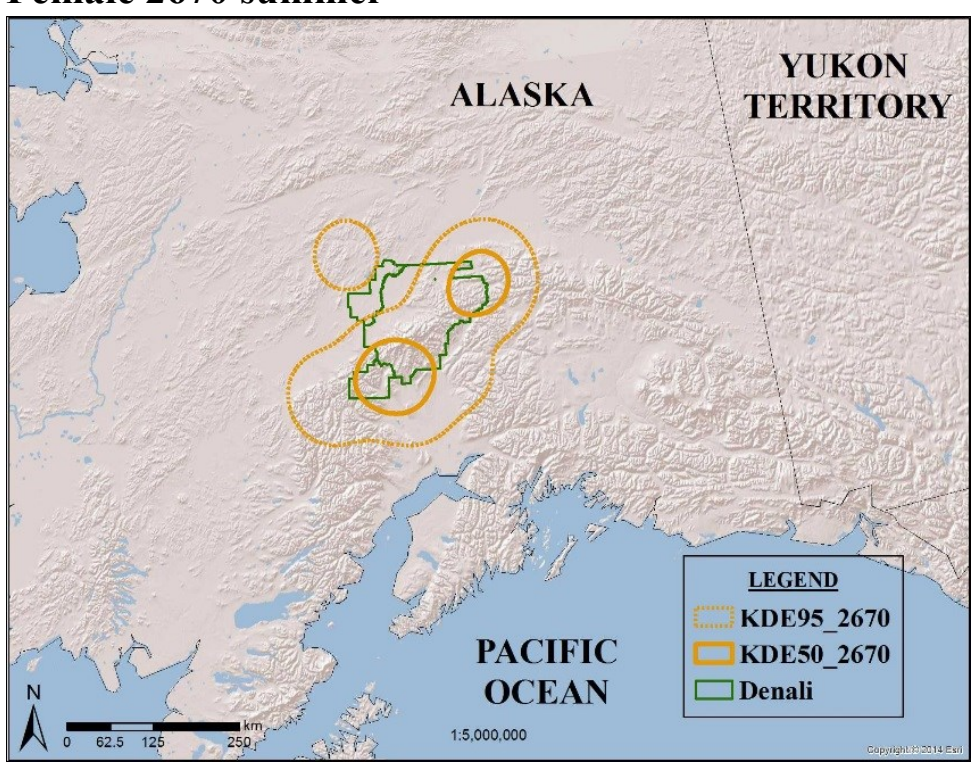

\section{Female 2685 summer}

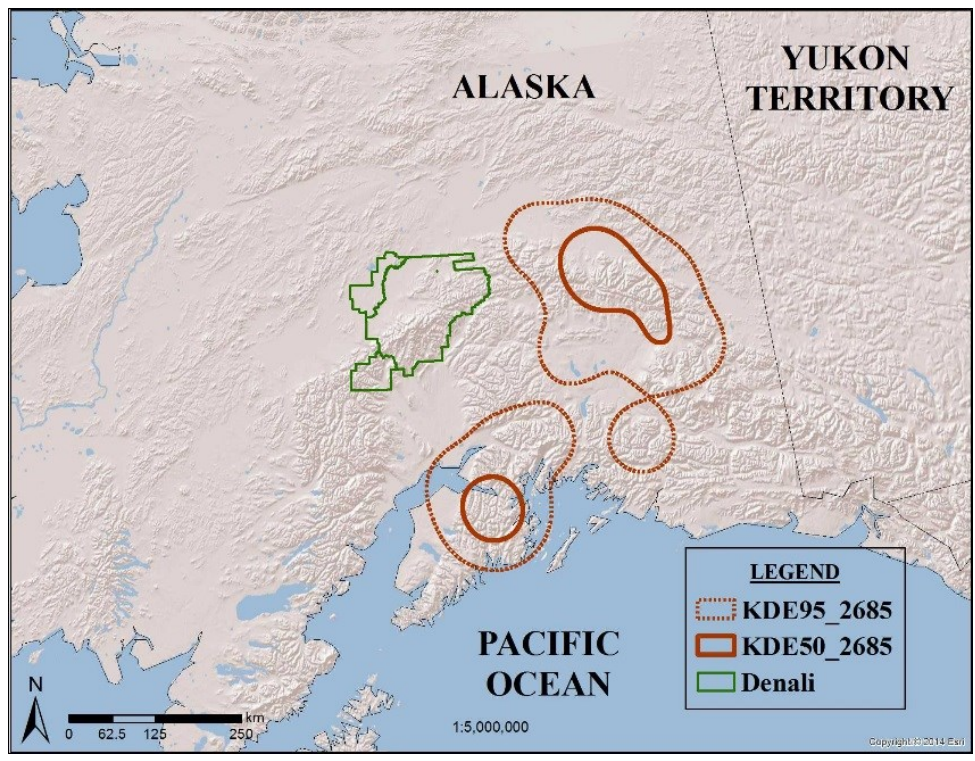

\section{Female 2681 summer}

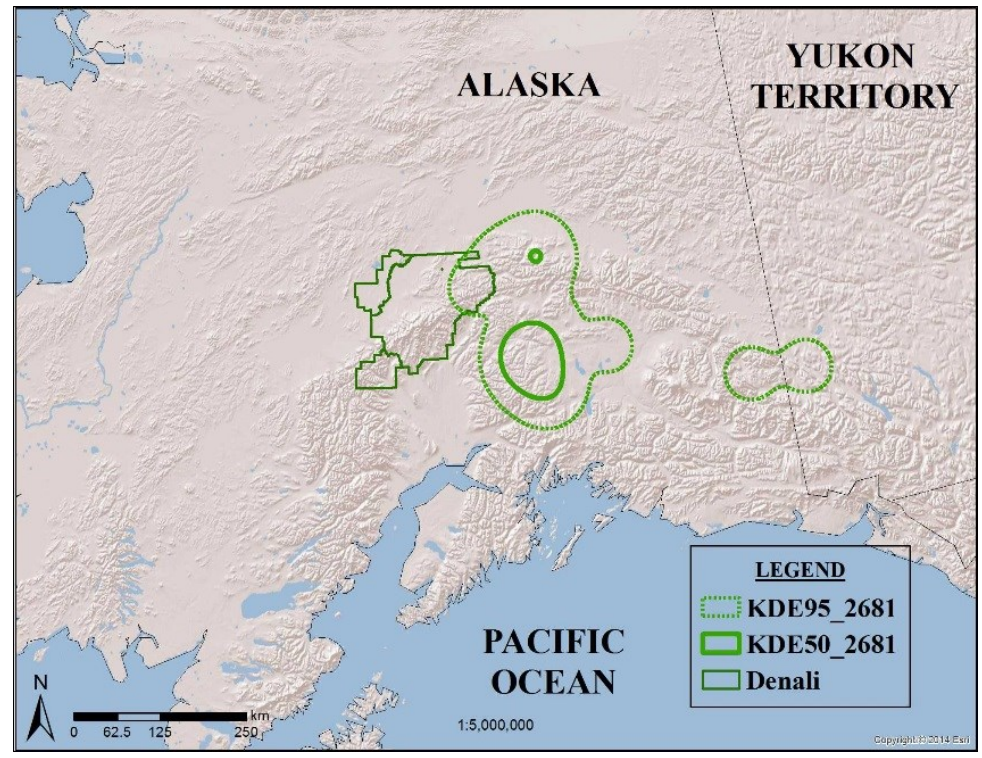

Female 2697 summer

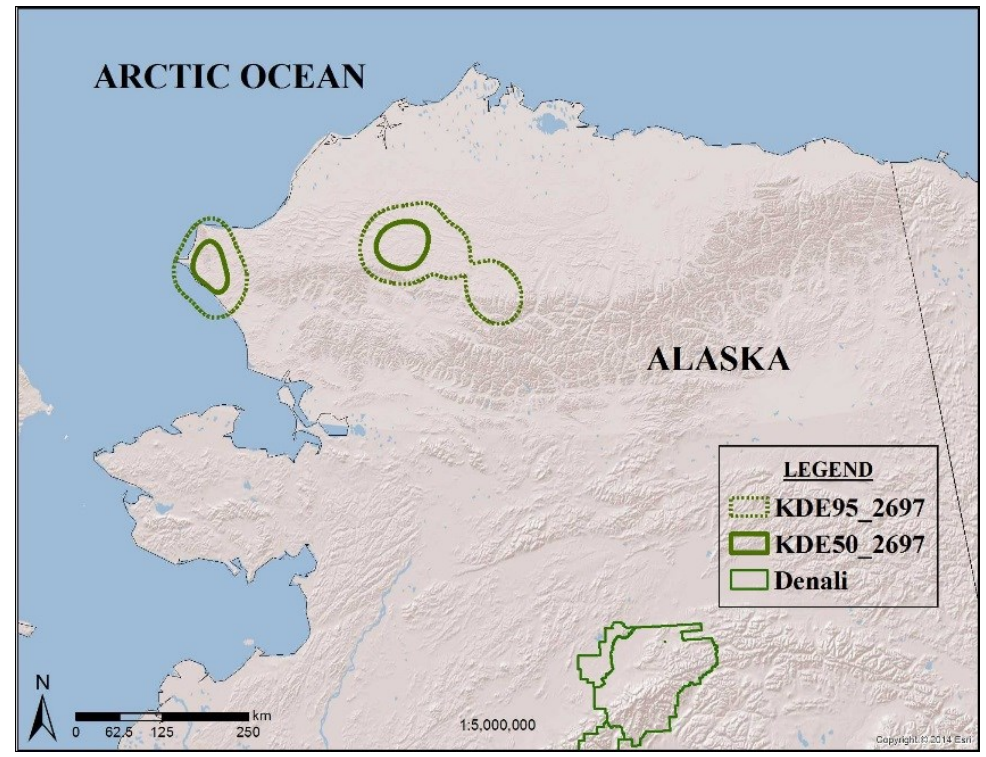


Male 2636 summer

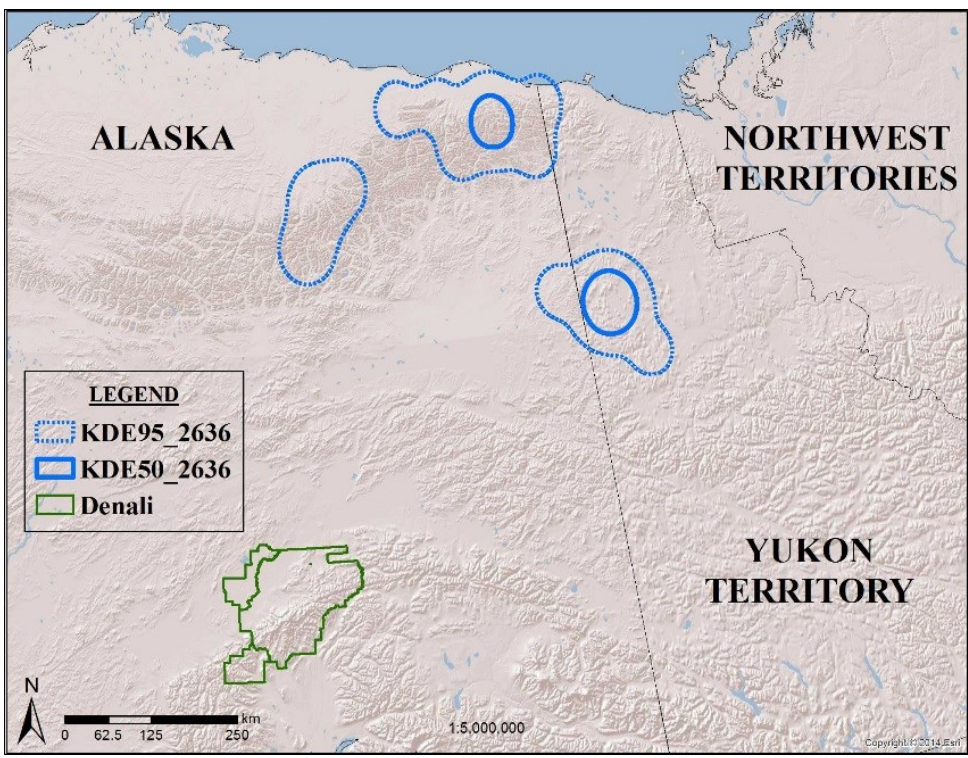

Male 2692 summer

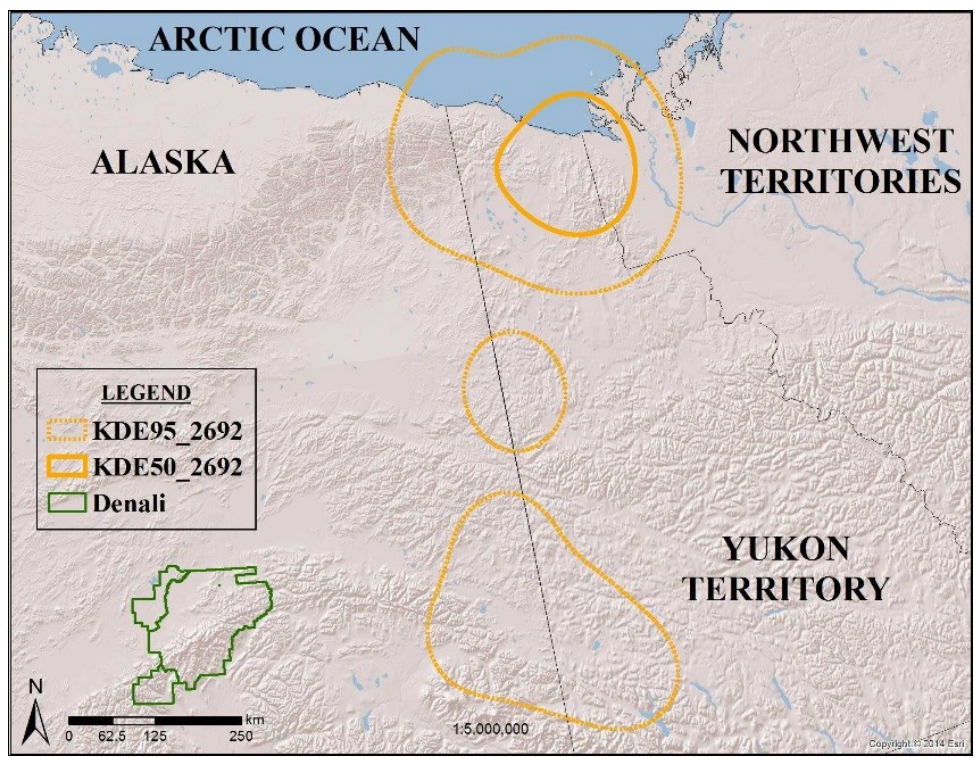

Male 2689 summer

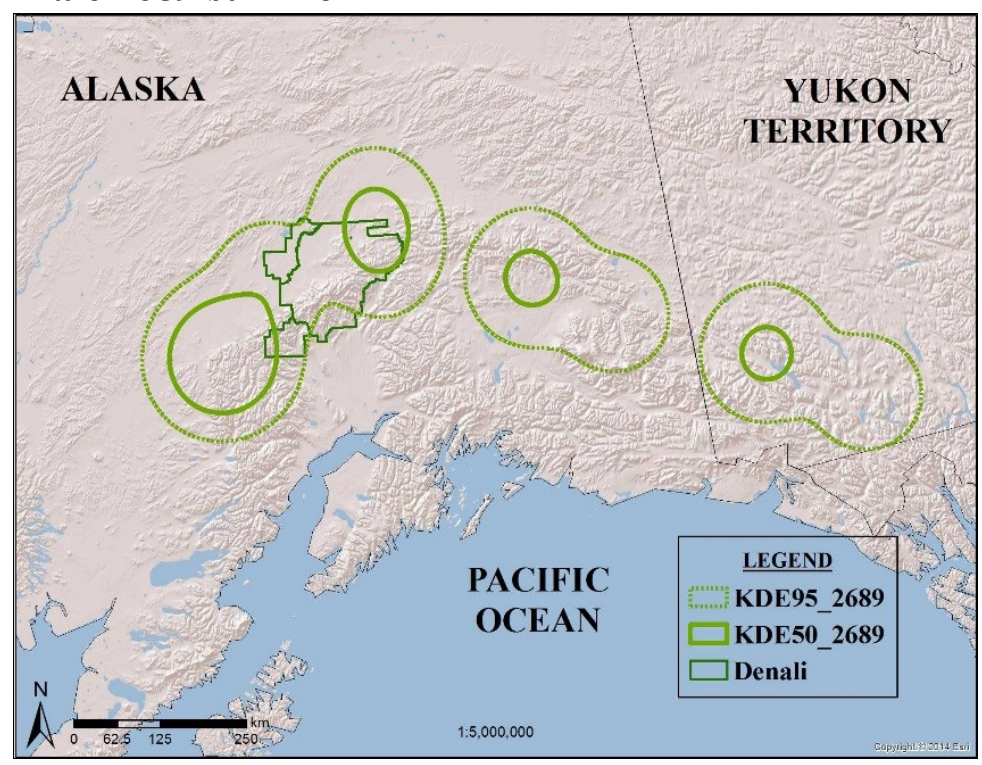

Male 2657 summer

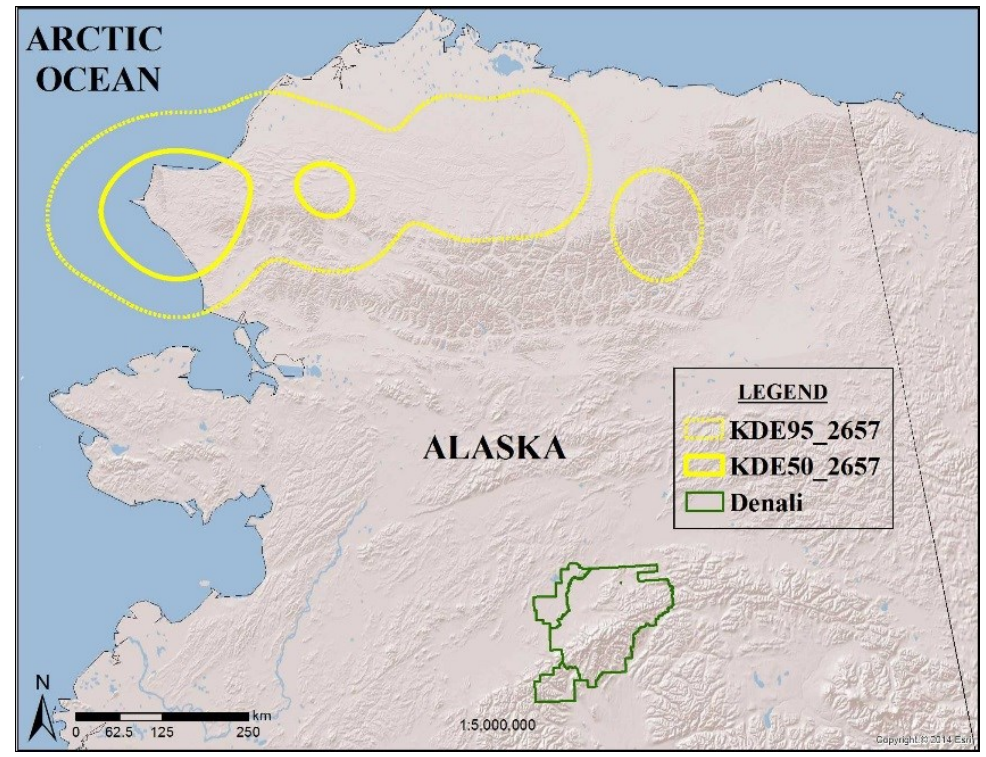


